Apoio à automatização de oráculos de teste para programas com interfaces gráficas 

SERVIÇO DE PÓS-GRADUAÇÃO DO ICMC-USP

Data de Depósito: 13/03/2012

Assinatura:

\section{Apoio à automatização de oráculos de teste para programas com interfaces gráficas}

\section{Rafael Alves Paes de Oliveira}

Orientador: Prof. Dr. Márcio Eduardo Delamaro

Dissertação apresentada ao Instituto de Ciências Matemáticas e de Computação - ICMC-USP, como parte dos requisitos para obtenção do título de Mestre em Ciências - Ciências de Computação e Matemática Computacional. VERSÃO REVISADA

USP - São Carlos

Março de 2012 
Ficha catalográfica elaborada pela Biblioteca Prof. Achille Bassi e Seção Técnica de Informática, ICMC/USP, com os dados fornecidos pelo(a) autor(a)

\begin{tabular}{|c|c|}
\hline \multirow[t]{3}{*}{$048 a$} & $\begin{array}{l}\text { Oliveira, Rafael Alves Paes } \\
\text { Apoio à automatização de oráculos de teste para } \\
\text { programas com interfaces gráficas / Rafael Alves } \\
\text { Paes Oliveira; orientador Márcio Eduardo Delamaro. -- } \\
\text { São Carlos, } 2011 . \\
\quad 122 \text { p. }\end{array}$ \\
\hline & $\begin{array}{l}\text { Dissertação (Mestrado - Programa de Pós-Graduação en } \\
\text { Ciências de Computação e Matemática Computacional) -- } \\
\text { Instituto de Ciências Matemáticas e de Computação, } \\
\text { Universidade de São Paulo, } 2011 .\end{array}$ \\
\hline & $\begin{array}{l}\text { 1. Teste de Software. } 2 \text {. Oráculos de Teste. } 3 . \\
\text { Egenharia de Software. } 4 . \text { CBIR. I. Delamaro, Márcio } \\
\text { Eduardo, orient. II. Título. }\end{array}$ \\
\hline
\end{tabular}


A meus pais Donizeti e Gorete, por me ensinarem repetidamente cada um dos princípios que exercito diariamente.

À minha irmã $\operatorname{Dr}^{a}$ Camila Oliveira, a primeira pessoa a me dizer que minhas capacidades superavam minhas limitações.

À Juliana Batel, simplesmente por existir e tornar melhor cada dia de minha vida. 

Agradeço ao apoio financeiro dos órgãos FAPESP (processo: 2008/07605-7) e CNPq (processos: 551002/2007-7 e 559915/2010-1) pelo apoio financeiro.

Este trabalho não seria o mesmo sem o apoio, incentivo e, principalmente, sem o amor de minha parceira, amiga e namorada Juliana Batel. Obrigado por mudar meu jeito de pensar e agir diante de determinadas situações. Mesmo longe, eu pude sentir sua presença positiva em cada minuto dos meus dias.

Àquele que é e continuará sendo meu melhor amigo sempre - meu pai Donizete P. Oliveira. À minha mãe - Maria Gorete Oliveira - pelas incansáveis doses de amor, zelo, carinho e cuidado em cada ligação e a cada reencontro. À minha irmã $-\operatorname{Dr}^{a}$. Camila A. P. Oliveira - pelo apoio, conselhos, amor e incentivo dados desde o início de minha jornada até os dias atuais.

Ao companheirismo, profissionalismo, paciência e confiança depositada pelo conselheiro das horas difíceis - meu orientador e grande amigo pessoal - Prof. Dr. Márcio Delamaro. Obrigado por tantas contribuições para minha formação.

Agradeço à atenção, interesse e cuidado gratuito da $\operatorname{Prof}^{a} \operatorname{Dr}^{a}{ }^{a}$ Fátima Nunes (EACH-USP). As dicas, conselhos, incentivos e conhecimentos técnicos oferecidos por essa admirável pessoa facilitaram muito a realização deste trabalho.

Às tias Deusa e Dálida, pelo cuidado, delicadeza, amor e zelo após cada retorno de São Carlos. Ao restante de minha família e à Ju, em especial, Carlos, Mara e Ricardo, pelo incentivo.

Aos meus cinco irmãos marilienses: Bruno, Felipe, José Vítor, Juliano e Rafael. Obrigado por servirem de referência para minhas tomadas de decisões e pelos contínuos momentos de alegria e bom humor a cada reencontro.

Aos professores: Masiero, Maria das Graças Nunes, Simone, Adenilso, Rodrigo Guido e Maldonado.

Aos bravos amigos de LaBES e revisores deste trabalho: Lucas Bueno (cabeça), André Endo, Marco Aurélio (Marcão), Faimison (pneu) e Rafael Durelli.

Aos parceiros de LaBES e da USP: Adriano Bezerra (delinha), Harry Trinta, Rodrigo (ronaldo), Fabiano Ferrari (falcão), Bruno Cafeo, Vinícius Durelli (fofo), David (pêxe), Jorge Cutigi (pio), Paulo G. Queiroz (ceará), Paulo H. Ribeiro (nerso), André Domingues (maluquinho), Sandro Bianchini (KLB), Marllos Prado (tiozão), Draylson Souza, Vânia Neves, Maria Adelina, Danilo Coimbra (pimpa), Douglas Rodrigues (AFA), José Augusto (tim), Willian Watanabe (japa), Marcelo Eler, Maurício Arimoto, Eduardo Steiner, Rafael Messias, Paulo Nardi, Otávio Lemos, André Abe, Flávio Dusse (sorín), Rodolfo, Luciano, Erinaldo, Miguel Rojas (miguelito), Kátia Felizardo, Arineiza Pinheiro (neiza), Joice Machado, Silvana, Eliana, Juliana Omori, Aretha Alencar, Maykon Capellari (Maringá) Alexandre (ruffos), Maicon Bernardino (gaúcho) e Miguel Rojas (miguelito). Aos funcionários do ICMC, em especial, às secretárias da pós e aos amigos Alexandre, Coletti, Gilberto, Sandro, Léo Martinussi, Erick, Márcio e Otávio. Valeu! 

Estratégias para automatização de atividades de teste de software são bem aceitas tanto pela indústria quanto pela academia. Um elemento essencial para automatizações de teste são oráculos de teste. Oráculos, que podem ser mecanismos, funções, execuções paralelas, etc, são fundamentais por determinarem se as saídas de uma aplicação em teste estão corretas. A automatização de mecanismos de oráculos é um ponto crítico quando as saídas dos sistemas se manifestam por meio de formatos não triviais como, por exemplo, uma Interface Gráfica com o Usuário (GUI - do inglês Graphical User Interface). Para esses casos, estratégias tradicionais de teste costumam ser custosas e exigir esforços consideráveis dos testadores. Este trabalho de mestrado propõe um método alternativo para a automatização de oráculos de teste para sistemas com GUIs. Para tanto, exploram-se conceitos de Recuperação de Imagens Baseada em Conteúdo para a composição de um método de automatização chamado de oráculos gráficos (Gr-O - do inglês Graphical Oracle). Como contribuição, desenvolveram-se extratores de características visuais de GUIs. A condução e análise de estudos empíricos revelaram que o uso do Gr-O pode reduzir os custos para definições de oráculos de teste para sistemas com GUIs. Deste modo, o método proposto pode ser alternativo ou complementar às técnicas de teste tradicionais identificadas na literatura. 

Strategies for automated software testing activities are well accepted by both industry and the academy. Essential elements for automation of testing are test oracles. Oracles, which may be mechanisms, functions, parallel executions, etc., are crucial in determining whether the output of an application under test is correct. The automation of oracles is critical when the output system manifested by non-trivial formats, for example, a Graphical User Interface (GUI). For these cases, traditional testing strategies tend to be costly and require considerable efforts of the testers. This master thesis proposes an alternative method for the automation of test oracles for systems with GUIs. To this end, we explore the concepts of Content-Based Image Retrieval for the composition of an automated method called Graphical Oracles (Gr-O). As a contribution, we developed characteristics extractors of GUIs. The conduct and analysis of empirical studies have shown that using of Gr-O can reduce costs for definitions of test oracles for systems with GUIs. Thus, the proposed method may be alternative or complementary to traditional testing techniques found in the literature. 

Abstract vii

1 Introdução 1

1.1 Contexto . . . . . . . . . . . . . . . . . . . . 1

1.2 Motivação . . . . . . . . . . . . . . . . . . . 3

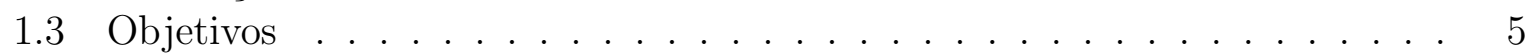

1.4 Organização do Trabalho . . . . . . . . . . . . . . . . . . . 6

2 Aspectos Conceituais 7

2.1 Considerações Iniciais . . . . . . . . . . . . . . . . . . . . . . . 7

2.2 Teste de Software . . . . . . . . . . . . . . . . . . . 7

2.2.1 Atividades de Teste de Software . . . . . . . . . . . . . . . . 9

2.2.2 Automatização do Teste . . . . . . . . . . . . . . . . . . . . 11

2.2.2.1 Teste Manual versus Teste Automatizado . . . . . . . . . 13

2.2.2.2 Frameworks, APIs e bibliotecas de apoio ao teste automatizado . . . . . . . . . . . . . . 17

2.2.3 Contexto de Automatização para o Trabalho Proposto . . . . . . . 20

2.3 Oráculos de Teste . . . . . . . . . . . . . . . . . . . 20

2.3.1 Definições, Conceitos e Taxonomias . . . . . . . . . . . . . . 21

2.3.1.1 Oráculos sem saídas pré-computadas . . . . . . . . . . 24

2.3.1.2 Oráculos com saídas pré-computadas . . . . . . . . . 25

2.3.1.3 Oráculos não determinísticos . . . . . . . . . . . . . 27

2.3.2 Implementação de Mecanismos de Oráculos . . . . . . . . . . . . . 28

2.3.3 Oráculos: considerações finais . . . . . . . . . . . . . . . 30

2.4 Considerações Finais . . . . . . . . . . . . . . . . . . 30

3 GUIs e CBIR 31

3.1 Considerações Iniciais . . . . . . . . . . . . . . . . . . . . . . . 31

3.2 Graphical User Interface . . . . . . . . . . . . . . . . . . . . . 31

3.2.1 APIs para o Desenvolvimento . . . . . . . . . . . 33

3.2 .2 Teste de sistemas com GUIs . . . . . . . . . . . . . . . . 35

3.2.3 Oráculos de teste para GUIs: Uma Revisão Sistemática . . . . . . . 37

3.2.3.1 Análise de Resultados . . . . . . . . . . . . . . 37 
3.2.3.2 Reexecução da Revisão Sistemática . . . . . . . . . . . . . 40

3.3 CBIR - Content-Based Image Retrieval . . . . . . . . . . . . . . . . . . . . 46

3.3 .1 Etapas . . . . . . . . . . . . . . . . . . 47

3.3.1.1 Extratores de Características . . . . . . . . . . . . 49

3.3.1.2 Funções de Distância ou Similaridade . . . . . . . . . . . 51

3.4 Considerações Finais . . . . . . . . . . . . . . . . . . . . 51

4 O Framework O-FIm

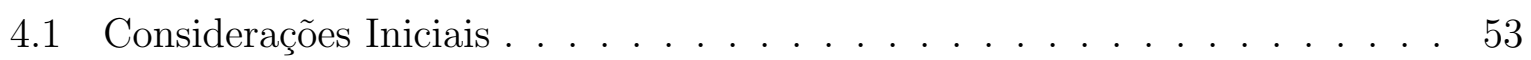

4.2 Arquitetura . . . . . . . . . . . . . . . . . . . 54

4.3 Plugins - Extratores e Funções de Similaridade . . . . . . . . . . . . . . 55

4.4 Núcleo . . . . . . . . . . . . . . . . . . . . . . . . . . . . 58

4.4.1 API do framework . . . . . . . . . . . . . . . . . . . 59

4.5 Oráculos Gráficos . . . . . . . . . . . . . . . . . . . . . 60

4.5.1 Descritores de Oráculos . . . . . . . . . . . . . . . . . 61

4.6 Aplicações . . . . . . . . . . . . . . . . . . . . . . . . . 62

4.6.1 Apoio ao Teste de Aplicações Web . . . . . . . . . . . . . . . 62

4.6.2 Apoio ao Teste de Esquemas CAD . . . . . . . . . . . . . . . 63

4.7 Considerações Finais . . . . . . . . . . . . . . . . 65

5 Insumos para Oráculos Gráficos em GUIs $\quad 67$

5.1 Considerações Iniciais . . . . . . . . . . . . . . . . . . . . 67

5.2 Extratores de Características . . . . . . . . . . . . . . . . . . 68

5.3 Funções de Similaridade . . . . . . . . . . . . . . . . . . . . . . . . . . 72

5.4 Oráculos para sistemas com GUIs: Método Gr-O versus Métodos Tradicionais 74

5.4 .1 Estudo Empírico Comparativo . . . . . . . . . . . . . . . . . . . 75

5.4.2 Condução Paralela dos Projetos . . . . . . . . . . . . . . . . 76

5.4 .3 Comparativo . . . . . . . . . . . . . . . . . . . 78

5.5 Considerações Finais . . . . . . . . . . . . . . . . . . . . . . . . 81

6 Gr-O e Sistemas com GUIs: Estudos de Caso 83

6.1 Considerações Iniciais . . . . . . . . . . . . . . . . . . . . . . . . . . . . . . . . . . . . . . 83

6.2 Materiais e Métodos . . . . . . . . . . . . . . . . . . . . 84

6.2.1 Estratégia de Estudo Empírico . . . . . . . . . . . . . . 84

6.3 Primeiro Estudo: GCalcTool . . . . . . . . . . . . . . . . 85

6.3.1 Resultados . . . . . . . . . . . . . . . 88

6.4 Segundo Estudo: Ferramenta JaBUTi . . . . . . . . . . . . . . . . . . . . . 89

6.4.1 Automatização da captura de screenshots da JaBUTi . . . . . . . . 90

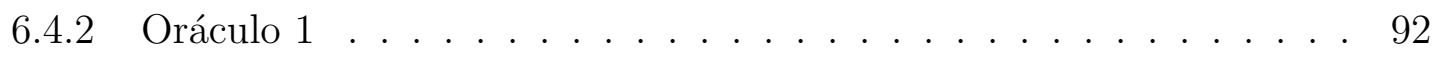

6.4.2.1 Resultados . . . . . . . . . . . . . . . . 94

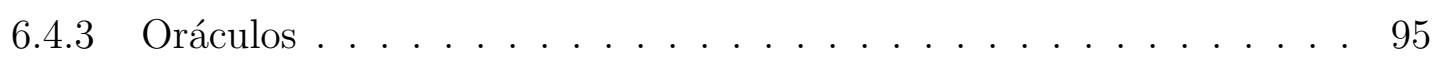

6.4.3.1 Oráculo $2 \ldots \ldots \ldots \ldots$

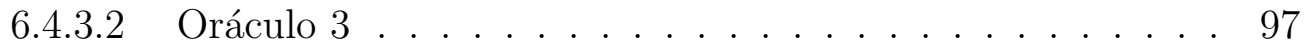

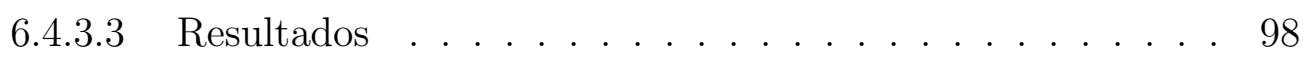

6.5 Considerações Finais . . . . . . . . . . . . . . . . 100 
7 Conclusões $\quad 101$

7.1 Limitações e Ameaças à Validade . . . . . . . . . . . . . . . . . . . 102

7.2 Trabalhos Futuros . . . . . . . . . . . . . . . . . 103

$\begin{array}{ll}\text { Glossário } & 105\end{array}$

$\begin{array}{ll}\text { Referências } & 117\end{array}$

A Wizard do framework O-FIm 119 

2.1 Representação gráfica do teste manual . . . . . . . . . . . . . . . . . . 13

3.1 GUI resultante da execução do código AWT exibido na Listagem 3.1. . . . 36

3.2 Dados estatísticos colhidos a partir da RS conduzida . . . . . . . . . . . 41

3.3 Script de teste visual da ferramenta Sikuli (adaptado de Chang et al. (2010)) 43

3.4 Grafo que relaciona autores das obras selecionadas na RS . . . . . . . . . 44

3.5 Sistemas de coordenadas de uma imagem digital . . . . . . . . . . . . . . 48

3.6 Esquema CBIR no contexto deste trabalho de mestrado (adaptado de Delamaro et al. (2011)) . . . . . . . . . . . . . . . 50

4.1 Arquitetura do framework O-FIm . . . . . . . . . . . . . 55

4.2 Diagrama de componentes do framework O-FIm (adaptado de Oliveira et

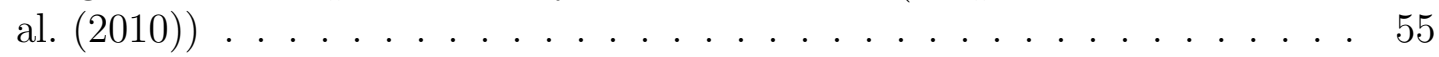

4.3 Estrutura de classes para extratores e funções de similaridade (adaptado de Delamaro et al. (2011)) . . . . . . . . . . . . . . . . . 58

4.4 Gramática de oráculos gráficos no formato BNF . . . . . . . . . . . . 61

4.5 Exemplo de um oráculo gráfico para a ferramenta $O$-FIm . . . . . . . . 62

5.1 GUIs com diferentes look and feel (adaptado de Delamaro et al. (2011)) . . 75

5.2 Calculadora Swing utilizada para o estudo empírico - a)estado inicial da calculadora; b)após um evento no botão "9"; c)após um evento no botão "sqrt"; d)após um evento no botão "C" . . . . . . . . . . . . . . . . . . . 76

6.1 GCalctool-a) básica; b) avançada; c) financeira; d) científica; e) programável 85

6.2 Comparativo entre GUIs operáveis e não operáveis - a) GCalctool com a resolução de $1024 \times 768$ pixels (operável); b) A GCalctool com a resolução de 720x400 pixels (não operável) . . . . . . . . . . . . . . . 86

6.3 Etapas do CountButtons - a) Screenshot da GCalctool em 256 níveis de cinza; b) Figura 6.3a após aplicação de um limiar; c) Figura 6.3b após a aplicação de um filtro de mediana . . . . . . . . . . . . . . . 88

6.4 Oráculo gráfico definido para o estudo empírico do método Gr-O com a

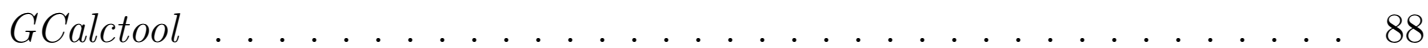

6.5 GUI da ferramenta JaBUTi . . . . . . . . . . . . . . . . . . . . . 90

6.6 Esquema de "dicas" para a geração de casos de teste da ferramenta JaBUTi 93 
6.7 Oráculo gráfico (oráculo 1) definido para o estudo empírico com a ferramenta JaBUTi . . . . . . . . . . . . . . . . . . . . . . . . . . . . . 94

6.8 GUIs da ferramenta JaBUTi - a)L\&F Metal; b) L\&F Motif . . . . . . . . 94

6.9 GUIs não aceitas pelo oráculo - a) L\&F Napkin; b)L\&F office2003 . . . . . 95

6.10 Ferramenta JaBUTi na visão de elementos requeridos por método . . . . . 96

6.11 GUIs da ferramenta JaBUTi na visão dos elementos requeridos - a) screenshot da aplicação modelo; b) screenshot da aplicação em teste . . . . . . 97

6.12 GUIs da ferramenta JaBUTi na visão de cobertura do critério todos-nós por métodos - a) screenshot da aplicação modelo; b) screenshot de uma das aplicações em teste . . . . . . . . . . . . . . . . . . . . 98

6.13 Oráculo gráfico (oráculo 3) definido para o estudo empírico com a ferramenta JaBUTi . . . . . . . . . . . . . . . . . . . . . . . . . . . . . . . . . 98

A.1 Interface principal do framework O-FIm . . . . . . . . . . . . . 120

A.2 GUI para instalação de plugin O-FIm . . . . . . . . . . . . . . . 120

A.3 GUI da O-FIm para pesquisas sobre plugins . . . . . . . . . . . . . 120

A.4 Interface de O-FIm com a imagem de um GUI carregada internamente . . 121

A.5 Interface de O-FIm após execução de um oráculo gráfico . . . . . . . . . . 122 


\section{Lista de Tabelas}

2.1 Prejuízos recentes gerados por sistemas de software problemáticos em grandes organizações (adaptado de Charette (2005)) . . . . . . . . . . . . . . . 10

2.2 Caracterizações do teste automatizado e do teste manual . . . . . . . . . . . 14

2.3 Vantagens e desvantagens da aplicação dos testes manuais e automatizados 15

2.4 Relação de ferramentas comerciais e acadêmicas de apoio ao teste automa-

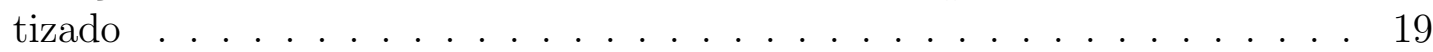

2.5 Oráculos por sua forma de automatização (adaptado de Hoffman (1998, 2006)) . . . . . . . . . . . . . . . . . . 23

3.1 Seleção preliminar de artigos . . . . . . . . . . . . . . . . . . . . 38

3.2 Artigos adicionados após a reexecução da Revisão Sistemática . . . . . . . 41

5.1 Tabela de comparativo de métricas entre as técnicas . . . . . . . . . . . . . 79

5.2 Aspectos negativos e positivos acerca do uso do uma técnica de captura e reprodução . . . . . . . . . . . . . . . . . . . 8 80

5.3 Aspectos negativos e positivos acerca do uso do método Gr-O $\quad$. . . . . . 80

5.4 Aspectos negativos e positivos acerca de uma técnica que explore estruturas 81

6.1 Resultados estudo de caso do método Gr-O com a GCalctool . . . . . . . 89

6.2 Resultados do segundo estudo de caso - oráculo 1 . . . . . . . . . . . . . 95

6.3 Resultados para segundo estudo de caso com o Oráculo 2 . . . . . . . . . . 99

6.4 Resultados para segundo estudo de caso com o Oráculo 3 . . . . . . . . . 99 



\section{Lista de Códigos}

2.1 Teste automatizado por meio do framework JUnit (2011) . . . . . . . . . . 18

3.1 Código de Interface implementada com a biblioteca AWT-Java . . . . . . . 35

4.1 Interface Java IExtractor . . . . . . . . . . . . . . . . . . . . 56

4.2 Interface Java ISimilarity . . . . . . . . . . . . . . . . . . . . 57

5.1 Método principal do extrator de cores . . . . . . . . . . . . 68

5.2 Método que ajusta propriedades do extrator de cores para componentes Swing . . . . . . . . . . . . . . . . . . . . 69

5.3 Método Java que implementa a função Euclidiana . . . . . . . . . . . . . . 73

5.4 Automatização do teste com a ferramenta FEST Swing . . . . . . . . . . . 77

5.5 Código de automatização do teste gerado com a ferramenta Window Tester 77

5.6 Automatização do teste com o método Gr-O . . . . . . . . . . . . . . . . 78

6.1 Código para automatização de captura de screenshots da ferramenta JaBUTi 91

6.2 Código gerado pela funcionalidade de captura da ferramenta WindowTester Pro . . . . . . . . . . . . . . . . . . . . . . 91 



\section{Lista de Abreviaturas e Siglas}

API Application Programming Interface

BNF Backus Naur Form

CBIR Content-Based Image Retrieval

CC Complexidade Ciclomática

CCSL Centro de Competência em Software Livre

CNPQ Conselho Nacional de Desenvolvimento Científico e Tecnológico

CRM Customer Relationship Management

ERP Enterprise Resource Planning

ES Engenharia de Software

FAPESP Fundação de Amparo à Pesquisa do Estado de São Paulo

Gr-O Graphical Oracle

GUI Graphical User Interface

IA Inteligência Artificial

ICMC Instituto de Ciências Matemáticas e de Computação

IDE Integrated Development Environment

HCI Human-computer interaction

JaBUTi Java Bytecode Understanding and Testing

L\&F Look and Feel

LOC Lines Of Code

MEF Máquina de Estados Finitos

MVC Model-view-controller

O-FIm Oracle For Image

PI Processamento de Imagem

RS Revisão Sistemática

SQL Structured Query Language

SUT System Under Test

UML Unified Modeling Language

USP Universidade de São Paulo

TOG Test Oracle Generator

TTCN-3 Testing and Test Control Notation Version 3

XP eXtreme Programming 


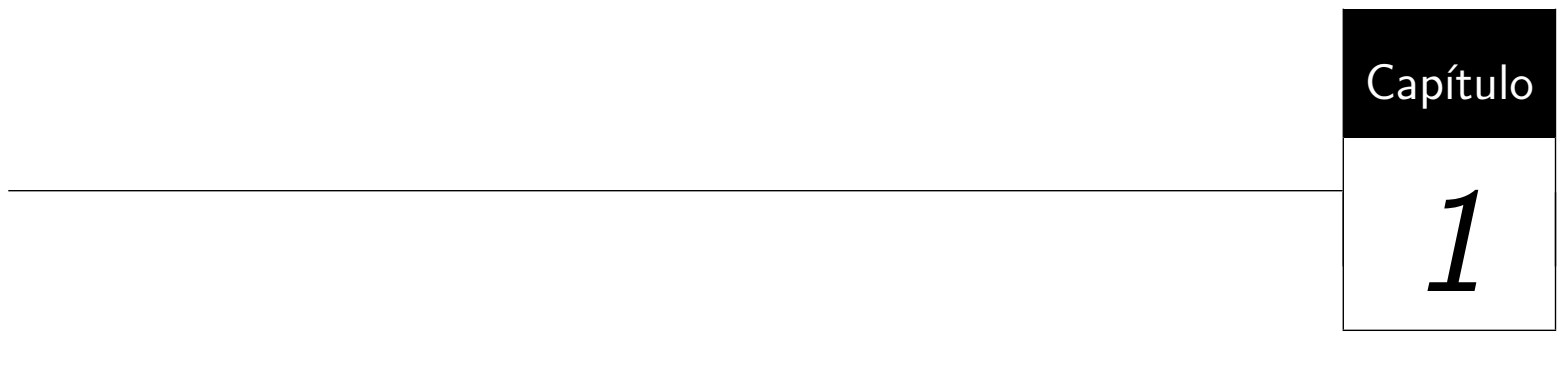

Introdução

\subsection{Contexto}

Este trabalho é consonante com as linhas de pesquisa do grupo de Engenharia de Software do Instituto de Ciências Matemáticas e de Computação (ICMC/USP) que definem e desenvolvem ferramentas que possibilitem a automatização das atividades de teste de software, em particular, de mecanismos de oráculos.

É crescente o conjunto de atividades e soluções providas por recursos computacionais. O software desenvolvido nos dias atuais é utilizado, direta ou indiretamente, por centenas de milhões de pessoas. São diversos os setores sociais diretamente envolvidos, ou até controlados, por sistemas computacionais. Esse crescimento tem se tornado uma tendência cada vez mais comum em áreas como transporte, finanças, educação, atividades editoriais, rádio e televisão etc. É possível afirmar que cada uma dessas áreas pode ser apoiada por sistemas de software que facilitem ou automatizem atividades ou processos. Adicionalmente, dada a importância desses setores, tais sistemas têm em sua correção uma característica fundamental e é essencial que um alto grau de confiança seja fornecido aos seus usuários.

Diante do cenário apontado, a qualidade é uma meta desejada pelos desenvolvedores de software e é fator crítico para o sucesso comercial de um produto. Por isso, gerentes de projeto têm dedicado grande atenção em atividades de verificação, validação e, em particular, teste de software. Notam-se esforços, por parte de pesquisadores, em definições 
de técnicas, critérios e em implementações de ferramentas que contribuam para que tais atividades sejam executadas com eficiência e custo reduzido.

No âmbito acadêmico, atividades de teste de software vêm ganhando cada vez mais notoriedade e espaço em congressos científicos e periódicos internacionais. No âmbito indústrial, atividades de teste podem ser sinônimo de ampla vantagem competitiva. Sobre esse cenário, pode-se afirmar que o mercado do software atual é caracterizado principalmente pela alta concorrência e competitividade. Por isso, é cada vez mais necessário que sejam desenvolvidos sistemas confiáveis e de qualidade com eficácia e rapidez. Para tanto, é fundamental que sejam empregadas as atividades de teste automatizadas.

A automatização é o processo que substitui os esforços manuais despendidos para o teste de um sistema. Podem ser incluídos recursos para a geração de entradas e resultados esperados, de modo que sejam executados diversos testes sem intervenções nem avaliações humanas (Binder, 1999). Consequentemente, o emprego de atividades automatizadas de teste contribui para o aumento da produtividade e representa uma forma de reduzir custos de projetos.

Um pressuposto fundamental do teste automatizado é o veredicto a respeito do comportamento, correto ou não, de um programa diante de determinada entrada. Nem sempre é uma tarefa trivial definir se os resultados de determinado teste são adequados. Assim, faz-se necessária a implementação de um mecanismo capaz de indicar se os resultados de uma execução estão corretos. Para que isso seja feito, uma das possíveis estratégias é fazer comparações de saídas, automática ou manualmente, com saídas pré-calculadas de algum modo e que, presumidamente, estejam corretas.

Desconsiderando problemas conhecidos como, por exemplo, a não executabilidade, a automatização completa do processo de teste requer um mecanismo capaz de fornecer resultados de referência de correção para determinados conjuntos de teste. Em resumo, faz-se necessária a figura de um oráculo de teste. Um oráculo pode ser definido como o mecanismo utilizado para determinar se a saída ou o comportamento de determinada execução é o correto (Hoffman, 2001). Todo método de teste automatizado é dependente da avaliação dos resultados das execuções. Embora os mecanismos de oráculo para domínios específicos possam ser muito variados, algumas classes de oráculos podem ser identificadas. Uma especificação formal, um programa ou simplesmente o conhecimento do testador a respeito de determinada aplicação podem configurar mecanismos de oráculos em um determinado ambiente de teste.

Quando é considerada a pluralidade dos testes, é comum que sejam identificados diferentes oráculos de teste para diversos domínios. Um cenário delicado para a automatização de mecanismos de oráculo é quando a saída de uma aplicação em teste é concebida em 
um formato não trivial como, por exemplo, por meio da tela de uma interface gráfica ou, então, por uma imagem qualquer.

O uso de diferentes aparências (L\&F - do inglês Look and Feel) de interfaces gráficas, diferentes plataformas e sistemas de cores, ou então, a operabilidade em resoluções distintas pode gerar determinados erros inesperados. A detecção automatizada desses erros é uma atividade complexa. Por isso, geralmente testadores são responsáveis por observar os resultados dos testes, detectando possíveis erros. A complexidade no formato de saída dessas aplicações faz com que avaliações de seu comportamento requeiram esforços significativos. Técnicas e estratégias de automatização específicas devem ser desenvolvidas para tanto, e constituem o tema central desta dissertação.

\subsection{Motivação}

Este trabalho pretende colaborar com os processos de qualidade em Engenharia de Software (ES) utilizando técnicas de Recuperação de Imagem Baseada em Conteúdo (CBIR do termo inglês, Content-Based Image Retrieval) como estratégia para permitir que oráculos de teste para sistemas com interfaces gráficas com o usuário (GUI - do termo inglês, Graphical User Interface) sejam definidos de forma flexível. Utilizando-se como fonte de informação, por exemplo, o screenshot de uma aplicação em teste. Neste trabalho, aspectos relacionados à exploração de CBIR como forma de estabelecer uma alternativa para a automatização do teste de sistemas com GUIs foram definidos e avaliados. Adicionalmente, por meio de resultados de estudos empíricos, pretende-se comparar o método proposto com os processos mais comuns para o teste de sistemas com GUIs apresentados pela literatura.

Paradigmas de suporte ao teste não acompanharam a evolução da linguagens de programação e continuam representando um dos elementos mais caros da Engenharia de Software (Hummel e Atkinson, 2005). Por isso, são valorizados os esforços que possam contribuir para o incremento de qualidade nos sistemas de software antes de sua liberação para uso.

GUIs são um exemplo bem definido de área que evoluiu desproporcionalmente a seus paradigmas de teste. GUIs configuram o método de intercomunicação entre humano e computador mais comum nos sistemas atuais. É uma tendência que elas ofereçam ambientes cada vez mais ricos em recursos para diferentes aplicações (Fischer et al., 2009). Isso permite, por exemplo, que um usuário trabalhe facilmente com várias aplicações de modo simultâneo por meio da organização das janelas em sua tela. GUIs permitem que usuários utilizem dispositivos de entrada de dados para realizarem eventos. De modo 
pragmático, eventos podem ser considerados entradas como, por exemplo, movimentos e toques no mouse, manipulação de objetos, toque em telas sensíveis, seleções em menus.

A concepção e a exploração de interfaces gráficas são consideradas as grandes responsáveis pela popularização dos computadores pessoais no mundo. Como consequência das facilidades proporcionadas pelo uso das GUIs aos usuários, fixou-se nos desenvolvedores o reconhecimento de suas ricas utilidades. Isso fez com que interfaces se estabelecessem como componentes críticos nos projetos de sistemas de software atuais. Por isso, em sistemas complexos, GUIs chegam a representar de $45 \%$ a $60 \%$ do código das aplicações (Memon, 2001; Myers, 1995). Adicionalmente, sistemas que exploram GUIs para promoverem sua intercomunicação com o usuário não estão isentos de erros. Tais sistemas podem ter falhas ocultas durante a comunicação entre eventos e códigos subjacentes.

Outros possíveis problemas podem surgir. O fato das aplicações poderem ser executadas (ou facilmente recompiladas) em plataformas diferentes daquelas que foram desenvolvidas originalmente pode ser visto como um conceito fundamental de programação de alto nível. Esta é a característica base de código de software que permite sua reutilização, em vez de criar um novo código de software quando são deslocados de um ambiente para outro. Por outro lado, se o aplicativo tem uma GUI, a sua execução em diferentes plataformas pode trazer problemas para o desenvolvedor. Tais problemas podem ocorrer, por exemplo, porque o L\&F da GUI, os sistemas de cores, as fontes e as resoluções de tela são diferentes de uma plataforma para outra. Por exemplo, se um programa tem uma interface gráfica que foi programada para ser inicializada em um determinado tamanho de tela, ele pode não funcionar corretamente quando executado em uma plataforma diferente. O mesmo pode ocorrer quando o L\&F ou o sistema de cores é diferente da original (Oliveira et al., 2010).

No que se refere ao teste de software de sistemas com interfaces gráficas, assegurar uma separação completa do código entre design da GUI e comportamento do programa exigiria um esforço significativo dos testadores. Diante disso, fazem-se necessárias propostas e estudos empíricos relatando novas abordagens, estratégias, metodologias e critérios que contribuam para a solução dessa problemática. Buscando cooperar com esse tema, a ideia central desta dissertação de mestrado é explorar a técnica CBIR como forma de oráculos de teste capazes de apoiar a automatização do teste de sistemas com GUIs. Para isso, este trabalho fornece subsídios para a exploração do framework O-FIm (do inglês Oracle For Image), apresentado em pesquisas anteriores (Delamaro et al., 2011; Oliveira et al., 2008, 2009a, 2010), e aprimorado neste trabalho, como estratégia de criação de oráculos de teste capazes de avaliar o estado final de sistemas de software com GUIs.

A despeito de diversas pesquisas terem sido dedicadas ao teste para sistemas com GUIs, os esforços manuais necessários ainda são grandes. Assim, quanto mais se tem escrito 
sobre estratégias para obter a correção em programas de diversas áreas de confiabilidade de software, o estado da arte continua a não satisfazer as necessidades de validação de tais sistemas. Ainda é possível afirmar que a maioria dos testes para essa vertente necessitam do acompanhamento de um testador ou são apenas semi-automatizados (Hoffman, 2001). A literatura aponta que, atualmente, técnicas e critérios de testes envolvendo GUIs são incompletas, ad-hoc ou com alta dependência de uma figura humana conduzindo tais atividades (Memon et al., 2000). Entretanto, negligenciar tais testes, muitas vezes, pode remeter à produção de software de baixa qualidade (Oliveira et al., 2009a).

\subsection{Objetivos}

O framework O-FIm viabiliza a automatização de oráculos de teste para domínios específicos utilizando o uso de conceitos de CBIR para automatizações de oráculos de teste. Para tanto, é necessário que sejam desenvolvidas estruturas (plugins) conhecidas como extratores de características de imagem e funções de similaridades. Diante disso, este trabalho tem como meta o fornecimento de subsídios para a utilização do framework O-FIm e de oráculos gráficos (método Gr-O, do inglês Graphical Oracle) como forma de apoio à automatização do teste de sistemas com GUIs.

Para tanto, a condução do trabalho visa a enaltecer como foi realizado o desenvolvimento de plugins - extratores de características de imagens capazes de abstrair características e aspectos visuais fundamentais para julgar a correção de um sistema por meio de sua GUI, baseando-se em características de uma interface modelo. Deste modo, diferentes extratores foram implementados, validados e disponibilizados como forma de software livre.

Adicionalmente, este trabalho visa a contribuir com a definição e avaliação de novas abordagens para a definição de oráculos de apoio ao teste de sistemas com GUIs. Utilizando como fonte de informação principal os aspectos visuais de screenshots de aplicações em teste, uma avaliação empírica foi elaborada e, desse modo, um estudo de caso foi conduzido. A partir de seus resultados é possível avaliar a estratégia, evidenciando seus pontos positivos e identificando suas limitações. Diante desse contexto, pretende-se, ainda, é fornecer uma visão geral e pragmática acerca da efetividade do uso da tecnologia CBIR como apoio a configuração de oráculos de teste para sistemas com GUIs.

É necessário ressaltar que o trabalho de mestrado apresentado por meio desta dissertação é um dos resultados dos projetos de pesquisa intitulados "Definição de oráculos de teste para programas com saída gráfica usando recuperação baseada em conteúdo" e "Apoio à sistematização e automatização da atividade de teste de software" fomenta- 
dos pelo Conselho Nacional de Desenvolvimento Científico e Tecnológico (CNPQ) sob os processos 551002/2007-7 e 559915/2010-1, respectivamente.

\subsection{Organização do Trabalho}

Neste capítulo introdutório foram apresentados contexto, motivação e objetivos do trabalho de mestrado desenvolvido. O restante da dissertação está assim organizada: no Capítulo 2 são descritos alguns aspectos conceituais acerca do teste automatizado e de mecanismos de oráculos. O Capítulo 3 tem a função de apresentar e exemplificar aspectos relacionados a GUIs e CBIR. Em seguida, no Capítulo 4, apresentam-se detalhes técnicos e aspectos operacionais do framework O-FIm. No Capitulo 5 são especificados os extratores de características visuais de GUIs implementados durante este trabalho. Adicionalmente, no mesmo capítulo, um estudo comparativo envolvendo Gr-O e métodos tradicionais para automatização de oráculos para sistemas com GUIs é apresentado. No Capítulo 6 é apresentado um estudo de caso realizado para apoiar o trabalho realizado. Por fim, no Capítulo 7 são apresentadas e discutidas as conclusões da realização do trabalho. 


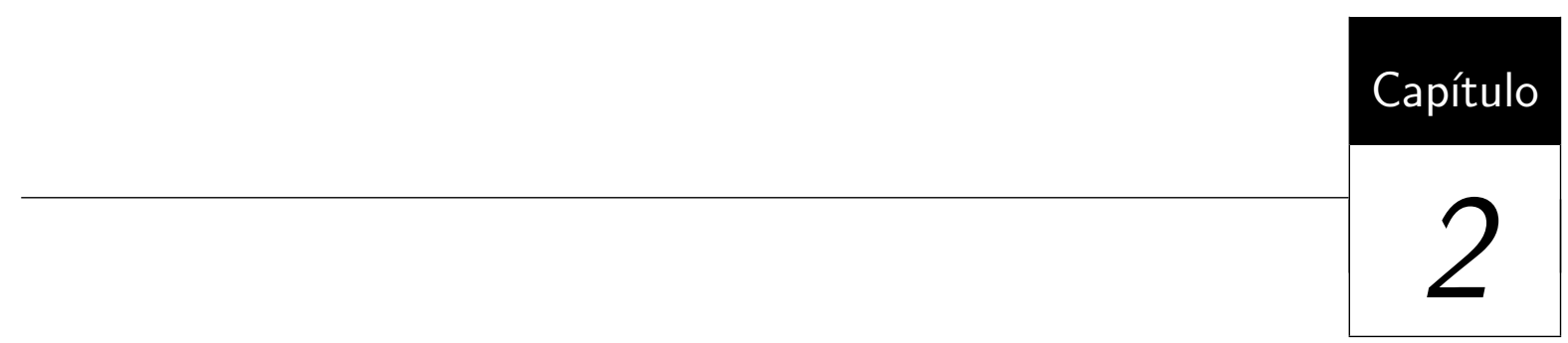

\section{Aspectos Conceituais}

\subsection{Considerações Iniciais}

Este capítulo tem o objetivo de apresentar conceitos fundamentais para o entendimento completo do trabalho de mestrado desenvolvido. Em termos gerais, os conceitos a serem apresentados foram definidos em torno de duas áreas fundamentais da Engenharia de Software - teste de software (Seção 2.2) e mecanismos e estratégias de oráculos de teste (Seção 2.3). Em relação à primeira área, este capítulo apresenta conceitos introdutórios suficientes para o bom entendimento e a contextualização do trabalho. Por outro lado, em relação à segunda área, são definidos e exemplificados conceitos mais profundos e específicos.

\subsection{Teste de Software}

A solução de um problema do mundo real projetada por um desenvolvedor de software, usando um sistema computacional, deve considerar diversos aspectos. Diferentes algoritmos, recursos e tecnologias podem ser aproveitados para que determinada solução seja implementada. Desconsiderando decisões particulares de cada projeto como, por exemplo, escolhas de tecnologias e linguagens de programação, pode ser que nem sempre o programa se comporte de acordo com sua especificação. Entre outros motivos, essas imperfeições podem ser causadas pelo fato de que o programador deve "escrever" o código 
do sistema. Um programador, durante o ato da escrita de um programa, pode cometer enganos (mistakes). Tais enganos configuram defeitos (faults) para a realização de um processo, método ou atividade. A manifestação de defeitos leva um sistema a um estado inconsistente e isso pode configurar diversos erros (errors). Por fim, quando uma parte defeituosa do código é executada e leva o sistema a um estado inesperado, que é propagado pela saída do sistema, falhas (failures) são reveladas (Delamaro et al., 2007; Mathur, 2007).

Conforme mencionado, outros motivos podem influenciar negativamente o comportamento de um sistema. Por exemplo, o programador pode ter interpretado de modo errado um requisito do sistema e, por isso, o código foi escrito de maneira indesejada. Outra possibilidade que pode gerar falhas é a execução dos sistemas em diferentes ambientes. Há algumas décadas, essas diversidades fazem com que pesquisadores dediquem esforços e pesquisas para a melhoria da qualidade de software. Na década de 70 foi publicada uma obra literária que pode ser considerada uma referência para a comunidade da computação e, principalmente, para a comunidade de Engenharia de Software. Myers (1979), intitulada "The Art of Software Testing", destacou-se por tratar de questões que revelavam a importância do teste nos projetos de desenvolvimento de software. Além disso, a obra serviu como veículo de divulgação de dados quantitativos interessantes da época como, por exemplo, o fato de que $50 \%$ do tempo dos projetos eram dedicados a atividades de teste e que, consequentemente, aproximadamente $50 \%$ do custos dos projetos eram despendidos com o teste. No ano de 2004, tal obra foi atualizada, reescrita, ajustada de acordo com novas tecnologias e publicada novamente. Myers (2004) revelou que, apesar da notável evolução dos sistemas computacionais, o cenário referente ao teste de software não sofreu grandes alterações. Assim, apesar do fato de que linguagens de programação, paradigmas e IDEs (do inglês Integrated Development Environment) tenham evoluído significativamente, o teste continua a desempenhar papel fundamental nos projetos de desenvolvimento de software (Myers, 2004).

Uma definição comum para as atividades de teste de software é como sendo o processo, ou série de processos, que têm a função de executar um sistema com a intenção de encontrar possíveis erros (Myers, 2004). Entretanto, por algum tempo, algumas definições encontradas na literatura baseiam-se na ideia de que as atividades de teste configuram processos que têm a finalidade de investigar se um software desempenha, de maneira correta, o papel que lhe é atribuído. Tal definição é rotulada como equívoca, baseando-se em dois argumentos: o primeiro é que um software pode fazer o que dele é esperado e ainda assim conter erros; o segundo é que quando um testador assimila tal definição, implicitamente ele deve esperar que o programa desempenhe o que lhe é atribuído de maneira correta, desviando seu foco principal - detectar e corrigir erros. 
Para a maioria dos sistemas em desenvolvimento, o processo de teste é o meio mais importante pelo qual tais sistemas são submetidos para terem sua conformidade com especificações verificadas (Hunter e Strooper, 2001). Por isso, o interesse da indústria de software por questões de qualidade é crescente. No entanto, a aplicação de técnicas e critérios de teste de software adequados, durante todas as fases do processo de desenvolvimento, implica aumento de custo para seu desenvolvedor. Em contraste a isso, negligenciar as atividades de teste, muitas vezes, pode remeter à produção de software de má qualidade e a prejuízos econômicos (Sommerville, 2004). Em casos particulares, nos quais o sistema em desenvolvimento consistir de um sistema crítico, o teste de software é valorizado ainda mais. Nesses casos, sua negligência pode causar resultados desastrosos.

Casos conhecidos como "Therac 25" (Leveson, 1993) e "voo Lufthansa 2974" (Associated Press/Houston Chronicle, 1993) configuram exemplos de erros de software que causaram resultados trágicos. O primeiro caso se refere a uma máquina de radioterapia na qual erros no sistema que controlava a dose de radiação provocaram acidentes que causaram pelo menos 5 mortes em 6 acidentes ocorridos entre os anos de 1985 e 1987 . O segundo caso se refere ao Airbus A320 que voava de Frankfurt (Alemanha) para Varsóvia (Polônia) em 14/09/1993. Um erro no software que auxiliava os procedimentos de pouso fizeram com que a aeronave da empresa alemã Lufthansa pegasse fogo durante a aterrissagem, provocando a morte de 2 passageiros e ferimentos em outros 54 .

Ainda nesse contexto, Charette (2005) destaca diversos episódios nos quais sistemas de software mal testados geraram prejuízos de grandes proporções para empresas de diferentes segmentos de negócio. Na Tabela 2.1 são ilustrados alguns dos prejuízos recentes, entre os anos de 2000 e 2005, gerados por erros de sistemas de software em grandes organizações.

\subsubsection{Atividades de Teste de Software}

Atividades de teste de software, aplicadas criteriosamente, agregam valores ao sistema em teste (SUT - do termo inglês, System Under Test). Quando um programa "P" é submetido a processos de teste, espera-se que, após a finalização de tais processos, defeitos tenham sido encontrados ou, caso contrário, seja aumentada a confiança de que "P" desempenha com sucesso o papel para o qual foi desenvolvido. Assim, agregar valor por meio de testes significa aumentar a qualidade e a confiabilidade do programa. Sob outra perspectiva, aumentar a confiabilidade do programa pode ser considerado como sendo a identificação e a eliminação de defeitos.

De um modo pragmático, as atividades de teste de software consistem em exercitar uma aplicação, observando seus resultados, comparando-os com alguns valores de resultados esperados e relatando suas consequências (Hoffman, 2001). Em uma visão genérica acerca do teste de software, pode-se considerar que atividades de teste são divididas em três fases: 
Tabela 2.1: Prejuízos recentes gerados por sistemas de software problemáticos em grandes organizações (adaptado de Charette (2005))

\begin{tabular}{|c|c|c|}
\hline Ano & Empresa & Consequência (custo em dólares) \\
\hline 2005 & Hudson Bay Co. (Canadá) & $\begin{array}{l}\text { Problemas com um sistema de inventário contri- } \\
\text { buíram para a perda de US } \$ 33.3 \text { milhões }\end{array}$ \\
\hline 2004-05 & UK Inland Revenue (UK) & $\begin{array}{l}\text { Erros de software contribuíram para o pagamento } \\
\text { de US } \$ 3.4 \text { bilhões de créditos de impostos indevi- } \\
\text { dos }\end{array}$ \\
\hline 2004 & Avis Europe PLC (UK) & $\begin{array}{l}\text { Foi cancelado o uso de um sistema ERP (do termo } \\
\text { inglês, Enterprise Resource Planning) após gasta- } \\
\text { rem US } \$ 54.4 \text { milhões }\end{array}$ \\
\hline 2004 & Ford Motor Co. (USA) & $\begin{array}{l}\text { Um sistema de compras foi abandonado após sua } \\
\text { implantação que custou cerca de US\$ } 400 \text { milhões }\end{array}$ \\
\hline 2004 & J Sainsbury PLC (UK) & $\begin{array}{l}\text { Um sistema de cadeia de fornecimento que custou } \\
\text { US\$ } 527 \text { milhões foi abandonado após sua implan- } \\
\text { tação }\end{array}$ \\
\hline 2004 & Hewlett-Packard Co. (USA) & $\begin{array}{l}\text { Problemas com um sistema ERP contribuíram } \\
\text { para a perda de US } \$ 160 \text { milhões }\end{array}$ \\
\hline 2003-04 & AT\&T Wireless (USA) & $\begin{array}{l}\text { Problemas em um sistema de Gestão de Relacio- } \\
\text { namento com Clientes (CRM do termo inglês Cus- } \\
\text { tomer Relationship Management) levaram à perda } \\
\text { de US } \$ 100 \text { milhões }\end{array}$ \\
\hline 2002 & McDonald's Corp (USA) & $\begin{array}{l}\text { Um inovador sistema de informação para compras } \\
\text { foi cancelado depois de terem sido gastos US } \$ 170 \\
\text { milhões }\end{array}$ \\
\hline 2002 & Sydney Water Corp. (Austrália) & $\begin{array}{l}\text { Um sistema de faturamento foi cancelado após te- } \\
\text { rem sido gastos US } \$ 32.2 \text { milhões }\end{array}$ \\
\hline 2002 & CIGNA Corp. (USA) & $\begin{array}{l}\text { Problemas em um sistema CRM contribuíram para } \\
\text { a perda de US } \$ 445 \mathrm{mi}\end{array}$ \\
\hline 2001 & Nike Inc.(USA) & $\begin{array}{l}\text { Erros em um sistema de cadeia de fornecimento } \\
\text { levaram à perda de aproximadamente US } \$ 100 \text { mi- } \\
\text { lhões }\end{array}$ \\
\hline 2001 & Kmart Corp. (USA) & $\begin{array}{l}\text { Um sistema de cadeia de fornecimento gerou gastos } \\
\text { de US } \$ 130 \text { milhões }\end{array}$ \\
\hline 2000 & Washington, DC (USA) & $\begin{array}{l}\text { Um sistema de folha de pagamentos da cidade foi } \\
\text { abandonado após sua implantação deixando um } \\
\text { prejuízo de US\$ } 25 \text { milhões }\end{array}$ \\
\hline
\end{tabular}

ajuste de condições no sistema (1), execução ou simulação de execução (2) e, por fim, averiguação de resultados (3). A primeira fase, muitas vezes negligenciada, é fundamental para a criação de condições necessárias para a manifestação de erros (assumindo a hipótese de que existam erros no SUT) e aumentando a produtividade das atividades. A segunda fase exercita o código por meio de entradas que possam provocar manifestações de defeitos. Por fim, é verificado se realmente há defeitos no código, tarefa a ser realizada na terceira fase das atividades de teste.

Tanto em paradigmas de teste manual quanto em paradigmas de teste automatizado, consideram-se essas etapas. O teste manual é configurado quando uma pessoa (testador) que alimenta o sistema em teste com entradas, avaliando os resultados do processamento de tais entradas nesse sistema (Hoffman, 2001). Em contrapartida, é aquele realizado com o apoio de ferramentas desenvolvidas especialmente para contribuírem com a qualidade dos sistemas em desenvolvimento. 
Atividades de teste mal conduzidas, sejam elas automatizadas ou manuais, aumentam o custo de manutenção do software, uma vez que correções precisarão ser feitas quando erros forem notificados pelos usuários. Com o pressuposto de facilitar a identificação e possibilitar a correção de erros em um determinado software, existem técnicas e critérios de teste. Tais técnicas e critérios apoiam a realização das atividades de teste de forma sistemática e criteriosa. Por isso, elas podem ser consideradas estratégias que buscam minimizar esforços e maximizar a eficácia em busca de defeitos no software.

Por exemplo, a técnica de teste baseada em erros utiliza informações sobre os tipos de erros mais frequentes no processo de desenvolvimento de software para derivar requisitos de teste (Delamaro et al., 2007). Essa técnica é focada nos erros que os programadores envolvidos no processo de desenvolvimento do software podem inserir no código, e como devem ser feitas abordagens para detectar esses erros. Uma das principais abordagens nesse contexto é o critério denominado análise de mutantes. Nesse critério, com o intuito de revelar os erros mais comuns introduzidos nos programas pelos programadores, são criadas várias versões modificadas (mutantes) a partir de um programa original em teste (DeMillo, 1989). Diante disso, o trabalho do testador é escolher casos de teste que revelem diferenças de comportamento entre programa mutante e programa original (Delamaro et al., 2007).

Técnicas e ferramentas são indispensáveis para a prática de atividades de teste de maneira sistematizada e com embasamento científico (Delamaro et al., 2007). O aproveitamento de ferramentas que realizam o teste de maneira sistemática traz o conceito de automatização das atividades de teste. A implantação do teste automatizado em projetos de desenvolvimento de software pode trazer uma economia significativa, sendo um fator auxiliar na redução de custos de análises. Automatizar processos de teste é uma questão de destaque para a área de Engenharia de Software pelo fato de promover abordagens de teste mais sistemáticas, produtivas e confiáveis (Ivory e Hearst, 2001). Todavia, automatizar mecanismos de teste não é um trabalho trivial. Na Subseção 2.2 .2 são especificados aspectos importantes para a automatização das atividades de teste.

\subsubsection{Automatização do Teste}

A dedicação especial requerida pelas atividades de teste, além de aumentar o custo de desenvolvimento, consome tempo de projeto considerável. Entretanto, o emprego de testes automatizados é uma boa prática para o aumento da produtividade e para a diminuição de custos. Neste tipo de teste, ao contrário do teste manual, um sistema de software é responsável por executar dados de teste, uma ou "n" vezes e avaliar seus resultados (Hoffman, 2001). Dados de teste são um conjunto de valores do domínio de entrada e os resultados esperados de sua execução. Em diferentes ambientes de desenvolvimento e teste, 
a automatização das atividades de teste pode ser configurada por programas ou scripts cujas principais capacidades sejam exercitar funcionalidades dos SUTs e fazer verificações automáticas com a intenção de identificar possíveis efeitos colaterais (Bernardo e Kon, 2008).

O termo teste automatizado pode assumir diferentes significados, dependendo do contexto no qual é inserido. Segundo o contexto do trabalho realizado por Hoffman (2001), o teste automatizado completo deve satisfazer algumas condições básicas:

- executar e reexecutar, automaticamente, casos de teste especificados ou conjunto de casos de teste;

- não necessitar de intervenção humana após ajustes dos testes;

- permitir ajuste automático de condições do sistema e persistência para estas condições/ajustes;

- permitir captura de resultados relevantes;

- promover a comparação com resultados esperados; e

- disponibilizar métodos para análise de resultados ("pass"/fail").

É comum que testes automatizados sejam idealizados a partir de conversões de testes manuais existentes e, assim, em muitos casos, podem configurar um processo difícil e complexo. Os aspectos mais familiares do teste automatizado envolvem atividades como organizar e executar casos de teste, capturando e verificando seus resultados (Hoffman, 2001). Diante disso, dependendo da aplicação, a implementação de mecanismos que automatizem atividades de teste configura um processo complexo e trabalhoso. Tecnicamente, a verificação automática de determinados resultados pode ser bastante difícil. Por exemplo, a implementação da verificação automática da sincronização entre uma trilha sonora qualquer e um vídeo pode ser uma atividade não trivial. Ainda nesse contexto, um testador pode encontrar dificuldades em automatizar os testes de um sistema capaz de editar matérias jornalísticas nas quais narração e imagens devem ter sincronismo pré-determinado por um editor-jornalista. Outro exemplo é automatizar mecanismos capazes de identificar se uma página impressa está de acordo com o que era exibido por um editor de textos qualquer.

Os exemplos mencionados mostram casos extremos de domínios que dificultam a automatização de um aspecto do teste por meio do computador. Adicionalmente, esses mesmos domínios configuram casos de verificação extremamente simples quando o teste manual é realizado. Para uma figura humana, a verificação visual dos resultados de execução de tais domínios, apesar de exigir atenção extrema, é uma atividade trivial. Diante disso, nota-se que o investimento para automatização de alguns domínios de testes é financeiramente inviável para as indústrias (Hoffman, 2001). 


\subsubsection{Teste Manual versus Teste Automatizado}

A implantação de testes manuais durante diversas fases de desenvolvimento de software é prática comum em diversas organizações. Genericamente, essa modalidade de teste é dividida pelas equipes de desenvolvimento, em seis etapas pré-definidas: escrita de código (1), atualização de código em alguns trechos (2), compilação (3), execuções manuais de código e, às vezes, preenchimento de formulários (4), checagem de arquivos de log, bases de dados, serviços externos, valores de variáveis, saídas na tela etc (5). Ao final dos passos, os resultados são verificados (6). No caso do código não funcionar conforme é esperado, as etapas anteriores devem ser retomadas (Bernardo e Kon, 2008; Hoffman, 2006). A Figura 2.1 foi estruturada como forma de representar graficamente as etapas genéricas do teste manual.

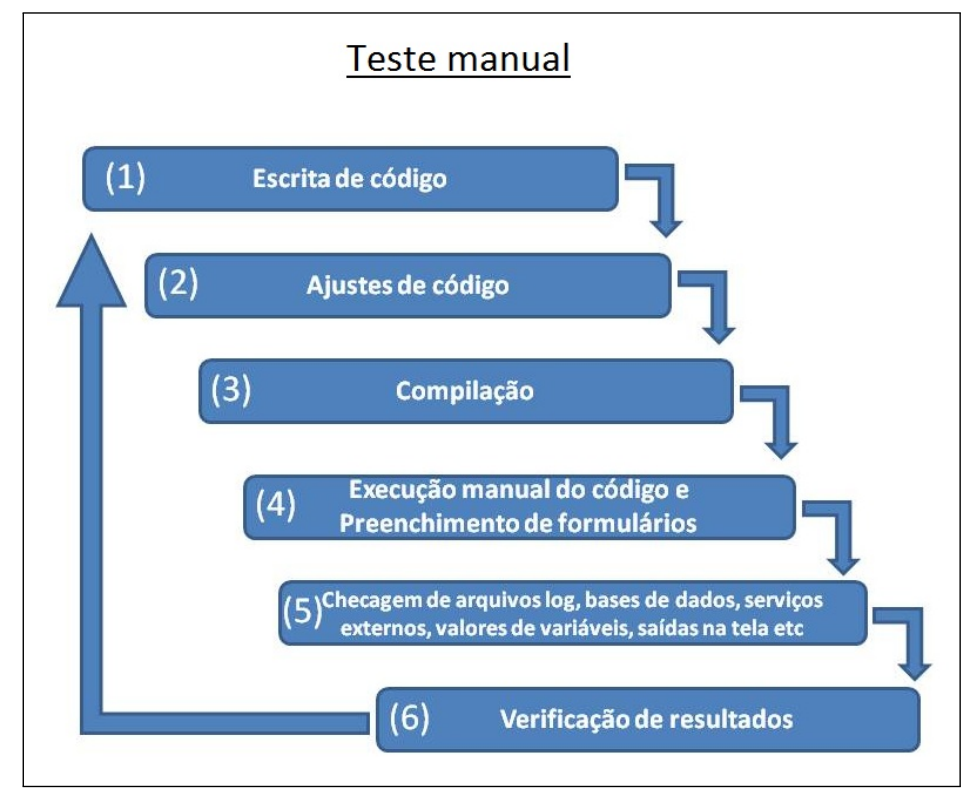

Figura 2.1: Representação gráfica do teste manual

A aplicação do teste manual pode ser inviável devido às diversas etapas ilustradas na Figura 2.1 e dependendo do tamanho do projeto em desenvolvimento. Por exemplo, a adição de um requisito em determinado módulo de um grande projeto ou, então, uma simples manutenção trazem a necessidade de atividades de teste em todos os outros módulos do sistema. Considerando a hipótese do teste manual de cada um dos módulos, por questões de tempo e custo, pode ser que reaplicações tornem-se impraticáveis (Ivory e Hearst, 2001).

Por meio da Tabela 2.2, podem-se analisar algumas características básicas das duas modalidades de teste, manual e automatizado. Tais características são apresentadas perante aspectos importantes em um ambiente de desenvolvimento e teste de software como, por exemplo, custo e produtividade. As vantagens de se aplicar o teste automatizado são 
notáveis: reexecução simples, suporte à regressão, tempo de projeto reduzido e uma maior produtividade são algumas delas. Por outro lado, o teste manual é mais simples de ser implementado e tem custo reduzido a curto prazo (Hoffman, 2006).

Tabela 2.2: Caracterizações do teste automatizado e do teste manual

\begin{tabular}{ccc}
\hline \multicolumn{2}{c|}{ teste manual vs teste automatizado } \\
\hline & teste manual & teste automatizado \\
\hline \hline Condução & humano & máquina \\
Reexecução & demorada/cansativa & simples/rápida \\
Suporte à regressão & não & sim \\
Implementação & simples & complexa \\
Custo & alto & baixo \\
Tempo de projeto & extenso & reduzido \\
Produtividade & baixa & alta \\
\hline
\end{tabular}

Qualquer comparação justa entre teste manual e automatizado deve desconsiderar variações nos tamanhos de projeto e de equipe. Tendo isso como parâmetro, além dos aspectos apresentados na Tabela 2.2, existem claras vantagens e desvantagens, tanto para o emprego de teste automatizados quanto para a utilização de teste manuais (Bernardo e Kon, 2008; Hoffman, 2006). Com o objetivo de expor esse cenário, na Tabela 2.3 foi elaborado um comparativo que enumera algumas vantagens e desvantagens do emprego das duas abordagens de teste pelas organizações.

A vantagem mais notável do teste manual sobre o automatizado se dá pelo fato de que uma pessoa executando testes manualmente é capaz de identificar comportamentos inesperados que o teste automatizado não seria capaz de identificar. Um humano seria capaz de perceber oscilações na tela, pausas demasiadamente longas para reexecuções do SUT ou, então, qualquer outro comportamento indesejado que um sistema de teste automatizado tivesse dificuldade de identificar. Além disso, no teste automatizado, pode ser que determinado caso de teste seja considerado como bem sucedido e depois disso, por diversos motivos, o sistema apresente problemas. Esse cenário indesejado também será facilmente identificado por uma figura humana acompanhando a execução dos testes. O fato é que falhas podem ser causadas por uma infinidade de motivos diferentes e o teste automatizado é capaz de checar apenas algumas delas (Hoffman, 2001).

Ainda considerando as vantagens do teste manual, é importante ressaltar que o SUT pode comportar-se de modo diferente dependendo de questões do ambiente de execução como, por exemplo, versão do sistema operacional, tamanho de memória, configuração de paginação, velocidade e número de processadores, tráfego de rede etc. Além disso, deve-se considerar que causas extremas podem gerar erros. Tais causas são ainda mais difíceis de serem testadas e previstas. Como exemplo, podem ser citados aspectos de temperatura, 
Tabela 2.3: Vantagens e desvantagens da aplicação dos testes manuais e automatizados

\begin{tabular}{|c|c|}
\hline Vantag & gens \\
\hline $\begin{array}{l}\text { *acompanhamento humano possibilita a noti- } \\
\text { ficação de diversos comportamentos inespe- } \\
\text { rados }\end{array}$ & $\begin{array}{l}\text { *a eficiência em detectar erros deve con- } \\
\text { siderar a fadiga humana } \\
\text { *determinados dados de teste, iterações e } \\
\text { combinações podem requerer automatização } \\
\text { *determinados aspectos podem não ter solu- } \\
\text { ções manuais (ex: análises de performance) } \\
\text { *a espera do testador por determinados er- } \\
\text { ros, após algumas repetições,prejudica a } \\
\text { detecção de defeitos }\end{array}$ \\
\hline \multicolumn{2}{|c|}{ Teste Automatizado } \\
\hline Vantagens & Desvantagens \\
\hline $\begin{array}{l}\text { *casos de testes mais complexos, bem ela- } \\
\text { borados e eficientes } \\
\text { *ferramentas aliam quantidade, produtivi- } \\
\text { dade e eficácia } \\
\text { *possibilidade de transferência de tecno- } \\
\text { logia entre indústria e academia } \\
\text { *eficiência para a detecção de tipos espe- } \\
\text { cíficos de erros em determinados domínios }\end{array}$ & $\begin{array}{l}\text { *alguns domínios de teste proporcionam di- } \\
\text { ficuldade extrema para automatizações } \\
\text { *verificação apenas das condições para as } \\
\text { quais foi projetado para averiguar } \\
\text { *dificuldades em definir quais as condiçõ- } \\
\text { es devem ser verificadas para classificar } \\
\text { um teste como bem sucedido } \\
\text { *automatizações que geram casos de teste } \\
\text { são de implementação complexa } \\
\text { *dificuldade em predizer como um SUT deve } \\
\text { se comportar e quais consequências são } \\
\text { esperadas em uma execução }\end{array}$ \\
\hline
\end{tabular}

campos magnéticos, descargas eletrostáticas e outros fatores físicos que influenciam o funcionamento de um software. Tais tipos de erros não são comuns, mas acontecem e devem ser considerados (Hoffman, 1998).

Por isso, outro fato a ser considerado é que a realização do teste manual pode ser eficaz sem que o testador tenha definido antecipadamente quais são os resultados esperados. Adicionalmente, após algumas reexecuções, por meio da adaptação, é possível que sejam verificados aspectos imprevistos em momentos diferentes do teste. Assim, quando algum comportamento inesperado é identificado, o testador pode rapidamente averiguar detalhes de especificação para defini-lo como correto ou não.

Conforme pode ser observado nas tabelas 2.2 e 2.3, a automatização das atividades de teste apresentam diversas vantagens sobre o teste manual, podendo, inclusive, servir como poderosas ferramentas para identificar determinados tipos de erros. Reexecuções manuais de dados de teste podem consumir muito tempo e serem cansativas para os testadores. Esforços consideráveis são necessários para executar todo o conjunto de testes manuais 
e dificilmente, após cada correção de um erro, o conjunto é executado novamente como seria desejável. Muitas vezes, isso leva a erros de regressão, que são erros em módulos do sistema que estavam funcionando corretamente e deixam de funcionar. A tendência é que esse ciclo se repita até que a manutenção do sistema se torne uma tarefa tão custosa para a equipe de desenvolvimento que passa a valer a pena reconstruí-lo completamente (Hoffman, 1998, 2001). Em contrapartida, quando há abordagens automatizadas para o teste de determinado sistema, a reexecução dos dados de teste torna-se uma tarefa trivial.

Além disso, para alguns dados, iterações de teste e combinações, pode ser que não haja outra maneira de realizar o teste se não for de modo automatizado. A capacidade do teste automatizado em realizar as atividades para as quais foi programado, quantas vezes forem necessárias, contribui para o aumento da produtividade e representa uma forma de reduzir os custos. Essa característica configura a grande vantagem de abordagens automatizadas, pois todos os casos de teste podem ser fácil e rapidamente repetidos a qualquer momento e com pouco esforço. Assim, a reprodução fiel e contínua dos testes permite simular situações específicas, de modo idêntico e inúmeras vezes, garantindo que passos importantes não sejam ignorados por falha humana e facilitando a identificação de um possível comportamento indesejado.

Alguns métodos de desenvolvimento ágeis como, por exemplo, $X P$ (do termo inglês, eXtreme Programming), recomendam o teste automatizado para ajudar a garantir a qualidade dos sistemas de software. No que se refere ao âmbito industrial, as vantagens do teste automatizado podem ser ainda maiores quando consideram-se questões como, por exemplo, vantagem competitiva e diferencial de produtos finais perante os concorrentes.

Por outro lado, no âmbito acadêmico, a exploração dos testes automatizados promove o uso de ferramentas capazes de auxiliar pesquisadores e alunos de Engenharia de Software a fixarem conceitos de teste. É sabida a necessidade de ensinar o desenvolvimento de software de alta qualidade para alunos iniciantes. Uma possível solução para isso é o ensino de técnicas e critérios de teste que possam ser aplicados por aprendizes durante o processo de desenvolvimento e criação de software. Desse modo, é possível que o desenvolvimento de software seja ensinado concomitantemente às técnicas de teste aplicáveis aos programas desenvolvidos durante o processo de ensino. O aluno pode fixar mais rapidamente a linguagem de programação posta em prática e criar o hábito de testar seus programas em desenvolvimento (Oliveira et al., 2011).

Sendo assim, é possível definir que ferramentas de teste podem auxiliar o processo de ensino de alunos iniciantes na programação por meio da implementação de um critério ou técnica de teste de software. Além disso, implementações de ferramentas acadêmicas permitem que tais ambientes sigam em constante evolução, contribuindo para o desenvolvimento de sistemas de software de qualidade (Vincenzi, 1998). 


\subsubsection{Frameworks, APIs e bibliotecas de apoio ao teste automatizado}

À medida que cresce a complexidade das aplicações e de seus processos de teste, cresce também a prática de aproveitar frameworks (arcabouços). Em termos gerais, para o contexto de Engenharia de Software, um framework consiste de um conjunto de funcionalidades que colaboram para realizar uma responsabilidade para um domínio de um subsistema da aplicação (Fayad e Schmidt, 1997). No contexto do teste automatizado, tais frameworks são explorados como forma de auxiliar a padronização e formalização de códigos para abordagens automatizadas de teste.

Frameworks de teste, inicialmente, foram desenvolvidos com o intuito de solucionar problemas oriundos de uma prática comum dos desenvolvedores que era a criação de funções de teste em cada módulo ou classe do sistema. Geralmente, essas funções continham algumas simulações do uso de unidades do sistema. Essa prática funcionava de modo similar à depuração, que é uma forma de monitorar determinada execução de um sistema qualquer, misturando código adicional de teste e código do próprio sistema e afetando negativamente a legibilidade do código. Por isso, o uso de frameworks é benéfico ao desenvolvimento de sistemas de software, melhorando a qualidade e reduzindo o tempo de desenvolvimento.

Adicionalmente, além de frameworks, bibliotecas e APIs (do inglês Application Programming Interface) têm sido desenvolvidas com o propósito de apoiar o teste automatizado de domínios específicos. Para o contexto do presente trabalho, não existem diferenças entre as definições de bibliotecas e APIs, e ambas podem ser consideradas como sendo o conjunto de rotinas e padrões preestabelecidos por um software para a simples utilização de suas funcionalidades por outros aplicativos. De um modo pragmático, bibliotecas e APIs são coleções de subprogramas, compostas por uma série de funções acessíveis somente por programação, utilizados no desenvolvimento de software (Deitel e Deitel, 2004). Apesar das funcionalidades principais serem as mesmas das APIs e bibliotecas, um framework é mais específico e pode até exigir determinada arquitetura para um projeto de software.

Uma arquitetura conhecida como $x$ Unit, muito utilizada em frameworks de teste, configura um exemplo de estrutura genérica capaz de introduzir mecanismos eficientes para apoiar desenvolvedores na adição de testes unitários (teste de unidade) automáticos, estruturados e eficientes em atividades normais de desenvolvimento. A arquitetura $x$ Unit pode, inclusive, ser considerada um padrão para frameworks automáticos de testes unitários ou de unidades. O teste de unidade pode ser definido como o processo que consiste na verificação da menor unidade do projeto de software (Delamaro et al., 2007).

O precursor dessa arquitetura é o framework SUnit (2011) para a linguagem de programação SmallTalk, que ganhou versões para outras linguagens de programação, tais 
como JUnit (2011) e TestNG (2011) para Java, JSUnit (2011) para JavaScript, CppTest (2011) para $\mathrm{C}_{++}$, csUnit $^{1}$ para .NET, entre outras (Bernardo e Kon, 2008). A maioria desses frameworks pode ser associada a IDEs de desenvolvimento no formato de plugins, facilitando a implementação e execução dos testes, bem como a visualização e a avaliação de seus resultados.

Na Listagem 2.1 é exibido um exemplo de como o framework JUnit (2011), que tem plugins para os IDEs Eclipse ${ }^{2}$ e NetBeans ${ }^{3}$, pode ser explorado para o teste de unidade. Na referida listagem, o código exemplifica o teste automatizado de um método que verifica se determinada obra, identificada por um nome (String), está, ou não, cadastrada em uma biblioteca (classe Library()).

Listagem 2.1: Teste automatizado por meio do framework JUnit (2011)

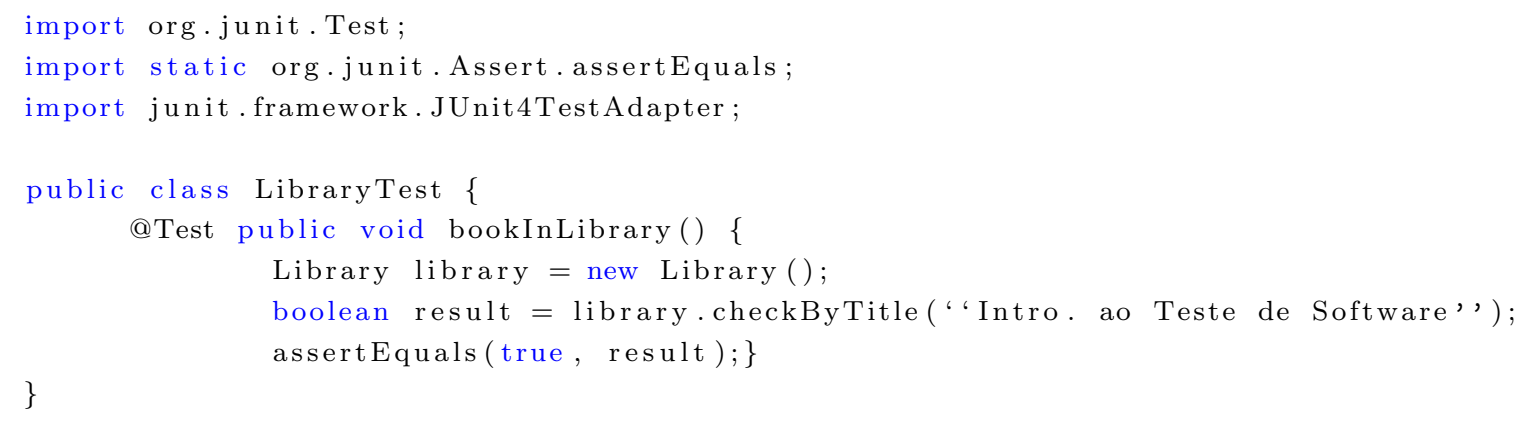

Além dos frameworks da família $x U$ nit, algumas bibliotecas e APIs de apoio à automatização das atividades de teste foram desenvolvidas e disponibilizadas. Ferramentas vêm sendo aproveitadas, tanto na indústria quanto na academia, para aumentar a qualidade e a confiabilidade dos produtos de software. Na Tabela 2.4 apresentam-se algumas ferramentas de teste automatizado. A análise da tabela revela uma pluralidade que é explicada pelo fato de que diferentes técnicas e critérios podem ser empregados no teste de um sistema, assim, muitas das ferramentas citadas podem ser utilizadas em um teste de modo a tornarem-se complementares.

A tabela é bem objetiva e apresenta o nome de cada ferramenta, uma breve descrição de suas funcionalidades, um link de acesso a seu website oficial e, por fim, seu tipo de licença de distribuição ${ }^{4}$.

No cenário industrial atual, nota-se que a maioria das organizações automatiza suas tarefas relacionadas ao teste de seus produtos como, por exemplo, teste de interface e teste de regressão. No entanto, apesar do expressivo número de ferramentas disponíveis para o teste automatizado de domínios específicos, é comum que as organizações desenvolvam suas próprias ferramentas de teste de acordo com as necessidades de cada novo projeto, o

\footnotetext{
1 acesse http://www.csunit.org/

${ }^{2}$ acesse http://www.eclipse.org/

${ }^{3}$ acesse http://netbeans.org/

${ }^{4}$ Definições para cada um dos tipos de licença encontram-se disponíveis no Glossário desta dissertação
} 
Tabela 2.4: Relação de ferramentas comerciais e acadêmicas de apoio ao teste automatizado

\begin{tabular}{|c|c|c|}
\hline Ferramenta & Funcionalidade & Licença \\
\hline DBMonster & $\begin{array}{l}\text { Automatiza o teste de estresse para bancos de dados pos- } \\
\text { sibilitando melhorias de projeto para seus desenvolvedores. } \\
\text { http://www.dbmonster.com/ }\end{array}$ & Opensource \\
\hline JMeter & $\begin{array}{lrrrrr}\text { API Java que automatiza } & \text { testes } & \text { funcionais } & \text { e } & \text { de } \\
\text { desempenho, } & \text { principalmente, } & \text { para } & \text { aplicações } & \text { web. } \\
\text { http://jakarta.apache.org/jmeter/ } & & & & \end{array}$ & Opensource \\
\hline DieselTest & $\begin{array}{l}\text { Automatiza o teste de estresse simulando centenas ou milhares de } \\
\text { usuários em um site. http://sourceforge.net/projects/dieseltest/ }\end{array}$ & Freeware \\
\hline WAPT & $\begin{array}{l}\text { Ferramenta de teste de estresse para sites da web, ser- } \\
\text { vidores web e aplicações de intranet com interface web. } \\
\text { http://www.loadtestingtool.com/ }\end{array}$ & Trial \\
\hline Grinder & $\begin{array}{l}\text { É um framework de testes de estresse para sistemas distribuídos } \\
\text { em Java que possibilita a realização de testes por meio de máqui- } \\
\text { nas injetoras de carga. http://grinder.sourceforge.net/ }\end{array}$ & Opensource \\
\hline WinRunner & $\begin{array}{l}\text { Ferramenta de teste de estresse na camada de GU1. Executada no } \\
\text { formato record-playback das interações do usuário com a interface. } \\
\text { http://www.loadtest.com.au/Technology/winrunner.htm }\end{array}$ & Freeware \\
\hline Xtest & 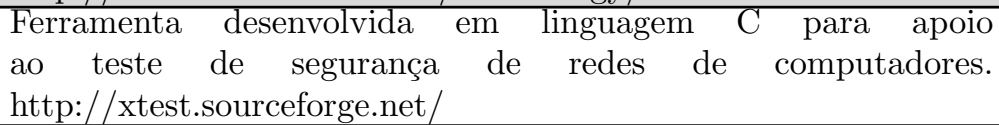 & Opensource \\
\hline Selenium & $\begin{array}{l}\text { Framework de apoio ao teste de aplicaçoes web por meio de me- } \\
\text { canismos de record/playback de scripts. http://seleniumhq.org/ }\end{array}$ & Opensource \\
\hline Clover & $\begin{array}{l}\text { Ferramenta comercial para o teste de cobertura de programas } \\
\text { Java. Oferece precisão nos testes e tem uma análise de cobertura } \\
\text { configurável. http://www.atlassian.com/software/clover/ }\end{array}$ & Trial \\
\hline JaBUTi & $\begin{array}{l}\text { Ferramenta de } \\
\text { gramas Java. } \\
\text { de controle e critérios baseados em fluxo de } \\
\text { http://ccsl.icmc.usp.br/pt-br/content/jabuti }\end{array}$ & Opensource \\
\hline Pascal Mutants & $\begin{array}{l}\text { Implementa o teste de mutação para programas Pascal, possibi- } \\
\text { litando o ensino de conceitos relacionados ao teste de mutação. } \\
\text { http://ccsl.icmc.usp.br/drupal5/pt-br/content/pascal-mutants }\end{array}$ & Opensource \\
\hline Poke-Tool & $\begin{array}{l}\text { Ferramenta acadêmica de apoio ao teste estrutural útil para exe- } \\
\text { cução de experimentos acadêmicos e ensino de técnicas de teste. } \\
\text { http://ccsl.icmc.usp.br/drupal5/pt-br/content/poke-tool }\end{array}$ & Opensource \\
\hline
\end{tabular}

que colabora com o aumento constante do número de ferramentas de teste para domínios específicos. Além disso, nas organizações, é comum a prática da exploração de mais de uma ferramenta para automatizar o teste de diferentes aspectos das aplicações em desenvolvimento (Mathur, 2007).

Conforme é apontado na Tabela 2.4, muitas das ferramentas de teste automatizado são distribuídas de modo Opensource e têm código aberto e disponível para alterações. No contexto de teste de software automatizado, é comum que grupos de pesquisa em Engenharia de Software alimentem portais eletrônicos disponibilizando gratuitamente ferramentas e frameworks que são frutos de pesquisas dedicadas à contribuição do desenvolvimento de software de qualidade. O CCSL $^{5}$ (Centro de Competência em Software Livre) do

\footnotetext{
${ }^{5}$ acesse http://ccsl.icmc.usp.br/drupal5/pt-br
} 
ICMC/USP configura um exemplo desses portais, disponibilizando para download diversas ferramentas e frameworks, muitos deles de apoio ao teste automatizado de software e úteis para o ensino prático de técnicas e critérios de teste.

\subsubsection{Contexto de Automatização para o Trabalho Proposto}

Para o propósito do presente trabalho, diversos aspectos podem ser automatizados como, por exemplo, verificação por meio de oráculos, captura de screenshots ou, então, captura de sequências de eventos de entrada. Levando em consideração que o domínio de teste a ser automatizado será constituído por sistemas de software com GUIs, a automatização do teste pode ser configurada quando um ambiente permite que o testador defina características que, se verificadas e julgadas como corretas, são suficientes para que a aplicação em teste seja bem sucedida. Para que tais características sejam julgadas, é possível que sejam utilizadas características de imagens modelo (telas capturadas screenshots de GUIs) como referências em substituição ao teste manual e à necessidade da figura humana do testador. Além disso, a estratégia de automatização serve como alternativa às técnicas usuais de teste de sistemas com GUIs que resumem em explorar a estrutura interna das GUIs para fazer o mapeamento de eventos e criar oráculos de teste.

Para que sejam bem sucedidos e incrementem a qualidade dos sistemas em desenvolvimento, testes automatizados devem ser bem planejados e projetados. Os testes automatizados mais eficientes são concebidos com a exploração de oráculos de teste (Hoffman, 2001, 2006). Há muitas estratégias para verificação em testes automatizados e diferentes tipos de oráculos podem ser utilizados. Na Subseção 2.3 pode-se ter uma ideia básica de como diferentes aspectos no domínio das aplicações em teste podem ser utilizados para que sejam definidos mecanismos fundamentais para a automatização eficiente do teste de software - os oráculos de teste.

\subsection{Oráculos de Teste}

Um ponto negativo para os processos de automatização do teste de software é o fato de não poderem ser generalizados. Em termos técnicos, qualquer técnica ou critério de teste - manual ou automatizado - depende direta ou indiretamente de um oráculo (Baresi e Young, 2001; Hoffman, 2001). O termo oráculo é originário da mitologia grega e geralmente era conhecido por se tratar da resposta de um sacerdote ou divindade, geralmente subjetiva e obscura, dada a uma questão de um consulente qualquer (Cultural, 1998). Na área da Computação, mais precisamente na área de Teste de Software, o termo difere muito disso, sendo apresentado na literatura como mecanismo (programa, processo ou dados) que indica ao testador se a saída ou comportamento obtido a partir de um 
caso de teste é aceitável ou não (Baresi e Young, 2001; Hoffman, 1998, 2001). Sob outra perspectiva, um oráculo pode ser um método utilizado para checar ou julgar se um SUT procede corretamente diante de uma execução particular. Aspectos dirigidos aos oráculos tratam de uma questão básica na atividade de teste - decidir se o comportamento de um programa qualquer $P$ com um determinado dado de teste é correto ou não. Entretanto, não é uma tarefa trivial determinar para $P$ um conjunto $O$ de saídas esperadas.

Por exemplo, considerando-se que $P$ deveria calcular o valor da constante $\pi$ com um número qualquer de casas decimais, a não ser que se suponha a existência de um outro programa $Q$, correto, que execute a mesma funcionalidade, não se pode afirmar, sempre, de maneira positiva, se o comportamento de $P$ é o esperado ou não. Um outro caso semelhante seria quando $P$ é um programa não determinístico, em que o conjunto $P(v k)$ pode corresponder a diversas saídas possíveis, todas elas corretas. Diante desse cenário, fazem-se necessárias fontes externas de informações sobre o conjunto de saídas $O$. Oráculos de teste desempenham exatamente esse papel e podem ser projetados, por exemplo, a partir de especificações de um programa, tabelas de exemplos, ou, simplesmente, baseando-se no conhecimento do programador acerca de como um determinado programa em teste deve funcionar (Delamaro et al., 2011).

Dados os diferentes domínios de teste, pode-se encontrar na literatura algumas modalidades de oráculos que foram definidas e aplicadas por diferentes pesquisadores. $\mathrm{Na}$ Subseção 2.3.1 são apresentadas e discutidas características que podem ser utilizadas como base para a definição de oráculos de teste para diferentes domínios e aplicações variadas.

\subsubsection{Definições, Conceitos e Taxonomias}

Oráculos de teste são um desafio bem conhecido pelos pesquisadores que dedicam seus esforços a pesquisas sobre automatização do teste e qualidade de desenvolvimento de software. A automatização do teste requer a incorporação de mecanismos de oráculo para que saídas possam ser avaliadas. Por isso, em abordagens de teste automatizado, a presença de um oráculo é assumida explícita ou tacitamente. Quando não há meios capazes de computar automaticamente o resultado correto para determinada execução, os testadores devem calcular os resultados manualmente ou, então, usar uma versão anterior da aplicação em teste. Os materiais literários disponíveis acerca de oráculos de teste são constituídos por pesquisas cujo tema central é o teste de software. Por isso, dependendo das aplicações e dos sistemas de teste, os oráculos podem assumir diferentes papéis e diferentes funções mas sempre com a mesma meta - identificar e revelar ao testador se determinada execução é válida ou não (Baresi e Young, 2001).

Weyuker (1982) definiu uma tônica que é válida até os dias atuais: é impraticável o aproveitamento de um único modelo de oráculo para diferentes comportamentos de de- 
terminada aplicação em teste. Um oráculo desenvolvido para um propósito específico é capaz, então, de predizer ou julgar o comportamento específico e particular de determinada aplicação. Durante a implementação de um sistema de teste, uma prática comum é a incorporação de diferentes oráculos para verificar diferentes condições e domínios para checar comportamentos e resultados como, por exemplo, funcionalidades específicas, navegações entre GUIs ou consumo de memória durante uma execução etc (Hoffman, 1998).

Na literatura podem ser encontradas obras que classificam oráculos de teste baseando-se em diferentes aspectos. McDonald e Strooper (1998) propuseram uma classificação entre as abordagens desse nicho de pesquisa. A referida pesquisa classifica os oráculos em duas modalidades:

- ativos: responsáveis por diretamente dirigir ou coordenar as atividades de testes. Um oráculo ativo reproduz o comportamento do componente de software sob teste, produzindo resultados esperados para possíveis entradas. Desse modo, são feitas comparações para verificar os resultados reais diante dos resultados esperados;

- passivos: oráculos menos complexos e que recebem como entrada o par - comportamento desejado, comportamento produzido. Em outras palavras, um oráculo passivo é capaz apenas de verificar o comportamento de um componente, entretanto não é capaz de reproduzi-lo. Testes com oráculos passivos têm apenas um elemento comparador que é capaz de confrontar ou, então, verificar uma determinada propriedade entre dois objetos, e produzir um veredicto acerca da igualdade entre os dois.

Interessado em características similares entre mecanismos, dados ou processos utilizados em oráculos de teste, Beizer (1990) identifica cinco modalidades de oráculos de acordo com a forma como o resultado de uma aplicação é julgada:

- Oráculo "Kiddie": baseado na observação das saídas de um sistema em teste. Em geral, determinado teste é executado, se sua saída parecer correta e coerente, então, a saída deve ser julgada como correta;

- Conjunto de Teste de Regressão: as saídas esperadas a serem consideradas pelo oráculo são derivadas de uma versão anterior e correta do sistema em teste;

- Validação de Dados: as saídas esperadas podem ser oriundas de uma tabela de valores, uma fórmula ou qualquer outra definição aceitável de saída válida;

- Conjunto de Teste Padrão: as decisões tomadas são baseadas em um conjunto de teste padrão, previamente criado e validado. Esse tipo de oráculo é comum para a validação de compiladores, navegadores Web e processadores de SQL (Structured Query Language); e

- Programa existente: o julgamento realizado por este tipo de oráculo deve ser feito com base em resultados de entradas executadas em um sistema já existente. As comparações são feitas de modo semelhante ao teste de regressão. 
Segundo Sneed e Mérey (1985), em determinados ambientes de desenvolvimento e teste, o oráculo deve ser capaz de assumir diversas formas e deve basear-se na especificação do programa sendo testado. Se essa especificação for, por exemplo, uma definição de requisitos feita informalmente, de maneira textual, provavelmente caberá ao testador desempenhar o papel de oráculo e decidir sobre o comportamento do programa em teste. Não pode haver um veredicto sobre uma execução qualquer sem um oráculo. Dessa forma, a definição da correção dos resultados dos testes requer a verificação de uma ou mais condições. Consequentemente, oráculos podem ser configurados em forma de axiomas ou premissas de teste, execuções de outros programas ou, por fim, uma especificação formal.

A Tabela 2.5 foi elaborada com base nas pesquisas realizadas por Hoffman (1998, 2001, 2006). Na tabela são especificados vários tipos de oráculos, algumas de suas características mais expressivas, vantagens e desvantagens. É importante ressaltar que os oráculos automatizados podem ser classificados em classes bem distintas, levando em conta forma de automatização. De acordo com Hoffman (1998, 2006), além de abordagens sem oráculos ou com oráculos humanos, outras dez modalidades de oráculos podem ser identificadas. São elas: oráculos verdadeiros $(i)$; oráculos de consistência $(i i)$; oráculos estocásticos ou randômicos $(i i i)$; oráculos de amostragens $(i v)$; oráculos de referência própria $(v)$; oráculos heurísticos $(v i)$; oráculos baseados em modelos(vii); oráculos de ajuste manual(viii); oráculos estatísticos $(i x)$; e, por fim, oráculos computacionais $(x)$.

Tabela 2.5: Oráculos por sua forma de automatização (adaptado de Hoffman (1998, 2006))

\begin{tabular}{|c|c|c|c|}
\hline Classificação & Definição & Vantagens & Desvantagens \\
\hline Sem Oráculo & $\begin{array}{l}\text { Abordagem sem apuração de resul- } \\
\text { tados }\end{array}$ & $\begin{array}{l}\text { Pode executar qualquer quantidade } \\
\text { de dados }\end{array}$ & $\begin{array}{l}\text { Apenas erros notáveis são percebi- } \\
\text { dos }\end{array}$ \\
\hline $\begin{array}{l}\text { Oráculo } \\
\text { Humano }\end{array}$ & $\begin{array}{l}\text { Figura humana que verifica e julga } \\
\text { resultados de testes }\end{array}$ & $\begin{array}{l}\text { Pode detectar erros não previstos } \\
\text { pelos desenvolvedores e engenheiros } \\
\text { de teste }\end{array}$ & $\begin{array}{l}\text { Demorado para grandes quantida- } \\
\text { des de dados de teste. Resultados } \\
\text { influenciados por fatores fisiológicos }\end{array}$ \\
\hline $\begin{array}{c}\text { Oráculo } \\
\text { Verdadeiro } \\
\text { (Completo) }\end{array}$ & $\begin{array}{l}\text { Geração independente de todos os } \\
\text { resultados esperados }\end{array}$ & $\begin{array}{l}\text { Todos os erros são encontrados na } \\
\text { área em teste }\end{array}$ & $\begin{array}{l}\text { Implementação cara e complexa. } \\
\text { Resulta em longas execuções }\end{array}$ \\
\hline $\begin{array}{l}\text { Oráculo de } \\
\text { Consistência }\end{array}$ & $\begin{array}{l}\text { Compara resultados atuais a resul- } \\
\text { tados anteriores como, por exemplo, } \\
\text { teste de regressão }\end{array}$ & $\begin{array}{l}\text { Método mais rápido e de simples ve- } \\
\text { rificação. Capaz de verificar gran- } \\
\text { des quantidades de dados }\end{array}$ & $\begin{array}{l}\text { Pode não detectar erros originais } \\
\text { (erros no programa modelo) }\end{array}$ \\
\hline $\begin{array}{l}\text { Oráculo } \\
\text { Estocástico } \\
\text { (Randômico) }\end{array}$ & $\begin{array}{l}\text { Verifica aleatoriamente uma amos- } \\
\text { tra de dados de teste }\end{array}$ & $\begin{array}{l}\text { Pode automatizar testes de modo } \\
\text { simples }\end{array}$ & $\begin{array}{l}\text { Pode ná notar erros específicos e } \\
\text { consumir muito tempo para verifi- } \\
\text { cação }\end{array}$ \\
\hline $\begin{array}{l}\text { Oráculo de } \\
\text { Amostragem }\end{array}$ & $\begin{array}{l}\text { Verifica uma amostra de dados de } \\
\text { teste previamente selecionada }\end{array}$ & $\begin{array}{l}\text { Geralmente promove rápida verifi- } \\
\text { cação }\end{array}$ & Pode não detectar erros específicos \\
\hline $\begin{array}{c}\text { Oráculo de } \\
\text { Referência } \\
\text { Própria }\end{array}$ & $\begin{array}{l}\text { Também chamado de oráculo de } \\
\text { auto-verificação, promove respostas } \\
\text { aos dados por meio de mensagens }\end{array}$ & $\begin{array}{l}\text { Permite ampla análise pós-teste. O } \\
\text { veredicto é dado no conteúdo das } \\
\text { mensagens. Pode gerar dados com- } \\
\text { plexos }\end{array}$ & $\begin{array}{l}\text { Deve definir respostas aos testes, } \\
\text { logo tem que promover a geração de } \\
\text { mensagens }\end{array}$ \\
\hline $\begin{array}{l}\text { Oráculo } \\
\text { Heurístico }\end{array}$ & $\begin{array}{l}\text { Verifica algumas características } \\
\text { úteis de valores ou dados }\end{array}$ & $\begin{array}{l}\text { Mais rápido e simples que oráculos } \\
\text { verdadeiros. Barato na maioria das } \\
\text { vezes }\end{array}$ & $\begin{array}{l}\text { Pode não capturar erros além de ge- } \\
\text { rar alarmes falsos }\end{array}$ \\
\hline $\begin{array}{l}\text { Oráculo } \\
\text { Baseado em } \\
\text { Modelo }\end{array}$ & $\begin{array}{l}\text { Aproveita um modelo digital de da- } \\
\text { dos sobre o comportamento do SUT }\end{array}$ & $\begin{array}{l}\text { Testes podem ser aproveitados em } \\
\text { múltiplos sistemas usando diferen- } \\
\text { tes modelos }\end{array}$ & $\begin{array}{l}\text { Manutenção para SUts complexos é } \\
\text { cara e modelos devem corresponder } \\
\text { a um comportamento esperado }\end{array}$ \\
\hline $\begin{array}{c}\text { Oráculo de } \\
\text { Ajuste Manual }\end{array}$ & $\begin{array}{l}\text { Resultados cuidadosamente defini- } \\
\text { dos pelo engenheiro de teste }\end{array}$ & Útil para SUTs complexos & $\begin{array}{l}\text { Faz sempre os mesmos procedimen- } \\
\text { tos e é limitado por determinado } \\
\text { número de casos de teste }\end{array}$ \\
\hline $\begin{array}{l}\text { Oráculo } \\
\text { Estatístico }\end{array}$ & $\begin{array}{l}\text { Aproveita correlações estatísticas } \\
\text { entre entradas e saídas }\end{array}$ & $\begin{array}{l}\text { Permite a checagem de grande es- } \\
\text { cala de dados e sistemas reais }\end{array}$ & $\begin{array}{l}\text { Pode não capturar erros sistemáti- } \\
\text { cos e não notar alguns erros aparen- } \\
\text { tes }\end{array}$ \\
\hline $\begin{array}{c}\text { Oráculo } \\
\text { Computacional }\end{array}$ & $\begin{array}{l}\text { Explora o comportamento da SUT } \\
\text { para converter resultados em entra- } \\
\text { das }\end{array}$ & $\begin{array}{l}\text { Muito útil para funções matemáti- } \\
\text { cas e simples transformaçôes }\end{array}$ & $\begin{array}{l}\text { Pode não capturar erros além de ge- } \\
\text { rar alarmes falsos }\end{array}$ \\
\hline
\end{tabular}


Os processos de teste de uma aplicação podem não ter a disponibilidade de um oráculo automatizado (sem oráculo). Isso dificulta identificações de erros complexos. Algumas organizações, simplesmente, automatizam suas atividades de teste e não se preocupam com mecanismos de verificação. Assim, nessa modalidade de verificação, os testes são executados e os julgamentos a respeito de seus resultados são feitos de modo ad-hoc. Essa "solução" é útil em problemas de falsos relatórios de erros e de custos de manutenção de oráculos. Ela também tem a vantagem de ser simples, barata e rápida (processos de testes podem ser finalizados mais rapidamente). Dessa forma, a grande desvantagem é que somente erros mais aparentes podem ser encontrados.

Outra abordagem a ser considerada é quando uma figura humana desempenha o papel de oráculo em determinados testes (oráculo humano). Essas abordagens de teste apresentam problemas de precisão e custo (Hoffman, 1998). A verificação manual dos resultados de execuções de teste é uma atividade demorada e, às vezes, propensa a erros. A despeito disso, há algumas vantagens como, por exemplo, permitirem interpretações mais técnicas dos comportamentos e leituras de especificações em linguagens naturais. A precisão de um oráculo humano é prejudicada quando ele lida com um número crescente de testes a serem interpretados. O processo de teste é tedioso e requer concentração e arbitrariedade constante por longos períodos e fatores fisiológicos podem prejudicar a detecção de falhas. Adicionalmente, um oráculo humano pode não ser satisfatório em diversos casos. Nem todos os efeitos de uma entrada para um sistema podem estar disponíveis visivelmente ou o volume de dados pode ser demasiadamente grande (Hoffman, 1998, 2001).

\subsubsection{Oráculos sem saídas pré-computadas}

Alguns oráculos ativos têm mecanismos capazes de prever saídas esperadas para as aplicações em teste. Entretanto, além de serem muito custosas, em casos mais gerais, pode ser que a aplicação de tais oráculos seja insuficiente para garantir a qualidade do sistema a ser desenvolvido (Baresi e Young, 2001). Uma alternativa a esses tipos de oráculos são abordagens que não exigem nem entradas/saídas pré-computadas, nem a disposição de versões

prévias do sistema em teste. O relatório técnico apresentado na obra de Baresi e Young (2001) explora com minúcias diferentes maneiras de se implementar oráculos, independentemente de predições de saída. Diante do cenário apontado, para o desenvolvimento de oráculos de teste sem saídas pré-computadas, destacam-se sistemas transdutores, linguagens assertivas, especificações extrínsecas e, por fim, trace checking e análise de arquivos de $\log$.

Sistemas transdutores são capazes de ler entradas e produzir saídas correspondentes mantendo relações lógicas entre estruturas de entradas e saídas. A maneira mais indicada para a implementação desse tipo de oráculo é expressando e checando a relação estrutural 
entre entrada e saída como, por exemplo, uma estrutura sintática e semântica que viabilize a comparação entre entrada e estrutura de saída (Day e Gannon, 1985).

Linguagens assertivas permitem a captura de diversos comportamentos do SUT, de modo conciso e sem ambiguidades, em pontos estratégicos definidos pelo desenvolvedor. Podem ser inseridas no código fonte do programa e funcionam como um predicado de interesse para a definição da correção do sistemas como, por exemplo, o valor de uma expressão lógica que pode ser verdadeira ou falsa. Assim, assertivas evitam a criação de variáveis auxiliares de apoio ao teste e por meio delas podem ser configurados oráculos úteis para o apoio ao teste de unidade e teste de subsistemas.

Especificações Extrínsecas são escritas em formato de anotações que não são ligadas à linguagem de programação e, assim, podem ser independentes de linguagem de programação. Existem linguagens de especificações particulares com as quais essas especificações podem ser vinculadas e utilizadas. Um exemplo disso é relacionar a especificação de um programa no formato de uma tabela às expressões de teste, configurando, então, oráculos de teste.

É comum que sejam disponibilizadas sequências de execuções ou caminhos de código exercitados por determinada entrada em um sistema. Desse modo, Trace checking e análise de arquivos de log podem ser considerados como sendo a avaliação dessas sequências e caminhos após determinada execução. É possível que tais sequências sejam aproveitadas para a configuração de oráculos que verifiquem sua conformidade com um modelo mais detalhado do comportamento operacional do programa em teste.

\subsubsection{Oráculos com saídas pré-computadas}

Diferentes estratégias podem ser utilizadas para a automatização de um oráculo de teste. Por exemplo, um modelo formal pode ser considerado como sendo uma ferramenta clássica para implementação de mecanismos de oráculos e testes automatizados (Fenkam et al., 2002). Quando, para um programa qualquer, existir um modelo formal (como, por exemplo, uma máquina de estados finitos (MEFs) ou, então, uma representação em Rede de Petri) a partir do qual pode-se extrair seu comportamento, é possível automatizar a função de oráculo. Tal função de oráculo pode ser obtida por meio da implementação de um comparador entre a saída produzida e o comportamento definido no modelo.

Outro método típico de implementação de oráculo são explorações de documentações ou especificações. É preciso destacar que satisfazer requisitos não é o mesmo que estar conforme uma especificação de requisitos. Uma especificação é uma declaração sobre uma solução particular proposta para um problema e, por isso, tal solução pode, ou não, atingir seus objetivos. Além disso, especificações são escritas por pessoas e, portanto, podem conter erros ou, então, serem não determinísticas. Entretanto, pode-se assumir que um 
sistema é confiável e atende a seus objetivos reais enquanto estiver consistente com suas especificações. Por isso, testar um programa usando suas especificações como um oráculo aumenta o valor da formalização de documentação formal, reduzindo o custo do teste e ajudando a garantir que os erros que ocorrem durante o teste sejam detectados (Hoffman, 2006; Takahashi, 2001). Desse modo, um oráculo baseado em documentação/especificação também pode ser usado para garantir que a documentação seja mantida até sua implementação. Isso permite que um programa possa sempre ser testado com base em sua documentação, contribuindo para a certeza de que o comportamento do sistema em teste é coerente com o que foi especificado por processos de Engenharia de Software (Peters e Parnas, 1994).

Jin et al. (2008) apresentam uma abordagem na qual é definido um compilador simples para analisar as especificações formais de um SUT. Os referidos autores revelam que a estratégia viabiliza a execução automática dos requisitos de teste de um sistema. Assim, a atuação dos oráculos de teste poderia ser derivada de forma independente. Para a predição de resultados de execuções, a abordagem utiliza heurísticas de Inteligência Artificial (IA). Tal estratégia de configuração de oráculos de teste serve como uma solução importante para o apoio ao teste de domínios específicos de software. Adicionalmente, é apresentada na abordagem uma estrutura de Rede Neural Artificial (RNA) para a geração direta e automática de oráculos, mais precisamente explorando o treinamento de neurônios artificiais.

Programas paralelos também são recursos que a literatura aponta úteis como fonte de predições para automatização de oráculos. Assim, um oráculo pode basear-se na execução de um outro programa $Q$, para que se decida sobre o resultado da execução de um dado programa $P$. É o caso do teste de regressão. Ao alterar-se um dado programa $Q$, produzindo-se uma versão atualizada $P$, pode-se decidir sobre a aceitação de $P$ por meio da comparação do comportamento $\mathrm{P}(\mathrm{T})$ com $\mathrm{Q}(\mathrm{T})$, onde $T$ é um conjunto de teste sobre o qual $Q$ já tenha sido testado e para o qual esteja correto.

Várias formas para o desenvolvimento de oráculos de teste, como os que utilizam especificações (Agerholm et al., 1998; McDonald e Strooper, 1998; Richardson et al., 1992; Treharne et al., 1998; Zhu, 2003), a documentação (Coppit e Haddox-Schatz, 2005; Peters e Parnas, 1998), e implementações em paralelo (Binder, 1999), têm sido relatadas em trabalhos científicos. Infelizmente, o desenvolvimento e a utilização de tais recursos (especificações, documentação e implementações paralelas) podem requerer um esforço considerável. Tais mecanismos podem ser caros tanto em relação ao desenvolvimento, quanto à manutenção.

A completa predição de resultados, com o passar do tempo e com as alterações de tecnologias, pode fazer com que o oráculo perca parte de sua capacidade de detecção de 
erros. Num cenário industrial de desenvolvimento e teste, isso ocorre pelo fato de que ambos, SUT e oráculo, dependendo da entrada e das condições do ambiente de teste, podem gerar um mesmo erro devido à partilha de um componente de implementação incorreta ou obsoleta. Nesse sentido, pode-se concluir que um oráculo ideal deve se limitar a promover meios para que uma execução, de determinado domínio, seja classificada como bem sucedida ou falha.

\subsubsection{Oráculos não determinísticos}

No cenário industrial há situações nas quais, mesmo dispondo do conjunto de saídas esperadas, a automatização de um oráculo não é uma tarefa trivial. Muitas vezes é difícil decidir quais características do SUT devem ser consideradas para se comparar saídas obtidas e saídas esperadas. Por exemplo, supondo que o resultado esperado $O$ da execução de um determinado programa $P$ deve situar-se no intervalo entre 22,5 e 23,5 e o valor do resultado de um teste qualquer $O_{i}$ após uma execução de $P$ é 52, esse erro pode ser facilmente detectado e, desse modo, o testador pode servir como oráculo humano. No entanto, e se $O_{i}$ é algum valor definido entre 22,5 e 23,5? Esta seria a resposta correta? Embora possa ser difícil determinar se $O_{i}$ é o resultado correto, ele está próximo de $O$. Nessas situações o testador deve ser responsável por decidir se $O_{i}$ é aceitável ou não, dependendo de $O$.

Abordagens de oráculos de teste apresentadas na Subseção 2.3.1.2 utilizam dados provenientes de execuções paralelas, funções matemáticas, versões anteriores, pré-definições de casos de teste etc, para definirem os resultados dos testes de aplicações como adequados ou não. É importante destacar que, em geral, resultados para atividades de teste de software são idealizadas em um senso binário - resultado correto ou resultado incorreto. Logo, não são permitidas considerações de resultados do tipo "pode estar ok" ou "possivelmente certo", como saídas. Assim, cria-se um ideia equivocada do conceito genérico de oráculo de teste e, consequentemente, considera-se a atividade de teste como sendo determinística - sempre deve haver uma resposta do tipo "passou" ou "falhou".

Conforme observado nesta seção, podem existir tanto oráculos determinísticos, quanto oráculos probabilísticos. Um mecanismo que apoia o testador definindo que uma aplicação em teste pode provavelmente falhar, pode ser considerada como sendo um oráculo probabilístico. Após a apresentação das abordagens citadas nesta seção, pode-se verificar abordagens práticas que exploram o uso de oráculos não determinísticos como fonte confiável para avaliar o resultados de testes. Em geral, quando as atividades de teste de software são projetadas, diversas características podem ser identificados e verificados para que seja garantida a confiança no SUT. Por isso, conclui-se que podem existir casos 
em que o oráculo existe apenas de maneira aproximada ou parcial, sendo considerado um oráculo não determinístico (Baresi e Young, 2001).

\subsubsection{Implementação de Mecanismos de Oráculos}

Conforme o que foi apresentado na Seção 2.3.1, alguns estudos primários enaltecem os benefícios e as facilidades trazidas quando se tem um oráculo automatizado para apoiar o teste de determinado domínio de aplicação. Por outro lado, diversas pesquisas apresentam fatores complicadores e limitações envolvidas com a prática da implementação de oráculos automatizados. A seguir, são expostos e discutidos alguns aspectos desses fatores que tornam a implementação de oráculo uma tarefa nada trivial:

- Resultados Ocultos: em alguns ambientes de teste para determinados domínios, mesmo quando estão presentes os oráculos, os resultados de execução de um software podem durar apenas uma fração de segundo, ou então, serem distorcidos ou ocultados atrás de uma arquitetura de hardware-software. Por isso, muitas vezes, alguns resultados podem não ser facilmente observados ou registrados. Em adição a isso, a observação ou o processo de captura dessas saídas pode introduzir novos erros ou incertezas sobre os resultados da execução (Tse et al., 2007);

- Definições de veredictos a partir de especificações: algumas abordagens de oráculos são determinadas a partir da especificação do software. Na prática, porém, uma especificação pode fornecer descrições de alto nível apenas do sistema e não pode incluir todos os detalhes de implementação. Assim, testadores de software também devem contar com o domínio do conhecimento acerca do comportamento do software em teste para não só avaliarem os resultados, bem como, para implementarem oráculos automatizados. Tais esforços são frequentemente sujeitos a erros (Peters e Parnas, 1998);

- Uso de Heurísticas ou Oráculo Verdadeiros: automatizar um oráculo verdadeiro que seja capaz de gerar e comparar os resultados das execuções de um sistema qualquer pode exigir muito conhecimento e tempo por parte do testador. É complexo implementar um sistema que seja mais simples que o sistema em teste e esteja correto para todos, ou para grande parte, dos valores do domínio de entrada. No caso da utilização de oráculos heurísticos, a automatização de um mecanismo que seja capaz de julgar as saídas de um sistema depende de um testador que tenha conhecimento completo da aplicação em teste. Mais uma vez pode ser gasto um tempo precioso na elaboração e implementação das heurísticas do oráculo durante seu processo de automatização (Hummel e Atkinson, 2005). Adicionalmente, essa limitação, em particular, valoriza o trabalho nesta dissertação, haja vista que tais dificuldades são 
redobradas quando a saída a ser comparada se dá em um formato complexo, como, por exemplo, uma interface gráfica;

- Custo de Implementação: o desenvolvimento de um oráculo para verificar automaticamente as execuções de testes pode ser tão caro como a implementação do programa original. Isso desencoraja a implementação de mecanismos de oráculos para apoiarem determinados testes. Além disso, o próprio oráculo de teste é tão sujeito a erros quanto o sistema a partir do qual ele foi derivado. Uma possível solução para amenizar os custos de implementação de oráculos de teste seria a exploração de técnicas, metodologias ou algoritmos pré-definidos e firmados pela literatura (Oliveira et al., 2010). Por exemplo, para o domínio GUI, uma alternativa seria a exploração de algoritmos de PI de forma a comporem oráculos de teste (Oliveira et al., 2010).

Ainda no contexto das dificuldades e limitações encontradas em uma classificação bem genérica acerca dos problemas enfrentados pelos desenvolvedores de oráculos, Baresi e Young (2001) identificam quatro grandes classes de problemas comuns que são definidos levando em conta aspectos de implementação (por exemplo, incorporações de assertivas no código ou analisadores de logs de execuções) e tipos de especificações formais aceitas pelos métodos. As quatro classes identificadas pelos autores foram nomeadas e caracterizadas, a saber:

- estado/comportamento concreto versus abstrato: muitos oráculos aproveitam de assertivas em código e/ou análises de log de execuções, que são dados considerados concretos, para definirem oráculos de teste por meio de comparações com especificações formais, que são dados abstratos. Baresi e Young (2001) explicam que a distância computacional entre entidades concretas e o formalismo de entidades abstratas prejudica e dificulta o desenvolvimento desta modalidade de oráculo;

- parcialidade: quando um oráculo explora algum tipo de notação de especificação própria, distinta das especificações utilizadas para outros fins diferentes do teste, normalmente esta é "parcial" no sentido de que apenas alguns comportamentos incorretos são identificados e documentados. Dessa forma, outros comportamentos incorretos podem não ser detectados pela estratégia. Weyuker (1982) denomina os oráculos que utilizam essas abordagens de "pseudo-oráculo";

- quantificação: a maioria das abordagens de oráculos de teste apresentadas na literatura não oferecem, de forma sólida, um equilíbrio entre complexidade e capacidade de detecção de erros (Baresi e Young, 2001). Em geral, essa necessidade de quantificação é comum tanto em abordagens que utilizam especificações ou notações, quanto em abordagens que implicam diretamente no código da aplicação em teste; e

- oráculos e seleção dos casos de teste: um sistema de oráculos de teste ideal deve fornecer meios para a seleção de casos de teste. No entanto, a maioria das abordagens 
de oráculos que são orientadas a especificações formais tem a característica de ser independente de casos de teste, que são criados por meio de algum modelo formal. Em geral, Baresi e Young (2001) defendem que tal limitação encontrada na maioria das abordagens diminui o poder de detecção de falhas desses oráculos.

Diferentes estratégias podem ser utilizadas para que sejam definidos resultados esperados um SUT: verificação manual de resultados, implementações paralelas do mesmos algoritmos, versões anteriores do programa em teste (regressão) especificações formais etc. Por isso, além das dificuldades apontadas nesta subseção, diversas outras podem ser notadas na literatura (Hoffman, 1998). Em geral, isso decorre do fato que o conceito de oráculo não se limita somente a um gerador dos resultados esperados. Por isso, oráculos de teste podem ser considerados mecanismos capazes de promover resultados plausíveis para que uma determinada execução seja julgada como correta ou não.

\subsubsection{Oráculos: considerações finais}

A literatura apresenta diversas abordagens, como as apresentadas nesta seção, que mostram que dados a serem explorados por sistemas de oráculos de teste podem ser gerados e utilizados antes, paralelamente, ou após a execução dos testes. A despeito de diferentes estratégias e ferramentas de apoio ao teste serem apresentadas na literatura, ainda assim existem organizações que confiam a avaliação de seus resultados de teste nas mãos dos mais caros e menos confiáveis oráculos de teste - o olho humano (Baresi e Young, 2001; Hoffman, 1998, 2001). Isso acontece mesmo com a ciência de que tais procedimentos sempre serão limitados pela capacidade de processamento humano.

\subsection{Considerações Finais}

O emprego de atividades de teste é necessário em todo tipo de organização de desenvolvimento de sistemas de software. Entretanto, o teste automatizado ainda é um desafio para pesquisadores e projetista interessados em aspectos de qualidade e teste. Para o contexto deste trabalho, em particular, conhecimentos sobre conceitos relacionados à automatização de teste e mecanismos de oráculos são indispensáveis. Por isso, neste capítulo foram contempladas as principais definições e taxonomias envolvendo teste de software e oráculos de teste. 


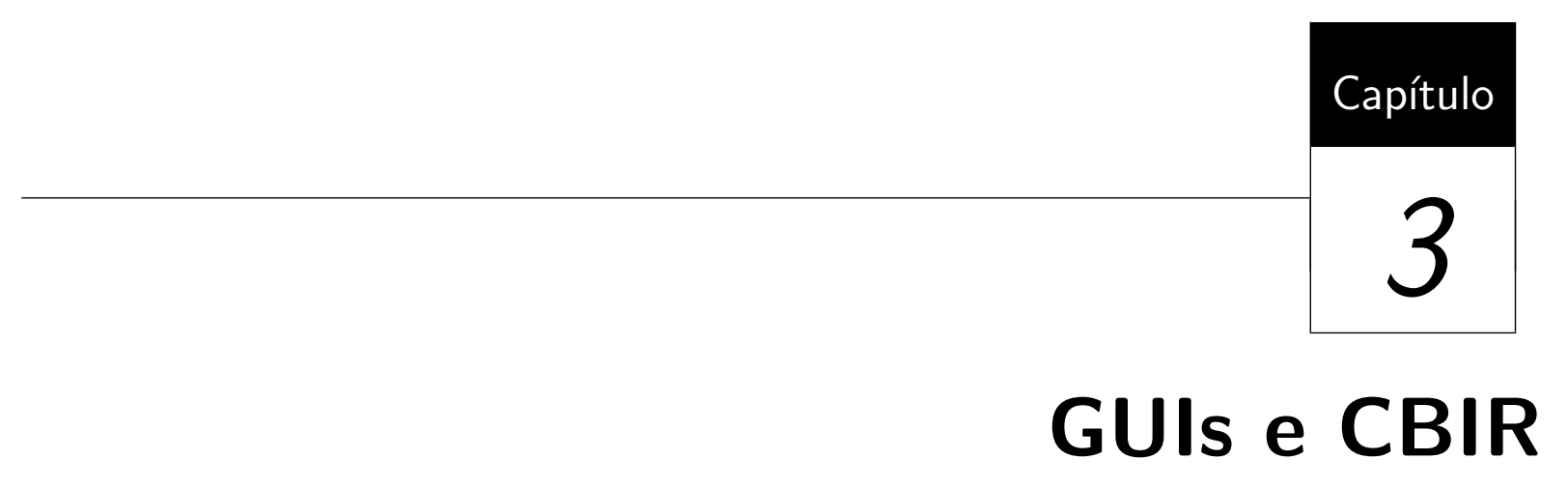

\subsection{Considerações Iniciais}

GUIs são elementos pervasivos e complexos em sistemas de software. Por isso, a adequação de sistemas com GUIs a qualquer processo ou técnica tradicional da Engenharia de Software é uma atividade não trivial. Para o melhor entendimento de aspectos particulares que tornam esses elementos delicados para contextos de Engenharia de Software, este capítulo define, exemplifica e contextualiza diferentes conceitos práticos e técnicos relacionados às GUIs (Seção 3.2). Adicionalmente, é apresentada uma revisão sistemática que relaciona GUIs a oráculos de teste (Seção 3.2.3). Além disso, o presente capítulo também serve como base para o entendimento de conceitos de CBIR (Seção 3.3). É importante salientar que, visando a apoiar a definição de conceitos de CBIR, são destacados alguns tópicos fundamentais da área de Processamento de Imagem (PI).

\subsection{Graphical User Interface}

O uso de complexas GUIs em diferentes tipos de sistemas de software tem aumentado. Em média, GUIs chegam a representar 60\% do código das aplicações (Memon et al., 2003a; Myers, 2004). O sucesso de uma aplicação, muitas vezes, depende de uma boa relação entre interfaces e funcionalidades. Interfaces gráficas são consideradas uma vertente de software e estão sujeitas aos mais diversos erros. Por isso, diversos pesquisadores têm 
voltado suas pesquisas para a criação e exercícios de técnicas e critérios de testes para sistemas com GUIs.

A tarefa fundamental das interfaces gráficas é a promoção de um meio simples para que o usuário possa interagir com o aplicativo que esteja operando. Segundo Deitel e Deitel (2005), sistemas com GUIs podem ter aparências e comportamentos distintos, fornecendo aos aplicativos componentes de interface com o usuário. Em geral, é esperado que tais componentes sejam consistentes e intuitivos. Dessa forma, uma GUI permite que o usuário se familiarize mais rapidamente com um aplicativo e possa, assim, utilizá-lo com maior produtividade. Um componente GUI pode ser definido como sendo um objeto com o qual o usuário interage via mouse, teclado, ou então, outro dispositivo de entrada como, por exemplo, um microfone.

Conceitualmente, um modelo de interface gráfica GUI é uma tupla (W,P,N): um conjunto de widgets (componentes) $\mathrm{W}=\left(w_{1}, w_{2}, \ldots, W_{l}\right)$ (por exemplo, botões, painéis, campos de texto) que constituem a GUI, um conjunto de propriedades $\mathrm{P}=\left(p_{1}, p_{2} \ldots\right.$, $p_{n}$ ) (por exemplo, a cor, tamanho, fonte) desses componentes, e um conjunto de valores $\mathrm{V}$ $=\left(v_{1}, v_{2}, \ldots, V_{n}\right)$ (por exemplo, vermelho, negrito, $16 \mathrm{pt}$ ) associado às propriedades. Cada GUI contém certos tipos de widgets com propriedades associadas. Em qualquer ponto durante a sua execução, a GUI pode ser descrita em termos dos elementos específicos que dispõe e nos valores de suas propriedades. O conjunto de elementos e suas propriedades é usado para criar um modelo de estado da GUI.

GUIs têm características diferentes das vertentes tradicionais da computação. Um estado de um componente GUI pode ser resumido em uma tripla $S=\left\{\left(\mathrm{W}_{i}, \mathrm{P}_{j}, \mathrm{~V}_{k}\right)\right\}$, na qual $\mathrm{W}_{i}$ representa o componente, $\mathrm{P}_{j}$ representa suas propriedades e $\mathrm{V}_{k}$ representa os valores das propriedades do componente (Memon et al., 2003a). Toda e qualquer interação do usuário que altere $S$, pode ocasionar alguma falha na aplicação. A ocorrência de eventos em uma interface altera $S$ para $S^{\prime}$. Após isso, os resultados visuais de $S^{\prime}$ são exibidos para o usuário. Cada evento fornecido pelo usuário à GUI representa chamadas às funções internas do sistema em operação. Desse modo, as GUIs são eficientes meios de comunicação entre usuário e código subjacente do sistema.

Em termos práticos, um exemplo de interação do usuário pode ser fornecido por meio de uma GUI hipotética "X" que contenha um componente "M" que represente um painel principal. Esse, por sua vez, contém um botão "B" que quando acionado por meio de um clique do mouse faz com que um evento acione o plano de fundo de "M", pintado-o da cor preta. Em outras palavras, isso implica afirmar que quando "B" for clicado, ou seja, quando determinado evento for iniciado a partir de "B", o valor da propriedade Cor do componente "M" será alterado para preto. 
Apesar de ser um requisito não funcional, a usabilidade da interface desempenha papel fundamental para o sucesso comercial de um sistema. Um dos fatores responsáveis pela popularidade dos sistemas de software são as interfaces gráficas com o usuário. Adicionalmente, GUIs intuitivas e claras são indispensáveis em projetos que envolvam Interação Humano-Computador (HCI - do inglês Human Computer Interaction). Por isso, diversas bibliotecas e APIs de apoio ao desenvolvimento de interfaces gráficas podem ser encontradas na literatura.

\subsubsection{APIs para o Desenvolvimento}

A implementação de GUIs é altamente dependente de bibliotecas de desenvolvimento. Muito pelo fato de existirem diversas linguagens de programação, muitas APIs e ferramentas para o desenvolvimento de GUIs podem ser encontradas na literatura. Pode-se considerar que os componentes de uma GUI são objetos pré-programados, depurados e testados previamente pelas organizações responsáveis por disponibilizar essas bibliotecas e APIs (Myers, 2004).

Essas APIs, em geral, oferecem estruturas pré-ajustadas para os usuários customizarem interfaces gráficas de acordo com suas necessidades. Desse modo, gerenciadores de layouts, painéis, janelas, ícones, eventos e botões, podem ser implementados com maior produtividade. Algumas APIs, inclusive, oferecem classes de componentes pré-definidos para serem utilizados pelos projetistas de software como, por exemplo, a classe JoptionPane da API Swing para a linguagem Java. Tal API fornece caixa de diálogos pré-empacotadas que permitem aos programas exibir janelas que contenham mensagens para o usuário - essas janelas são chamadas de diálogos de mensagens. Esses diálogos podem conter caixas de texto, opções de escolha do usuário ou, simplesmente, uma mensagem de texto no corpo da interface gráfica. Assim, a classe JOptionPane é um exemplo de como APIs de desenvolvimento de GUIs oferecem, de modo simples, eficiente e objetivo, recursos para a implementação de interfaces gráficas elegantes.

Adicionalmente, existem plugins para IDEs de desenvolvimento que oferecem meios para que usuários criem e editem GUIs utilizando o recurso conhecido como drag-and-drop. Por meio desse recurso é possível criar GUIs arrastando e redimensionando componentes na interface da IDE. Feito isso, os plugins são capazes de gerar o código referente a GUI ajustada visualmente. Além de elementos gráficos pré-definidos e recursos drag-and-drop, uma API de desenvolvimento de GUIs oferece recursos para a criação de interfaces gráficas seguindo algumas etapas simples. Geralmente essas etapas são bem intuitivas e não diferem muito de biblioteca para biblioteca. Sierra e Bates (2005) resumem e exemplificam a utilização da API Swing para a criação de uma interface com o usuário por meio de quatro etapas, a saber: 
1. Criar uma moldura (um objeto JFrame);

- JFrame frame = new JFrame();

2. Criar um elemento gráfico (botão, campo de texto);

- JButton button = new JButton("Button");

3. Adicionar o elemento gráfico à moldura; e,

- frame.getContentPane().add(button);

4. Exibir a GUI (fornecer um tamanho e torná-la visível).

- frame.setSize $(300,300)$;

- frame.setVisible(true);

Devido à pluralidade de linguagens de programação, são muitas as bibliotecas de apoio ao desenvolvimento de GUIs. Tais bibliotecas seguiram à risca a tendência evolutiva da computação e tornaram-se complexas e elegantes. Muitas vezes, a GUI de determinado sistema pode determinar seu sucesso comercial proporcionando altos níveis de aceitação do mercado. A seguir, são descritas as principais bibliotecas que apoiam o desenvolvimento de GUIs:

- Abstract Window Toolkit (AWT) ${ }^{1}$ : é considerada a principal e primeira ferramenta gráfica originalmente disponibilizada com a linguagem Java. Utiliza a classe abstrata java.awt.Graphics como base de todas as outras classes que viabilizam aspectos gráficos, permitindo que um aplicativo desenhe sobre seus componentes. Além disso, a AWT oferece um conjunto básico de componentes como, por exemplo, janelas, botões, etc. Para isso, diversas classes representam propriedades como, por exemplo, Color, Font, Paint, Stroke e Composite. Em relação aos recursos para composições de GUIs, o toolkit oferece diversos widgets como, por exemplo, Checkbox, Button, MenuBar, MenuItem, etc;

- Swing ${ }^{2}$ : a exemplo do toolkit AWT, o Swing é um toolkit que apoia o desenvolvimento de interfaces gráficas em linguagem Java. É importante destacar que o desenvolvimento de interfaces gráficas por meio de Swing pode ser associado a componentes AWT. Isso se dá pelo fato de que Swing foi desenvolvido para ter total compatibilidade com AWT, servindo a ela como biblioteca complementar. A API Swing conta com um conjunto de classes e métodos capazes de renderizar/desenhar cada um de seus componentes de forma autônoma. Ao contrário da maioria das APIs de interface gráfica, que delegam a tarefa de desenhar seus componentes para o sistema operacional da plataforma de execução;

\footnotetext{
${ }^{1}$ acesse: http://bit.1y/taEmHy

2acesse: http://bit.ly/toVryo
} 
- SWT (Standard Widget Toolkit)33: para desenvolvedores Java, é a principal alternativa àqueles que preterirem AWT e Swing. Em geral, o código das aplicações SWT é mais rápido para executar e a criação de uma interface gráfica de uma aplicação SWT típica pode ser realizada seguindo algumas etapas: criação de um display, criação de um ou mais Shells, criação de um componente dentro do Shell, abertura da janela do Shell e, por fim, exibição do display;

- JFace ${ }^{4}$ : utiliza recursos de SWT para promover a implementação de interfaces gráficas em linguagem Java. JFace encapsula a complexidade de tarefas que, se implementadas em SWT, consumiriam muito tempo de desenvolvimento e dedicação por parte dos projetistas e da equipe de desenvolvimento. O diferencial de JFace em relação a SWT está nos eventos com o usuário como, por exemplo, cliques em botões ou seleções de itens em menus. JFace tem o padrão de permitir a combinação de controle e recebimento de eventos em um só pacotes de dados, dessa forma o desenvolvedor pode se dedicar em tratar as respostas dadas ao evento sem precisar identificar qual o componente que o disparou. Em geral, para a implementação de interfaces complexas essa característica é muito valorizada e pode se tornar um poderoso diferencial.

Na Listagem 3.1 é apresentado um exemplo de como as classes de bibliotecas GUIs podem ser aproveitadas por desenvolvedores. A referida listagem configura um exemplo de como pode ser desenvolvida uma interface gráfica com um botão (Button), um rótulo de texto (TextField) e um botão de checagem (CheckButton). Na Figura 3.1 é apresentada a interface obtida como resultado de execução da Listagem 3.1.

Listagem 3.1: Código de Interface implementada com a biblioteca AWT-Java

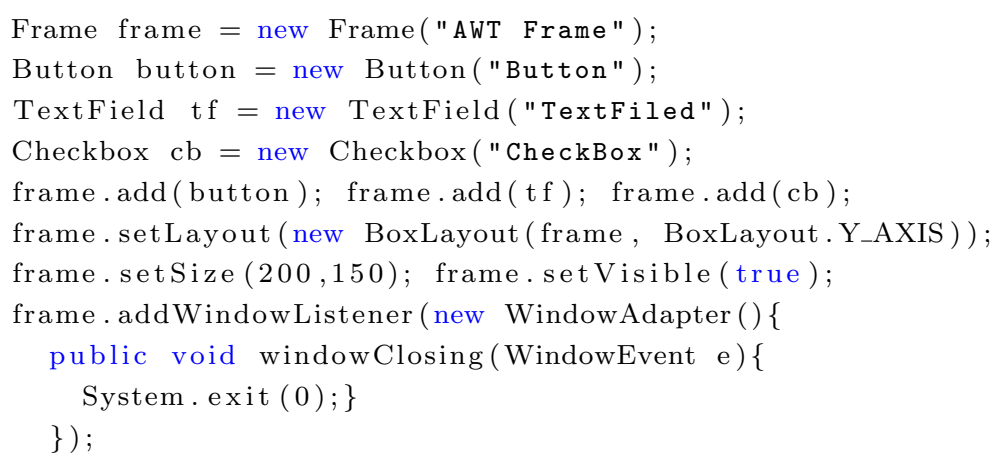

\subsubsection{Teste de sistemas com GUIs}

Atividades de teste de software que envolvam interações por meio de GUIs geralmente são complexas e demoradas. Na indústria, são amplamente usadas abordagens com ferramen-

\footnotetext{
3 acesse: http://bit.ly/hxW72k

4 acesse: http://bit.1y/b4w JHm
} 


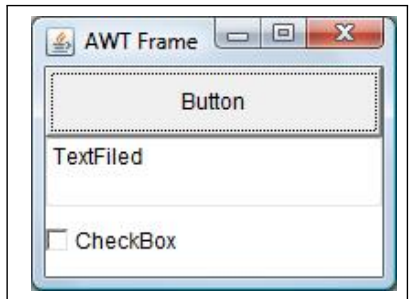

Figura 3.1: GUI resultante da execução do código AWT exibido na Listagem 3.1.

tas de captura e reprodução (record/playback) - que capturam e reproduzem sequências de eventos. De uma forma geral, uma sequência de eventos e interações, feitas por meio da interface, são gravadas e reproduzidas $n$ vezes para que o comportamento da interface seja testado (Baresi e Young, 2001). Fato esse que, inicialmente, requer a figura humana de um testador interagindo com a interface. No que diz respeito a oráculos de teste, os testes realizados por meio de ferramentas de captura e reprodução automatizada configuram um exemplo de oráculo baseado em um conjunto de entradas e saídas pré-computadas.

Baresi e Young (2001) destacam que uma abordagem alternativa às ferramentas de captura e reprodução de eventos é o teste baseado em modelos de operações da interface. Desta forma, um modelo de operações pode ser "executado" por meio de estímulos em um cenário de exemplos e os testes automatizados podem ser realizados de modo semelhante a outras técnicas de teste. Uma sequência de eventos é passada para o modelo da GUI e sua correção é julgada pela avaliação das sequências resultantes. Um exemplo desse tipo de abordagem foi realizada por Memon et al. (2000). Em tal ocasião, foi desenvolvido um oráculo capaz de apoiar o teste de GUIs por meio de especificações formais externas que definiam estados da GUI e operadores capazes de mudar tais estados.

Apesar de constituir um domínio específico, existem diversas estratégias de automatização de oráculos capazes de apoiar o teste de interfaces gráficas. Durante o período de elaboração deste trabalho de mestrado, uma Revisão Sistemática (RS) foi conduzida com o objetivo de identificar modalidades de oráculos de teste aproveitados para o teste de sistemas com GUIs. Essa RS foi publicada no trabalho apresentado por Oliveira et al. (2009b). Inicialmente, o objetivo principal foi a identificação de estudos que empregassem técnicas de PI como estratégia para automatização de oráculos de teste para sistemas com GUIs. Após algumas investigações preliminares, devido à escassez de trabalhos relacionando os temas PI e GUIs na literatura, a RS foi conduzida com o intuito de elucidar quais métodos têm sido usados por pesquisadores para a automatização de oráculos de teste para sistemas com GUIs. Por isso, é importante destacar que, apesar de alguns dos resultados da RS tratarem-se de abordagens para o teste de interfaces gráficas, o trabalho de mestrado apresentado por meio desta dissertação não constitui uma abordagem desse tipo de teste. 
Os pontos mais essenciais do trabalho apresentado por Oliveira et al. (2009b) são apresentados na Seção 3.2.3. Posteriormente, a revisão sistemática foi reexecutada e novos estudos foram incluídos nos resultados finais.

\subsubsection{Oráculos de teste para GUls: Uma Revisão Sistemática}

Segundo Kitchenham (2004), quando se conduz uma revisão de literatura sem o estabelecimento de um protocolo de revisão há um direcionamento por interesses pessoais, o que leva a resultados pouco confiáveis. No que diz respeito à Engenharia de Software, as pesquisas conduzidas com a negligência de protocolos caracterizam-se por serem pouco abrangentes, não replicáveis, pouco confiáveis e dependente de revisores (Mafra e Travassos, 2006). Uma RS é caracterizada por ser um meio para avaliar e interpretar todas as pesquisas disponíveis, referentes a uma questão de pesquisa particular, tema, área ou fenômeno de interesse. As RSs têm por objetivo apresentar uma avaliação justa de um tema de pesquisa, utilizando uma metodologia confiável, rigorosa e auditável (Kitchenham, 2004).

Uma RS é um método de pesquisa científica planejado para responder a uma ou mais perguntas específicas. Tal método utiliza recursos explícitos e sistemáticos para identificar, selecionar, avaliar criticamente os estudos e para coletar e analisar os dados dos estudos incluídos na revisão. Em outras palavras, uma RS implica na forma mais adequada para se identificar, avaliar e interpretar toda pesquisa importante para um tema em particular (Biolchini et al., 2005). Uma RS configura um alicerce para novas atividades de pesquisa acerca de determinado tema. Neste projeto de mestrado realizou-se uma RS com intuito de conhecer o estado da arte acerca de oráculos que apoiem o teste de programas cuja interação com o usuário se dá por meio de GUIs.

Detalhes acerca de planejamento e condução da RS podem ser consultados no trabalho de Oliveira et al. (2009b). A Tabela 3.1 exibe todas as obras pré-selecionadas após a realização das buscas e do processo de seleção preliminar. As obras de índices 1 a 11 foram pré-selecionadas a partir da busca na fonte $S c o p u s^{5}$ e as obras de índices 12 a 17 foram pré-selecionadas por meio da busca na fonte $\mathrm{IEEE}^{6}$. As situações dos artigos depois de sua análise também são apresentadas na referida tabela.

\subsubsection{Análise de Resultados}

A literatura revela diversas abordagens de teste realizados por meio de métodos que geram casos de teste e utilizam oráculos para testar GUIs, baseando-se em definições de sequência de eventos, componentes, propriedades, valores de propriedades e estados GUI. Em geral, testadores de sistemas com GUIs devem ter em mente que seu domínio de teste está sujeito

\footnotetext{
5 acesse: http://www. scopus.com

${ }^{6}$ acesse: http://www.ieee.org/
} 
Tabela 3.1: Seleção preliminar de artigos

\begin{tabular}{|c|c|c|c|c|}
\hline id & Nome do Trabalho & Autoria & Comentários & Situação \\
\hline 1 & $\begin{array}{l}\text { An event-flow model of } \\
\text { GUI-based applications for } \\
\text { testing }\end{array}$ & Memon (2007) & $\begin{array}{c}\text { Abordagem acerca do uso de oráculos em } \\
\text { testes GUI }\end{array}$ & Incluído \\
\hline 2 & $\begin{array}{l}\text { Piping Classification to } \\
\text { Metamorphic Testing: An } \\
\text { Empirical Study towards } \\
\text { Better Effectiveness for the } \\
\text { Identification of Failures in } \\
\text { Mesh Simplification Programs }\end{array}$ & Chan et al. (2007) & $\begin{array}{c}\text { Aborda novos métodos de geração de casos } \\
\text { de teste para GUIs }\end{array}$ & Excluído \\
\hline 3 & $\begin{array}{l}\text { Towards the Integration of } \\
\text { Visual and Formal Models for } \\
\text { GUI Testing }\end{array}$ & Paiva et al. (2007) & $\begin{array}{l}\text { Abordagem de Teste Baseado em Modelos. } \\
\text { Não especifica oráculos de teste. }\end{array}$ & Excluído \\
\hline 4 & $\begin{array}{l}\text { Persistent Code Caching: } \\
\text { Exploiting Code Reuse Across } \\
\text { Executions and Applications }\end{array}$ & $\begin{array}{l}\text { Reddi et al. } \\
\qquad(2007)\end{array}$ & $\begin{array}{c}\text { Abordagem de uso de oráculos em base de } \\
\text { dados }\end{array}$ & Excluído \\
\hline 5 & $\begin{array}{l}\text { Automated oracle based on } \\
\text { Multi-Weighted Neural } \\
\text { Networks for GUI testing }\end{array}$ & Ye et al. (2007) & $\begin{array}{l}\text { Abordagem de oráculos para teste GUI } \\
\text { por meio de Inteligência Artificial }\end{array}$ & Incluído \\
\hline 6 & $\begin{array}{l}\text { Designing and comparing } \\
\text { automated test oracles for } \\
\text { GUI-based software } \\
\text { applications }\end{array}$ & $\begin{array}{l}\text { Xie e Memon } \\
(2007)\end{array}$ & $\begin{array}{c}\text { Abordagem comparativa de oráculos para } \\
\text { o apoio ao teste GUI }\end{array}$ & Incluído \\
\hline 7 & $\begin{array}{l}\text { Employing user profiles to test } \\
\text { a new version of a GUI } \\
\text { component in its context of use }\end{array}$ & Memon (2006) & $\begin{array}{l}\text { Relata dificuldades encontradas no } \\
\text { desenvolvimento de oráculos para GUIs }\end{array}$ & Incluído \\
\hline 8 & $\begin{array}{l}\text { Developing cost-effective } \\
\text { model-based techniques for gui } \\
\text { testing }\end{array}$ & Xie (2006a) & $\begin{array}{c}\text { Abordagem do uso de oráculos para } \\
\text { interfaces GUI }\end{array}$ & Incluído \\
\hline 9 & $\begin{array}{l}\text { Using score distributions for } \\
\text { query-time fusion in } \\
\text { multimediaretrieval }\end{array}$ & $\begin{array}{l}\text { Wilkins et al. } \\
\qquad(2006)\end{array}$ & Abordagem de recuperação multimídia & Excluído \\
\hline 10 & $\begin{array}{l}\text { Automating regression testing } \\
\text { for evolving GUI software }\end{array}$ & $\begin{array}{l}\text { Memon et al. } \\
\text { (2005) }\end{array}$ & $\begin{array}{c}\text { Abordagem que utiliza oráculos para o } \\
\text { teste GUI }\end{array}$ & Incluído \\
\hline 11 & $\begin{array}{l}\text { Specification-based Testing for } \\
\text { Gui-based Applications }\end{array}$ & $\begin{array}{c}\text { Chen e } \\
\text { Subramaniam } \\
(2002)\end{array}$ & $\begin{array}{c}\text { Utiliza máquinas de estados finitos para o } \\
\text { apoio ao teste GUI }\end{array}$ & Excluído \\
\hline 12 & $\begin{array}{c}\text { DART: A Framework for } \\
\text { Regression Testing } \\
\text { "Nightly/daily Builds"of GUI } \\
\text { Applications }\end{array}$ & $\begin{array}{l}\text { Memon et al. } \\
\qquad(2003 \mathrm{a})\end{array}$ & $\begin{array}{c}\text { Ferramenta que aborda oráculos de para o } \\
\text { domínio GUI }\end{array}$ & Incluído \\
\hline 13 & $\begin{array}{l}\text { What Test Oracle Should I } \\
\text { Use for Effective GUI Testing? }\end{array}$ & $\begin{array}{l}\text { Memon et al. } \\
(2003 \mathrm{~b})\end{array}$ & $\begin{array}{l}\text { Abordagem comparativa da efetividade do } \\
\text { uso de oráculos no teste de GUIs }\end{array}$ & Incluído \\
\hline 14 & $\begin{array}{l}\text { Studying the Fault-Detection } \\
\text { Effectiveness of GUI Test } \\
\text { Cases for Rapidly Evolving } \\
\text { Software }\end{array}$ & $\begin{array}{l}\text { Memon e Xie } \\
(2005)\end{array}$ & $\begin{array}{l}\text { Apresenta resultados quantitativos do uso } \\
\text { de oráculos no teste GUI }\end{array}$ & Incluído \\
\hline 15 & $\begin{array}{l}\text { Empirical Evaluation of the } \\
\text { Fault-Detection Effectiveness } \\
\text { of Smoke Regression Test } \\
\text { Cases for GUI-Based Software }\end{array}$ & $\begin{array}{l}\text { Memon e Xie } \\
\quad(2004 \mathrm{~b})\end{array}$ & $\begin{array}{l}\text { Abordagem que utiliza oráculos } \\
\text { pré-definidos para o teste GUI }\end{array}$ & Excluído \\
\hline 16 & $\begin{array}{l}\text { On Random Testing of Image } \\
\text { Processing Applications }\end{array}$ & $\begin{array}{l}\text { Mayer e Guderlei } \\
(2006)\end{array}$ & $\begin{array}{l}\text { Abordagem quantitativa acerca de } \\
\text { oráculos para o teste GUI }\end{array}$ & Incluído \\
\hline 17 & $\begin{array}{c}\text { Using transient/persistent } \\
\text { errors to develop automated } \\
\text { test oracles for event-driven } \\
\text { software }\end{array}$ & $\begin{array}{l}\text { Memon e Xie } \\
\quad(2004 \mathrm{a})\end{array}$ & $\begin{array}{l}\text { Configuração de oráculos para o teste GUI } \\
\text { com erros persistentes e transientes }\end{array}$ & Incluído \\
\hline
\end{tabular}

a dois tipos distintos de erros comuns: erros persistentes e erros transientes (Xie, 2006b; Xie e Memon, 2007). Erros transientes são aqueles que ocorrem durante a execução de um caso de teste, mas não são notados após a execução do último evento na GUI. Erros persistentes são aqueles que ocorrem durante a execução de um caso de teste e podem ser notados após a realização de todos os eventos do caso de teste. Logo, erros persistentes podem ser detectados com chamadas a um oráculo depois do último evento do caso de teste e erros transientes somente são detectados quando a chamada de um oráculo ocorre depois de cada evento da GUI.

Os casos de teste, para o contexto de sistemas com GUIs, consistem em uma sequência de eventos a serem disparados. Em geral, casos de teste devem ser gerados e executados rapidamente, além disso, devem gerar uma cobertura adequada das funcionalidades da 
GUI e serem capazes de alertar o desenvolvedor de possíveis erros. Casos de teste não devem ser sensíveis às mudanças nas GUIs (Memon e Xie, 2005).

Testes aplicados em GUIs e, por consequência, os oráculos para esse domínio, diferem dos moldes de sistemas tradicionais (Mayer e Guderlei, 2006; Memon et al., 2003a; Memon e Xie, 2004a). Quando técnicas e critérios de teste de sistemas de software tradicionais são comparadas ou aplicadas ao teste de sistemas com GUIs, diversos pontos incomuns são notados. Um desses pontos é exatamente o fato de que testes e oráculos para sistemas com interfaces gráficas remetem a diferentes dificuldades incomuns em testes tradicionais como, por exemplo, o não determinismo de eventos.

Outro ponto incomum é exatamente o fato de que critérios de cobertura de teste tradicionais não funcionam quando aplicado em GUIs. Isso se dá pelo fato de que o mapeamento entre eventos é muito complexo, o que justifica pelo fato de que GUIs diferem muito dos códigos tradicionais em seu nível de abstração. No contexto de implementações de oráculos, a RS como um todo revelou que há grande dificuldade de especificação exata dos resultados esperados, haja vista que apenas parte deles podem ser representados quantitativamente. Exemplos disso são coordenadas em uma tela, tamanho de widgets ou cores de componentes e o grande número de estados nos quais uma GUI pode estar (Memon et al., 2003a; Memon, 2007).

Em contrapartida, ainda explorando a comparação das duas abordagens de teste, ou seja, teste de sistemas com interfaces GUI e teste de sistemas tradicionais, a RS revelou algumas semelhanças. As duas abordagens exigem a determinação de critérios de cobertura, a geração de entradas de casos de teste, especificações de software e especificações de estruturas (Memon et al., 2003a). Para interfaces GUI, nas quais entradas podem ser cliques do mouse ou seleções em menus, sempre é necessário gerar saídas esperadas com o objetivo de compará-las com saídas obtidas após a execução de casos de teste. Outro fator comum notado é a necessidade em determinar um momento no qual as aplicações foram testadas o suficiente e, a partir desse ponto, analisar os resultados (Memon, 2007; Ye et al., 2007).

Em linhas gerais, a pesquisa apontou que oráculos que apoiam o teste de sistemas com interfaces GUIs diferem de oráculos para o teste de aplicações tradicionais. Sendo assim, no domínio GUI, oráculos de teste podem ser usados para comparar estados durante a execução de determinado caso de teste (Memon, 2006; Xie e Memon, 2007). Conceitualmente, os exemplos mais comuns de oráculos para GUIs aproveitam a composição e transitoriedade de estados da interface do sistema para determinar uma "arquitetura" a ser seguida (Memon et al., 2003a). Nesse contexto, um oráculo pode lançar mão de um caso de teste, executar todos seus eventos, computar o estado esperado, obter o estado atual da interface, comparar os dois estados e estabelecer um veredicto. Em diferentes 
abordagens, o estado esperado é obtido por meio de especificações formais de uma GUI (conjunto de elementos e suas propriedades) (Memon et al., 2003a; Memon e Xie, 2005).

Quando é levado em consideração o fato de que GUIs podem ter erros persistentes e transientes, pode-se afirmar que se um oráculo não verificar a interface depois de cada etapa de execução em um caso de teste, estados errados da GUI não detectados podem se tornar uma dificuldade, principalmente se o estado final for esperado pelo oráculo. Logo, saídas intermediárias podem estar incorretas (Memon et al., 2005; Xie, 2006b).

Outra abordagem interessante é a feita por Takahashi (2001). O autor identifica algumas das formas pelas quais um programa pode produzir suas saídas, como texto, arquivo, memória, janela, dados de comunicação ou imagem. Disposto a evitar a comparação pixel a pixel entre as saídas de duas execuções de um programa com saída gráfica, o autor propõe um sistema que intercepta chamadas à API gráfica e guarda/compara tais informações. É importante destacar que tal obra não foi identificada por meio da RS, pois pertencia ao controle da revisão, que é o "baseline" ou conjunto de dados iniciais previamente conhecidos pelo pesquisador (Kitchenham, 2004).

Em relação aos estudos incluídos, numericamente, observou-se que cerca de $73 \%$ (id $5,6,8,10,12,13,14$ e 17) apresentam uma nova abordagem de oráculos para apoiar o teste de sistemas com interfaces GUIs. Enquanto 27\% (id 6, 8 e 17) fazem considerações e apresentam resultados sobre a problemática que é a criação de oráculos para o teste de sistemas com GUIs. Os estudos que revelam dados quantitativos acerca dos oráculos representam $82 \%$ (id $1,5,6,10,12,13,14,16$ e 17) dos resultados. 90\% (id 1, 6, 7, 8, 10, 12, 13, 14, 16 e 17) apresentam dados qualitativos. Por fim, 9\% (id 12) configuram ferramentas para a confecção automatizada de oráculos para interfaces GUIs. O gráfico ilustrado na Figura 3.2 apresenta visualmente os dados estatísticos colhidos a partir da RS.

\subsubsection{Reexecução da Revisão Sistemática}

RSs ou Mapeamentos Sistemáticos são instrumentos importantes para pesquisas científicas por serem meios seguros para a elucidação real de determinada área de pesquisa (Kitchenham, 2004). Um dos recursos mais valiosos das RSs é, exatamente, a possibilidade de reexecução. Para tanto, em termos práticos, é necessário que seja seguido o protocolo que foi estabelecido na revisão a ser replicada. Assim, utilizam-se os mesmos critérios de exclusão e inclusão, as mesmas questões de pesquisa, as mesmas palavras chave e, por fim, os mesmos métodos de avaliação de resultados.

A RS, descrita com minúcias na Subseção 3.2.3 desta dissertação, foi finalizada no mês de abril do ano de 2009. Dado o considerável intervalo de tempo entre sua finalização e a data da escrita da redação final da dissertação, foi necessário reexecutar a revisão com 


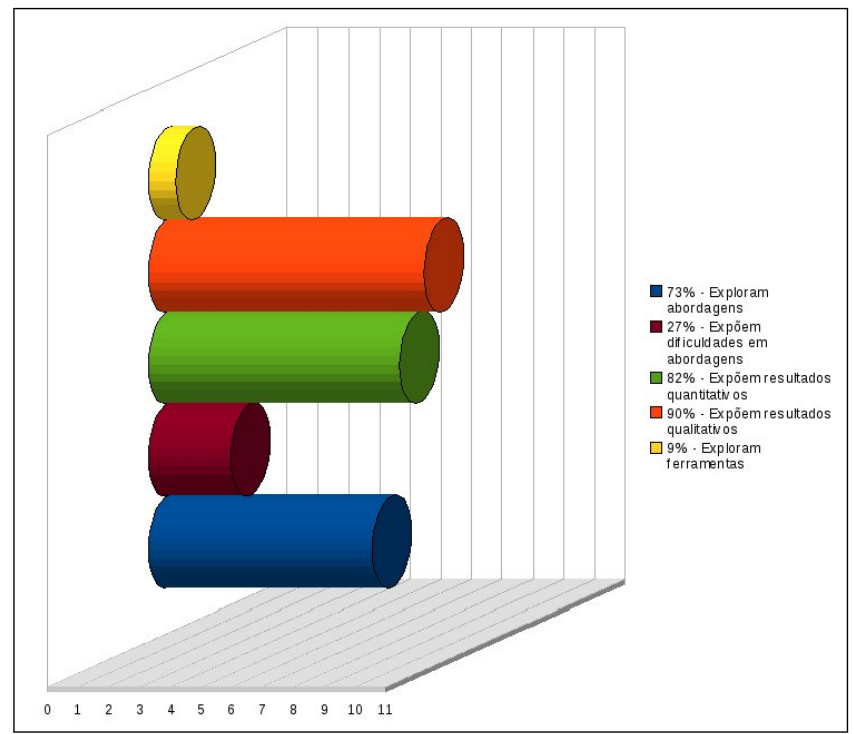

Figura 3.2: Dados estatísticos colhidos a partir da RS conduzida

o objetivo de identificar estudos que tenham sido publicados nesse período de dois anos. Diante desse cenário, no mês de setembro de 2011, o protocolo da RS foi consultado e a revisão foi atualizada. O resultado da reexecução da revisão é descrito nesta subseção. Ao todo, após a exclusão de artigos repetidos, foram encontrados 10 artigos, dentre os quais, 6 deles foram incluídos. Na Tabela 3.2 podem ser identificados os trabalhos selecionados na reexecução da RS.

Tabela 3.2: Artigos adicionados após a reexecução da Revisão Sistemática

\begin{tabular}{|c|c|c|c|}
\hline id & Nome do Trabalho & Autoria & Comentários \\
\hline 1 & $\begin{array}{c}\text { Towards Automated Oracles for GUI } \\
\text { Input Validation }\end{array}$ & $\begin{array}{c}\text { Zenarosa e } \\
\text { Leonard }(2011)\end{array}$ & $\begin{array}{c}\text { A estratégia faz a leitura de requisitos de } \\
\text { teste, realizando os testes } \\
\text { automaticamente }\end{array}$ \\
\hline 2 & $\begin{array}{c}\text { Test Case Generation from Mutated } \\
\text { Task Models }\end{array}$ & $\begin{array}{l}\text { Barbosa et al. } \\
(2011)\end{array}$ & $\begin{array}{l}\text { Utiliza um modelo de tarefas como oráculo } \\
\text { e contempla a geração de casos de teste }\end{array}$ \\
\hline 3 & $\begin{array}{l}\text { Ontology Driven Semantic } \\
\text { Annotation Based GUI Testing }\end{array}$ & Rauf et al. (2010) & $\begin{array}{l}\text { Anotações semânticas são utilizadas como } \\
\text { oráculos para o teste GUI. }\end{array}$ \\
\hline 4 & $\begin{array}{c}\text { GUI Test Case Definition with } \\
\text { TTCN-3 }\end{array}$ & $\begin{array}{l}\text { Xing e Jiang } \\
\quad(2009)\end{array}$ & $\begin{array}{c}\text { Relato de experiências do uso de oráculos } \\
\text { para sistemas com GUI criados por meio } \\
\text { da tecnologia TTCN-3 }\end{array}$ \\
\hline 5 & $\begin{array}{l}\text { GUI Savvy end-to-end Testing with } \\
\text { Smart Monkeys }\end{array}$ & Hofer et al. (2009) & $\begin{array}{c}\text { A abordagem utiliza oráculos baseados em } \\
\text { uma MEF para GUIs }\end{array}$ \\
\hline 6 & $\begin{array}{c}\text { A Systematic Capture and Replay } \\
\text { Strategy for Testing Complex GUI } \\
\text { Based Java Applications }\end{array}$ & Ariss et al. (2010) & $\begin{array}{c}\text { Utiliza modelos comportamentais e } \\
\text { funcionais criados a partir de } \\
\text { especificações dos sistemas em teste como } \\
\text { oráculos }\end{array}$ \\
\hline
\end{tabular}

Zenarosa e Leonard (2011) relatam experiências em automatizar mecanismos para generalizar o teste baseado em especificações para a validação de entradas para uma linha de produto para aplicações Web. A estratégia consiste em explorar recursos de uma ferramenta de teste GUI para implementar um interpretador que lê requisitos de teste em especificações e realiza as averiguações correspondentes automaticamente. Desse modo, seguindo alguns padrões para a escrita de especificações, testadores podem escrever 
testes e consequentemente oráculos para determinadas aplicações Web. Em ambientes nos quais uma série de aplicações Web são similares, configurando uma linha de produto, a abordagem se mostrou bastante valiosa.

Barbosa et al. (2011), interessados em colaborar com a geração de casos de teste para sistemas com GUIs, apresentam um estudo no qual, a partir de um modelo de tarefas (conjunto de atividades visando a um objetivo específico) de uma determinada GUI são gerados oráculos cujo comportamento pode ser comparado ao comportamento de sistemas em teste. O estudo revela que o fato de GUIs possibilitarem diferentes tipos de interações podem fazer com que modelos demasiadamente grandes sejam requeridos para tanto. Nesse contexto, uma possível solução é o aumento do nível de abstração dos modelos. Para tanto, é proposto um algoritmo de mutação de modelos de tarefas, detectando padrões nos modelos "mutados" e promovendo uma estratégia para capturar consequências de suas execuções. Estudos experimentais apontam que o uso do modelo de tarefas foi capaz de reduzir consideravelmente os esforços para a produção de oráculos de teste.

Estratégias de automatização de testes para GUIs geralmente envolvem grafos de fluxo de eventos ou, então, modelos de fluxo de eventos. Adicionalmente, a essas estratégias, Rauf et al. (2010) propuseram a utilização de uma ontologia para o teste de interfaces gráficas. A ontologia proposta, em particular, utiliza anotações semânticas dos possíveis eventos para a geração de casos de teste. Desse modo, a ontologia somadas às anotações semânticas podem ser consideradas como sendo um oráculo de teste capaz de verificar as saídas dos casos de teste. O trabalho ainda está em fase de desenvolvimento e os resultados preliminares são baseados apenas em conceitos teóricos.

O estudo apresentado em Xing e Jiang (2009) relata experiências do uso oráculos para sistemas com GUI criados por meio da tecnologia TTCN-3 (Testing and Testing Control Notation version 3), que se trata de uma linguagem para definição de casos de teste. TTCN-3 vem sendo usado para a especificação e definição de testes para diferentes tipos de sistemas reativos. Resultados empíricos da abordagem demonstraram que o uso de TTNC-3 para o teste GUI é de fácil manutenção e acesso, além de permitir rápida averiguação de resultados. Um template para definições de estados esperados facilita, flexibiliza e aumenta a produtividade durante a definição de oráculos de teste.

Hofer et al. (2009) trazem a estratégia de realizar teste GUI com o uso de testes com Smart Monkeys, que podem ser considerados os processos de teste que exercitam randomicamente um sistema por meio de uma ferramenta de teste automatizada. Assim, uma estratégia de teste com Monkeys pode ser considerada como sendo uma instância do teste randômico. Quanto aos oráculos, a estratégia de teste utiliza decisões baseadas 
em uma máquina de estados para GUIs. A criação dessa máquina é feita baseada no algoritmo randômico que realiza o teste.

A abordagem apresentada em Ariss et al. (2010) consiste de uma ferramenta de captura e reprodução que pode ser empregada para diferentes propósitos de teste GUI: teste funcional, teste de convergência e teste de regressão. Para a implementação de oráculos, a estratégia utiliza modelos comportamentais e funcionais criados a partir de especificações dos sistemas em teste. Um estudo empírico foi realizado e mostrou que a abordagem pode ser útil para a detecção de erros funcionais em GUIs.

Adicionalmente, o trabalho de Chang et al. (2010) foi indicado por especialistas e, assim, deve ser mencionado como um dos resultados da reexecução da RS. Apesar de não contemplar diretamente a definição de mecanismos de oráculos de teste e, por isso, não ter sido encontrado por meio da reexecução da RS, essa pesquisa consiste de uma abordagem que utiliza conceitos de visão computacional para realizar o teste de interfaces gráficas em sistemas. Um dos recursos da abordagem é a criação de scripts de teste que funcionem como assertivas visuais que desempenhem o papel feito por um oráculo humano. Para tanto, o trabalho apresenta o Sikuli Test ${ }^{7}$, um framework de teste baseado em visão computacional que permite que testadores automatizem tarefas de teste por meio de scripts. Na Figura 3.3 pode ser visualizado como a seguinte tarefa de teste pode ser escrita em um script por meio do framework Sikuli: "clicar no botão play e verificar se o aspecto visual dele se altera para o botão pause". A obra conclui que a abordagem de teste proposta oferece três grandes diferenciais: os scripts permitem fácil leitura de casos de teste, a abordagem é independente de plataforma e, por fim, separação e diferenciação entre projeto e implementação. Entretanto, a técnica apresenta duas limitações - não consegue detectar resultados inesperados e, adicionalmente, a estratégia não é capaz de detectar erros relacionados a aspectos internos das interfaces.

$$
\operatorname{Click}(\square) \text {; assertexist }(I I) \text { ); assertnotExist }(\square) \text {; }
$$

Figura 3.3: Script de teste visual da ferramenta Sikuli (adaptado de Chang et al. (2010))

Após a reexecução da RS, 18 estudos compuseram o conjunto final de artigos, dentre os quais 6 foram encontrados após a reexecução da RS e 1 indicado por um especialista. Diante desse cenário, alguns dados interessantes podem ser citados. Um deles é que a maioria dos trabalhos com abordagens acerca de oráculos para GUI incluíam os autores Atif Memon e Qing Xie. Entre obras selecionadas, 50\% tem um desses dois pesquisadores como primeiro autor. Tais pesquisadores estão ligados ao grupo de pesquisa em

\footnotetext{
${ }^{7}$ acesse: http://sikuli.org/
} 


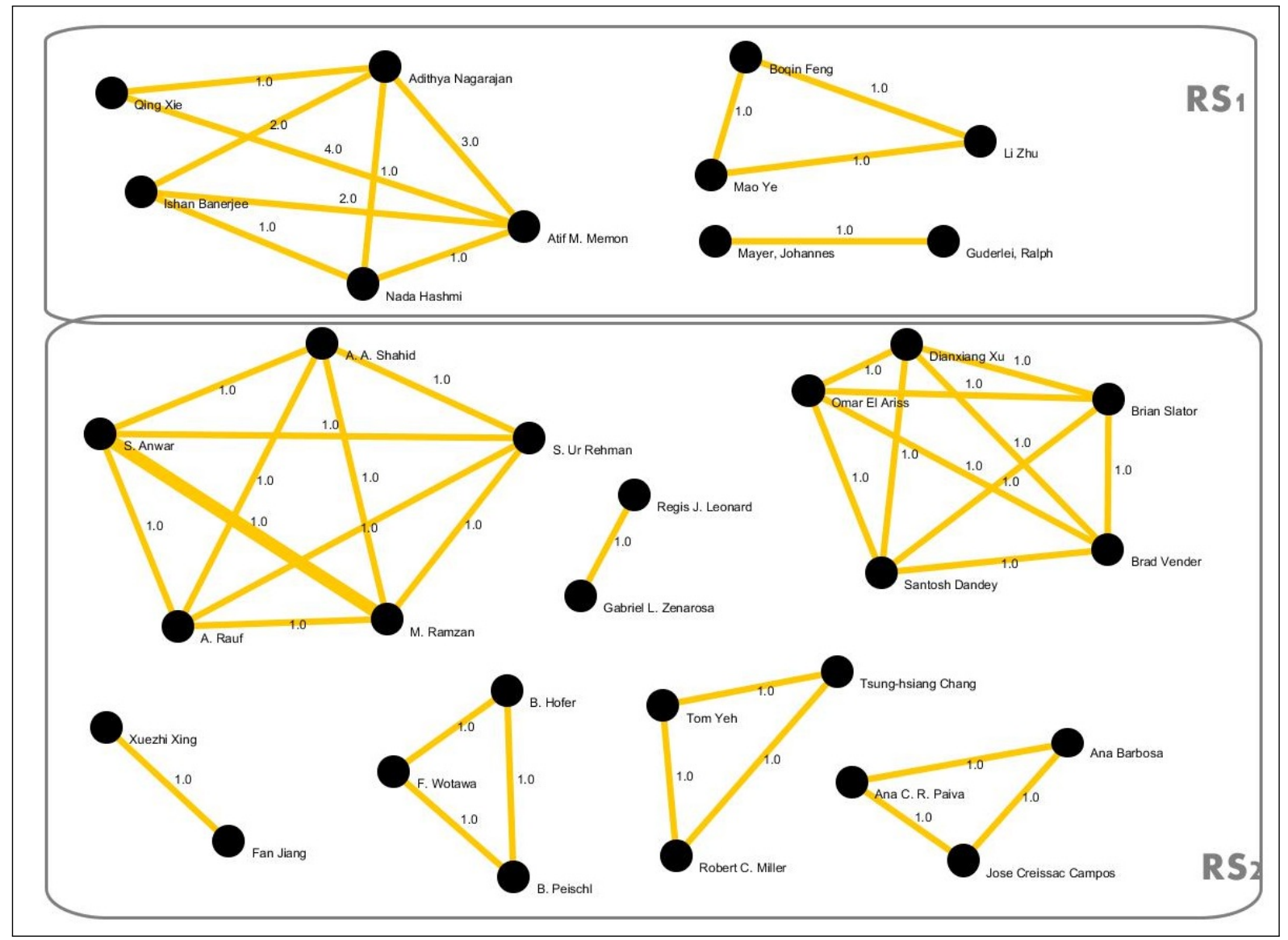

Figura 3.4: Grafo que relaciona autores das obras selecionadas na RS

Engenharia de Software da "University of Maryland" nos Estados Unidos. Na Figura $3.4^{8}$ pode ser visualizado um grafo que associa os autores dos estudos selecionados ao final da reexecução da RS. Cada nó do grafo representa um autor. Em cada aresta entre os nós (autores) há um número que representa o número de trabalhos incluídos na RS nos quais os autores publicaram conjuntamente. É interessante destacar que a rede localizada na parte superior da figura (tag RS1) corresponde à rede de colaboração de autores resultante da primeira execução da revisão. Consequentemente, a rede localizada na parte inferior da figura (tag RS2) corresponde à rede de colaboração gerada após a reexecução da RS. Isso revela que, em poucos anos, surgiram alguns diferentes grupos de pesquisa na área de teste com sistemas com GUIs. Assim, espera-se que, dentro de alguns anos diferentes grupos surjam, aumentando assim a rede de colaboração dessa área de pesquisa. Vale ressaltar que os grupos foram identificados a partir dos veículos consultados no caso dessa pesquisa, em particular. Portanto, pode ser que outros grupos tenham surgido no período.

Uma constatação importante é que, com exceção do trabalho de Chang et al. (2010), que pode ser considerado da área de visão computacional, não foram encontradas abor-

\footnotetext{
${ }^{8}$ Essa figura foi gerada por meio das funcionalidades da ferramenta de visualização de dados acadêmicos $\mathrm{Sci}^{2}$ - acesse: https://sci2.cns.iu.edu/
} 
dagens que utilizem técnicas de PI para apoiar a construção dos oráculos. Sendo assim, conclui-se que todos os oráculos aplicavam-se aos eventos ocorridos em interfaces GUI e, geralmente, o estado esperado é obtido por meio de especificações formais de uma GUI. Ou seja, a partir do conjunto de elementos GUI e suas propriedades é possível que oráculos sejam ajustados.

Diante do cenário revelado pela RS, pode-se afirmar que as técnicas mais comuns para a realização do teste de sistemas com GUIs são baseadas na exploração de aspectos internos como, por exemplo, nome de componentes em código e tipos de retornos para funções que representem eventos. Por isso, nos capítulos seguintes desta dissertação de mestrado busca-se fornecer subsídios para o uso de uma abordagem alternativa às abordagens encontradas na literatura. Adicionalmente, no Capítulo 6 é feita uma avaliação empírica completa visando à comparação do teste de sistemas com GUIs usando suas estruturas internas e o mesmo teste utilizando o método Gr-O. Tal método, explorado em trabalhos anteriores (Delamaro et al., 2011; Oliveira e Delamaro, 2010), consiste na estratégia de utilizar conceitos de CBIR para automatização de oráculos gráficos.

No tocante à concepção de oráculos de teste para sistemas com interfaces gráficas, de acordo com Xie e Memon (2007), na prática, podem ser utilizadas quatro abordagens diferentes. A forma mais popular pode ser considerada a exploração de oráculos manuais. Nesses casos, um testador pode interagir com uma interface gráfica disparando eventos diversos como, por exemplo, copiar e. colar textos, digitar textos em campos etc, e verificar se o estado da GUI decorrente dos eventos disparados contém erros (Marick, 1998). A segunda abordagem identificada pelos autores é, exatamente, a exploração de ferramentas de captura/reprodução. Nesse tipo de ferramenta, o testador deve interagir com a interface, para que simultaneamente, a ferramenta, por meio de seus recursos para gravação, possa capturar a ordem de eventos disparados por ele. Em geral, as ferramentas desse tipo oferecem recursos para que o testador ajuste estados esperados no decorrer das interações. Os recursos de reprodução da ferramenta permitirão que as interações gravadas sejam reproduzidas. Enquanto isso, o programa monitora e verifica se os comportamentos apresentados são os esperados. Entretanto, a confiança plena no uso desse tipo de ferramenta para o teste de sistemas com interfaces gráficas pode gerar problemas de manutenção pois cada versão nova da interface do sistema exigirá alterações expressivas nos scripts de teste.

Xie e Memon (2007) indicam que a terceira maneira para que sejam configurados oráculos de teste para sistemas com GUIs é por meio do uso de sentenças assertivas explícitas. Em geral, o uso desse tipo de sentença exige que o testador implemente classes paralelas de teste para suas interfaces. O uso de assertivas explícitas é comumente associado a ferramentas de teste que podem ser consideradas extensões do framework JUnit (JFCUnit, 
Abbot, Pounder, e Jemmy Module). Esses programas são capazes de executar as assertivas, verificando a correção das interfaces. Por fim, a última maneira identificada por Xie e Memon (2007) é a utilização de abordagens conhecidas como hard-code. Abordagens hard-code são aquelas nas quais os testadores definem em código resultados esperados para determinadas operações. Essas saídas são, geralmente, avaliadas por chamadas a métodos que verificam determinadas condições do sistema em teste.

\subsection{CBIR - Content-Based Image Retrieval}

O aumento do uso de documentos digitalizados por parte de diversas organizações levou à necessidade da criação de eficientes algoritmos de recuperação, indexação e técnicas de classificação. Em particular, quando tais dados são fornecidos no formato de imagens, cabe ressaltar que diversas áreas da ciência foram amplamente beneficiadas por tal evolução, com destaque especial para a área das ciências médicas. Por exemplo, em sistemas de auxílio a diagnósticos, conhecidos como esquemas CAD (do inglês, Computer-Aided Diagnosis), o médico compõe um diagnóstico levando em consideração o resultado de processamento de um sistema computadorizado que executa baseando-se em processamentos e análises de imagens ou até em dados clínicos de pacientes (Gato et al., 2004).

Diversos pesquisadores voltaram os esforços de suas pesquisas para a área do processamento de imagens e da computação gráfica como um todo, fazendo com que novas tecnologias e métodos de trabalho surgissem na área - CBIR foi um deles. Na presente seção, busca-se esmiuçar os conceitos de CBIR e introduzir as contribuições que a exploração de tal tecnologia pode trazer para a configuração de oráculos de teste capazes de apoiar o teste de sistemas com saídas gráficas.

Processar uma imagem digital é um procedimento que envolve sistemas de software com funções para objetivos específicos. Afirmar que um objeto qualquer é digitalizado implica em definir que ele é representado por uma quantidade discreta de seus pontos ou amostras. Digitalizar uma determinada cena do mundo real significa, simplesmente, capturar um sinal analógico e representá-lo fielmente em um formato digital (Gonzalez e Woods, 2006).

Uma determinada imagem, para ser processada adequadamente, deve ser digitalizada tanto espacialmente quanto em sua amplitude. A digitalização das coordenadas espaciais e da amplitude configuram os conceitos do que a literatura apresenta como amostragem e quantização. Numericamente, considerando que $Z$ e $R$ sejam os conjuntos de números inteiros e reais, respectivamente, a amostragem pode ser dita como sendo a partição de um plano de uma imagem qualquer em uma grade na qual as coordenadas do cruzamento são um par de elementos contido no produto cartesiano de $Z \times Z$. Assim, uma imagem 
é definida como sendo digital quando, $f(x, y)$ for digitalizada ao longo de $x$ e $y$, e na amplitude $Z=f(x, y)$. Assim, é feita uma amostragem (normalmente uniforme) de $f(x, y)$ nas direções $x$ e $y$, gerando uma matriz de amostras, seguida de uma quantização da função $f(x, y)$ que deve definir um valor de nível de cor, que deve ser um número, a cada par de coordenadas $(x, y)$ distinto. Essa definição da quantidade de cores que pode ser representada em cada ponto digitalizado é, exatamente, o processo de quantização da imagem (Gonzalez e Woods, 2006).

A Computação Gráfica permite que as imagens digitais possam ser geradas, modificadas e combinadas para uma grande variedade de efeitos visuais. No contexto de Processamento de Imagens digitalizadas, os esforços dedicados para a descoberta de novos métodos e algoritmos de processamento eficiente de imagem têm duas áreas de aplicação principais: melhoria da informação visual para interpretações humanas e processamento de dados de cenas visuais para percepção automática por meio de máquinas (Gonzalez e Woods, 2006).

Para a primeira área de aplicação, em particular, são comuns aplicações para a área médica como, por exemplo, processos computacionais e algoritmos para melhora de contraste, enfatização de regiões, redução de degradações, codificação de cores e redução de ruídos de aplicações. Além da área médica, outros setores também beneficiados são: - arqueologia (restauração digital de registros únicos achados, perdidos ou danificados) e física (realces de imagens experimentais) (Gonzalez e Woods, 2006). Adicionalmente, quando o objetivo do processamento é dado para a segunda área de aplicação, que é a percepção automática de situações por máquinas - interesse, inclusive, do trabalho de mestrado apresentado nesta dissertação - diversas funcionalidades podem ser citadas: sistemas robóticos de inspeção automática, sistemas de segurança, reconhecimento de impressões digitais, reconhecimento de padrões, monitoração de plantio etc (Gonzalez e Woods, 2006).

O entendimento dos esquemas de PI necessitam da explanação dos conceitos dos sistemas de coordenadas de uma imagem digital. Tal sistema de coordenadas é utilizado para que seja feita a identificação de cada ponto possível da imagem na tela. Por definição, o canto superior esquerdo de um componente GUI têm as coordenadas $(0,0)$. Um par de coordenadas é composto por uma coordenada x (coordenada horizontal) e uma coordenada y (coordenada vertical). Na Figura 3.5 é ilustrada uma imagem digital e seu sistema de coordenadas.

\subsubsection{Etapas}

Tradicionalmente as pesquisas em bases de imagens utilizam palavras-chaves (Lieberman et al., 2001; Ogle e Stonebraker, 1995) que consistem em atributos textuais, numéricos, ou similares. Para tanto, deve-se previamente cadastrar descritores capazes de definir 


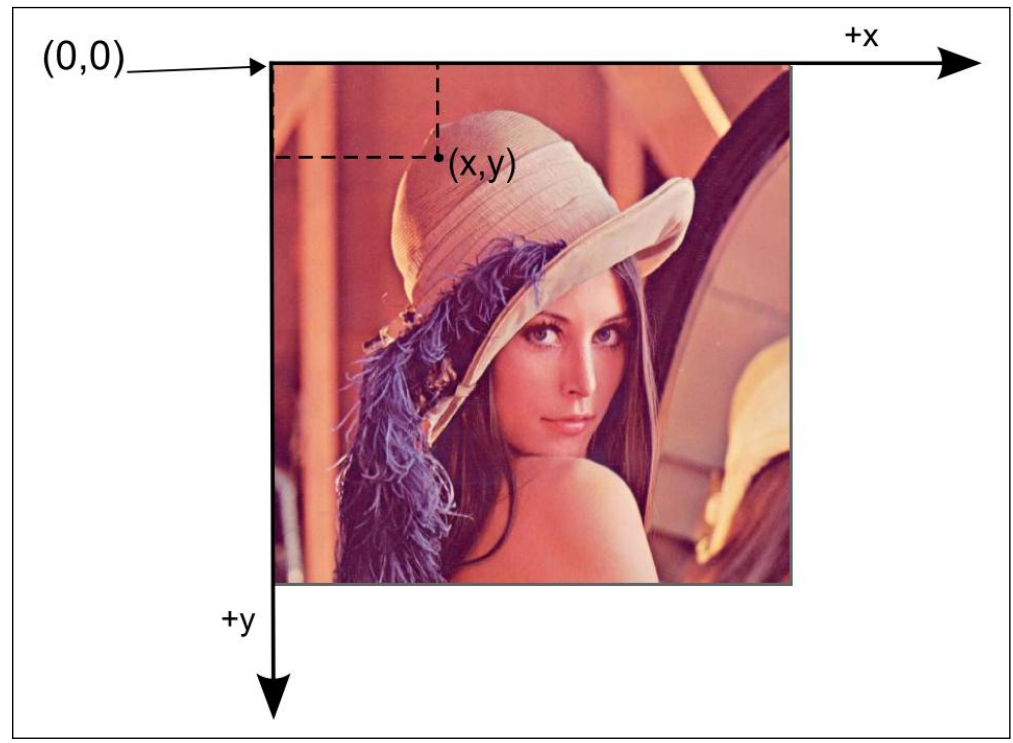

Figura 3.5: Sistemas de coordenadas de uma imagem digital

uma imagem para, então, viabilizar consultas por meio de palavras como, por exemplo, “ "clara", "escura", "baixo contraste" etc. Essa forma tradicional de pesquisa tem diversas limitações que tornam algumas buscas ineficientes. O conceito de CBIR vem suprir esta necessidade. Segundo Datta et al. (2008), as pesquisas em CBIR foram iniciadas na segunda metade da década de 1990, proporcionando um diferencial na recuperação de informação quando o assunto a ser pesquisado envolve imagens.

CBIR é definida como qualquer tecnologia que ajude a organizar arquivos digitais de imagens por meio do seu conteúdo visual (Datta et al., 2008). Os sistemas de CBIR são sistemas computacionais que visam a localizar em uma base de imagens aquelas mais similares a uma imagem de consulta, de acordo com um ou mais critérios fornecidos (Bueno et al., 2002). Sob outras perspectivas, sistemas CBIR permitem a recuperação de um conjunto finito de imagens similares a uma imagem exemplo. Os critérios de similaridade são obtidos a partir da extração de características da imagem como cor, textura e forma. Por isso, é dito que a recuperação é feita por meio do uso de informações inerentes à própria imagem. Tais informações se resumem nas características das imagens e podem tanto ser obtidas por especialistas como ser extraídas das imagens por algoritmos automáticos alcançando melhores resultados (Gato et al., 2004). Os sistemas automatizados de CBIR envolvem várias áreas da Computação, sendo as principais PI e Banco de Dados.

O propósito do CBIR nem sempre é buscar a imagem exatamente igual à imagem de consulta, o que poderia acontecer por uma comparação pixel a pixel, e sim buscar a imagem mais parecida. A comparação de objetos por similaridade é essencial para tratar dados complexos e capturar o que é mais representativo a fim de extrair informações que os representem de modo mais fiel (Bellotti et al., 2006; Paquerault et al., 2004). Pode-se classificar CBIR como um processo que exige muito tempo de processamento, por isso a 
comparação entre as imagens é feita utilizando um conjunto de características extraídas das imagens. Esse conjunto de características forma o seu vetor de características, que é utilizado na sua indexação e recuperação. Pode-se concluir que as características extraídas representam a imagem no momento de sua busca, pois é a partir delas que uma determinada imagem é recuperada do banco de imagens (Paquerault et al., 2004). O conjunto de características em si não é suficiente para determinar o resultado da recuperação, visto que a escolha da medida de similaridade entre as imagens vai, também, ter influência nele.

Existem diversas classificações de etapas de processamento para sistemas CBIR. Segundo Araújo et al. (2002), são etapas básicas para sistemas CBIR:

- aquisição: consiste em, por algum meio físico, obter as imagens digitais a serem utilizadas;

- pré-processamento: baseia-se em melhorar a imagem, por meio de técnicas para realce de contraste, remoção de ruído, isolamento de regiões e etc. Esta etapa tem como objetivo maior o aumento das chances de sucesso dos processos seguintes;

- extração de características: tem por meta extrair informações ou dados particulares da imagem, as quais serão utilizadas na busca na base de dados;

- indexação: consiste em aperfeiçoar e facilitar a consulta à base de dados de imagens;

- recuperação: consiste da varredura de toda a base de dados, de forma a recuperar as imagens mais similares à imagem exemplo.

De forma simplificada e dentro do contexto do framework O-FIm, um sistema de CBIR é composto basicamente por quatro partes: extratores de características, algoritmos de indexação, algoritmos de ordenação e funções de similaridades (Smeulders et al., 2000), conforme o esquema apresentado na Figura 3.6. Entretanto, no trabalho realizado durante este mestrado, apenas duas dessas partes foram utilizadas - extratores de características e funções de similaridade. Ambas são descritas nas duas seções seguintes. O uso da tecnologia no trabalho proposto é mais bem descrito no Capítulo 6.

\subsubsection{Extratores de Características}

Os extratores são métodos computacionais que extraem características das imagens a partir de algoritmos que analisam cores, formas, texturas ou outros aspectos relacionados à imagem como um todo ou a parte dela. Quando as imagens são consideradas como um conjunto de pixels, esses extratores podem referir-se a relações existentes entre os pixels em um determinado trecho da imagem, considerando uma classe particular de características. Por exemplo, definindo-se as cores como uma classe particular de interesse, um extrator específico poderia retornar o valor do contraste de um determinado trecho da imagem, que poderia ser medido calculando-se a média de cores de tal objeto dividida pela média 


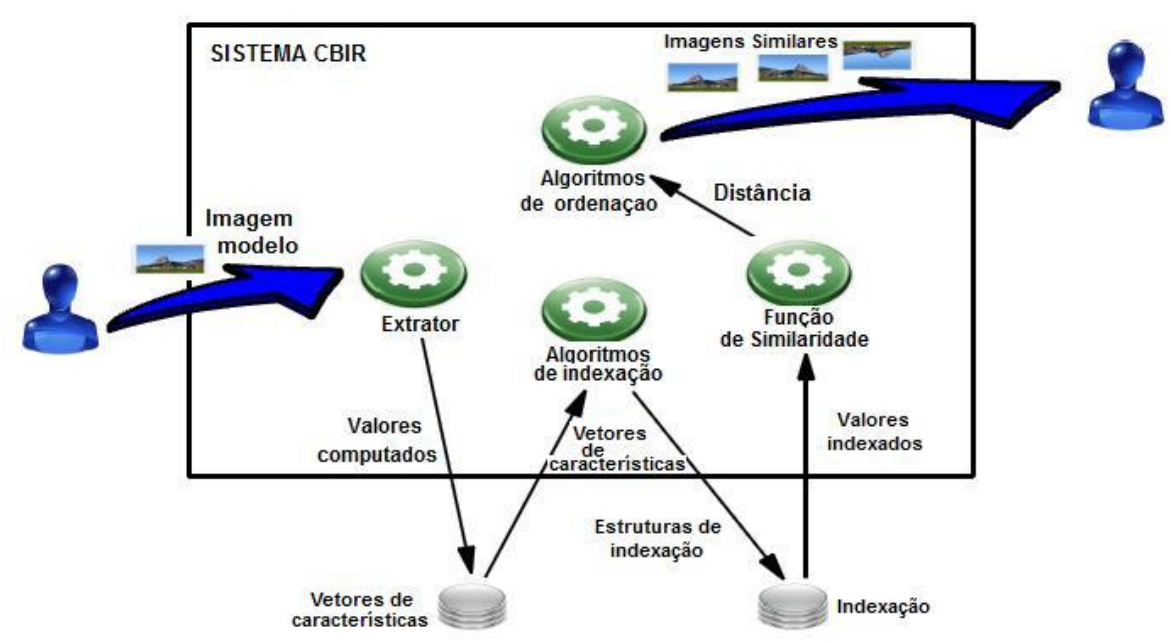

Figura 3.6: Esquema CBIR no contexto deste trabalho de mestrado (adaptado de Delamaro et al. (2011))

de cores do fundo da imagem - composto pelos pixels que circundam o trecho em questão (Delamaro et al., 2011).

As características extraídas são, em geral, transformadas em um valor que, posteriormente, pode ser comparado com o valor obtido para a mesma característica de outra imagem (El-Naqa et al., 2004). Comumente vários extratores são desenvolvidos em um sistema CBIR, sendo que cada um deles refere-se a um aspecto da imagem. Por exemplo, em um sistema simples de CBIR, o extrator que calcula o contraste de um determinado trecho da imagem, exemplificado anteriormente, pode retornar o valor zero quando o contraste é nulo ou outro valor no intervalo entre zero e um, representando o nível de contraste entre a estrutura considerada e o fundo da imagem (Delamaro et al., 2011). No processo de extração de características deve ser levado em conta o foco da aplicação, pois dependendo do tipo de imagem e aplicação, as características de interesse podem variar e até mesmo serem muito específicas. No entanto, é possível definirem-se extratores aplicáveis a diversas classes de imagens. Extração de características geralmente ocorre depois de uma etapa de pré-processamento e segmentação da imagem, no qual o objeto de interesse é localizado e rotulado de forma que fique isolado. Na segmentação, o objeto é separado do fundo gerando uma região ou apenas identificando a borda (Gonzalez e Woods, 2006). A partir daí, o processo de extração de características fica responsável por obter aspectos inerentes ao objeto segmentado ou região de interesse, de acordo com algum critério pré-estabelecido.

O conjunto de características extraídas de uma imagem forma o seu vetor de características, que é utilizado na sua indexação e recuperação. As características extraídas representam a imagem no momento de sua busca, pois é a partir delas que uma determinada imagem é recuperada do banco de imagens. O conjunto de características em si 
não é suficiente para determinar o resultado da recuperação. Outro elemento que vai influenciar nos resultados da busca é a escolha de medidas de similaridade entre as imagens (Vasconcelos, 2004).

\subsubsection{Funções de Distância ou Similaridade}

Uma função de distância ou, similaridade, é um algoritmo que compara dois vetores de características e retorna um valor não negativo. Quanto menor o valor retornado, maior é a semelhança entre a imagem modelo e a imagem procurada (Delamaro et al., 2011). Existem várias funções de distância disponíveis para comparar vetores de características. Alguns exemplos são a distância Euclidiana entre histogramas (Hafner et al., 1995; Swain e Ballard, 1991), a distância de Mahalanobis entre o valor médio das características da imagem (Manjunath e Ma, 1996; Smith e Chang, 1997), ou métricas derivadas de critérios de otimização relacionados (Rubner et al., 1998). Vasconcelos (2004) faz uma detalhada análise sobre a eficiência da avaliação de sistemas de CBIR usando funções de similaridade probabilísticas. A partir da composição do vetor de características e da definição da função de similaridade a ser empregada, o sistema está pronto para realizar as consultas. A recuperação por similaridade pode ser por abrangência (usa a distância a partir de um ponto de referência para a recuperação da imagem) ou pelos $k$ vizinhos mais próximos (a partir de um ponto de referência recupera as $k$ imagens mais similares à imagem de consulta) (Ciaccia et al., 1997).

\subsection{Considerações Finais}

Pode-se classificar o trabalho a ser realizado como multidisciplinar pois nele são explorados conceitos de CBIR (Processamento de Imagem) para apoiar uma estratégia de teste de software (Engenharia de Software). Este capítulo é responsável por apresentar conceitos básicos sobre GUIs e sobre a técnica CBIR. Adicionalmente, o capítulo visa a introduzir aspectos técnicos sobre a utilização de CBIR no contexto dos oráculos gráficos. Desse modo, no próximo capítulo desta dissertação, são firmados mais conceitos sobre a utilização do método Gr-O para a automatização de oráculos gráficos para sistemas com GUIs. Além disso, é descrito o framework utilizado e aprimorado durante o período de condução do trabalho. 



\section{O Framework O-FIm}

\subsection{Considerações Iniciais}

Capaz de apoiar o teste de sistemas com saídas gráficas, o O-FIm inicialmente era composto apenas por um núcleo de funcionalidades e um parser identificador para seus oráculos. O-FIm foi desenvolvido em linguagem Java e atualmente é distribuído como software livre $^{1}$. Para o contexto do presente trabalho, tal framework foi acrescido de algumas funcionalidades e algumas estruturas foram adicionadas ou reimplementadas. Além disso, foi implementada uma API Java cuja principal utilidade é fornecer métodos intuitivos e de fácil utilização para a criação de oráculos para teste de modo simples, sistemático e com mais produtividade.

Neste capítulo são descritos os principais aspectos de implementação da O-FIm. É importante destacar que a estratégia de utilizar CBIR como alternativa em processos de Engenharia de Software é recente (Delamaro et al., 2011; Oliveira et al., 2009b). O objetivo deste trabalho, em particular, é concentrado em investigar, estudar e relatar experiências do uso da extração de características e informações de screenshots de GUIs de forma adequada para o processamento computacional, apoiando a automatização do teste de funcionalidades do sistema subjacente. Desse modo, a utilização do framework O-FIm para a automatização de oráculos foi inerente à metodologia proposta.

\footnotetext{
${ }^{1}$ acesse: http://ccsl.icmc.usp.br/pt-br/content/o-fim-oracle-images
} 


\subsection{Arquitetura}

Para permitir que CBIR seja utilizada como estratégia para automatização de oráculos para GUIs, neste trabalho buscou-se utilizar um framework que permitisse ao testador criar seus oráculos de forma flexível e simples, independentemente do domínio a que se destine. Pode-se afirmar que tais características são oferecidas pela arquitetura do framework O-FIm.

Diante desse cenário, para que CBIR sirva como alternativa para automatização de oráculos de teste, devem ser fornecidos recursos para a definição de extratores, função de similaridade e as regiões da imagem nas quais cada extrator deve ser aplicado. Para suprir todos esses requisitos, sem que as atividades de teste se tornem caras e propensas a erros humanos, o framework O-FIm utiliza como estratégia uma arquitetura que atende, principalmente, a alguns requisitos fundamentais como flexibilidade, simplicidade e facilidade de uso.

Uma limitação expressiva das técnicas e estratégias de teste que podem ser encontradas na literatura é a falta de flexibilidade. Geralmente, uma técnica, ou até uma ferramenta, é definida e validada por meio de estudos empíricos para o funcionamento em apenas um domínio específico. Entretanto, a flexibilidade da arquitetura estabelecida no O-FIm permite ao testador criar oráculos para diversas aplicações com saídas gráficas distintas. Para tanto, é necessário definir e implementar os extratores de características e funções de similaridade que o testador pretende usar no seu oráculo.

Para o contexto desta dissertação e com o objetivo de criar uma estrutura que aliasse flexibilidade e facilidades de instalação e operação, a arquitetura do framework originalmente proposto por Oliveira et al. (2008) foi ajustada conforme é ilustrado na Figura $4.1^{2}$. Desse modo, como resultado da utilização do framework O-FIm, o testador obtém um programa Java que é capaz de comparar duas imagens (em geral armazenadas em arquivos) respondendo se são ou não similares, de acordo com as características por ele definidas.

Entretanto, de um modo pragmático, alguns pontos particulares precisam ser definidos: a arquitetura permite ao testador interagir com o núcleo da estrutura diretamente, por meio de comandos específicos, ou indiretamente por meio do wizard. O núcleo tem a tarefa de reconhecer e instalar plugins (extratores ou funções de similaridade) na ferramenta. O parser é capaz de reconhecer um descritor de oráculos válidos e fazer chamadas às classes correspondentes, ajustando o sistema para a realização dos testes. As descrições de oráculos podem ser criadas manualmente, o que não é uma tarefa simples, ou por meio

\footnotetext{
${ }^{2}$ Os ícones utilizados nesta figura são disponibilizado pelo pacote de ícones "crystal clear" disponível em http://everaldo.com/crystal/
} 


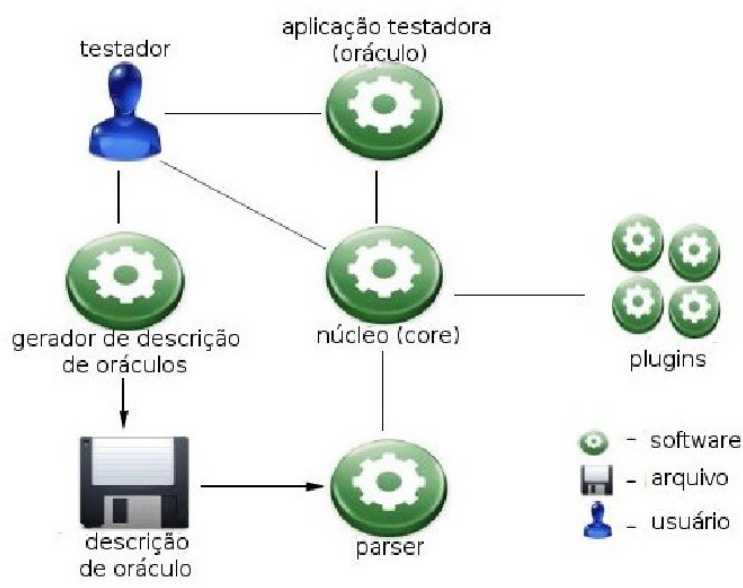

Figura 4.1: Arquitetura do framework O-FIm

do wizard. Os resultados de um teste qualquer podem ser visualizados no wizard ou, então, ajustados por meio de um console.

Na Figura 4.2 é apresentado o Diagrama de Componentes definido para a implementação das funcionalidades adicionais necessárias para o O-FIm dar suporte aos estudos empíricos deste trabalho. Em termos gerais, Diagramas de Componentes da linguagem de modelagem UML (Unified Modeling Language) servem como ferramentas ilustrativas da organização de um sistema baseando-se em noções de componentes de trabalho. Sendo assim, a Figura 4.2 pode ser considerada como uma representação visual da estrutura estática do modelo de implementação.

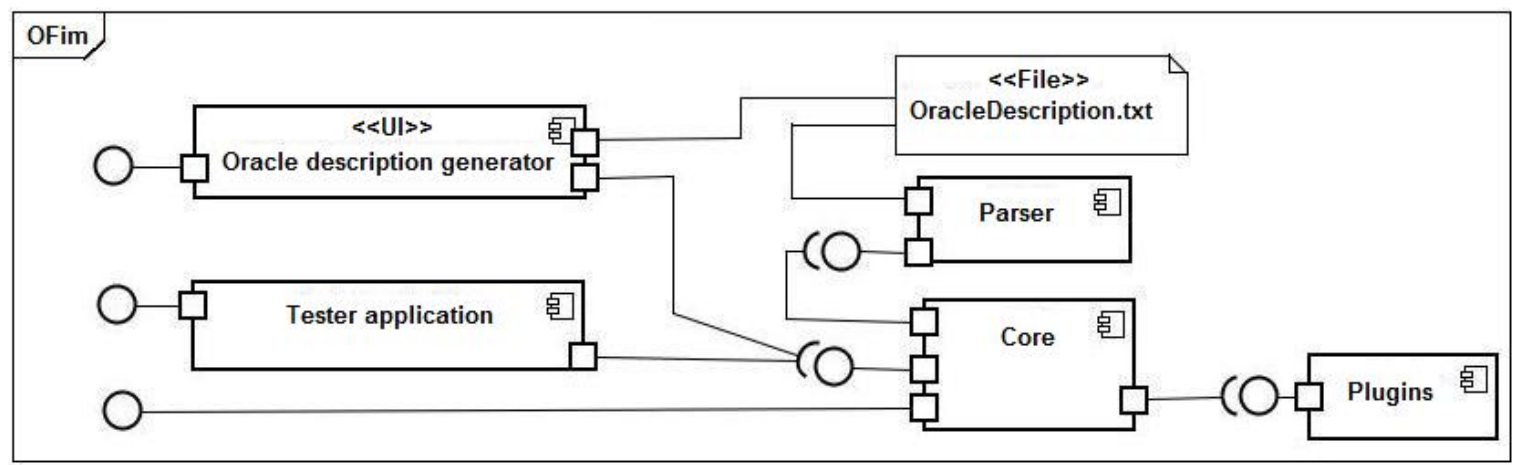

Figura 4.2: Diagrama de componentes do framework O-FIm (adaptado de Oliveira et al. $(2010))$

\subsection{Plugins - Extratores e Funções de Similaridade}

A flexibilidade que permite aos usuários configurarem o framework O-FIm para o teste de diversos domínios que tenham saídas gráficas é possibilitada por conta dos plugins. É 
importante destacar que plugins podem ser desenvolvidos para domínios específicos e, por isso, são as contribuições do testador para a criação do oráculo. Plugins são adicionados ao framework por meio de chamadas ao núcleo e podem ser de dois tipos - extrator de características ou função de similaridade. Por isso, conforme foi mencionado na Seção 3.3.1, apenas duas etapas do conceito de CBIR são aproveitadas para o contexto do presente trabalho. Um extrator de característica pode ser, por exemplo, uma classe na qual, por meio de algoritmos de processamento de imagem, sejam feitas análises específicas de uma determinada região que corresponda a um componente em um screenshot.

O primeiro tipo de plugin representa um extrator de características e é exatamente nele em que o testador deve implementar os seus algoritmos de processamento de imagem que irão identificar uma característica ou padrões presentes em uma determinada imagem e quantificá-la. Para permitir que o testador implemente um extrator e que o framework reconheça-o como tal, o núcleo disponibiliza uma interface chamada IExtractor. Essa interface contém métodos que, se implementados de modo pertinente, são o suficiente para que um extrator de características qualquer componha um oráculo de teste configurado pelo O-FIm. Desse modo, é requisito que, ao desenvolver um extrator, o testador crie uma classe Java que implemente essa interface. Na Listagem 4.1 é apresentada a interface IExtractor.

Listagem 4.1: Interface Java IExtractor

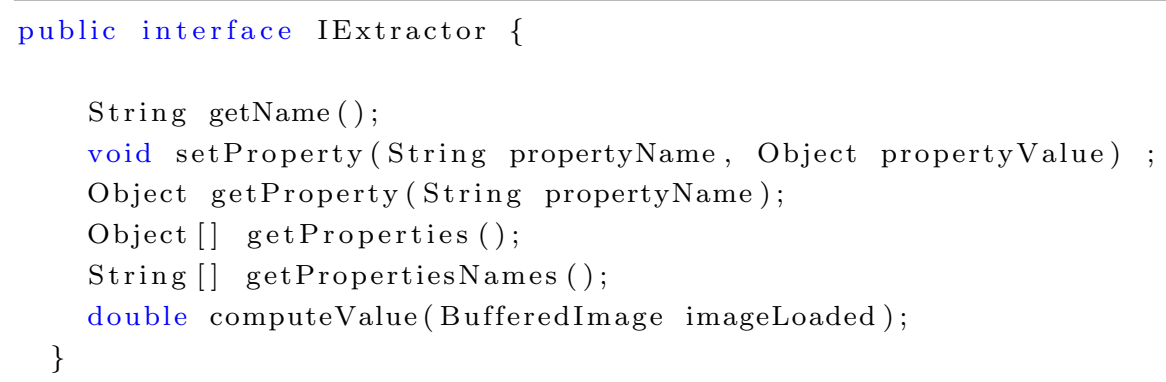

Cada um dos métodos da interface tem uma funcionalidade básica que é necessária para o funcionamento correto do plugin em um teste. A seguir, a função principal de cada um dos métodos da IExtractor é detalhada:

- void setName(java.lang.String): atribui um nome ao extrator. Tal nome será utilizado em possíveis oráculos configurados pela O-FIm;

- java.lang.String getName(): retorna o nome atribuído ao extrator;

- setProperty(java.lang.String, java.lang.Object): cada extrator pode ter um conjunto próprio de atributos que define e especifica seu comportamento. Por exemplo, se o extrator deve ser aplicado a uma região da imagem e não à imagem como um todo, a classe que implementa o extrator pode definir uma propriedade "rectangle" que deve receber um valor antes que o extrator seja usado. Como esse 
é um método genérico para qualquer que seja o tipo do atributo, a chamada no caso de "rectangle" recebe como segundo argumento um array de quatro números inteiros. É obrigação do método setProperty verificar a validade do nome e do tipo dos argumentos;

- String [] getProperties(): retorna um arranjo de String com os nomes das propriedades utilizadas pelo extrator;

- double computeValue (java.awt.image.BufferedImage): calcula o valor relativo à propriedade/característica que o extrator implementa para uma determinada aplicação (imagem) em teste.

O segundo tipo de plugin que o testador pode adicionar ao framework representa, na estrutura de CBIR, uma função de similaridade, já que diferentes formas de combinar os resultados produzidos pelos extratores podem ser utilizadas. Esses plugins são responsáveis por definir métricas de similaridade que atribuirão um valor numérico que represente a diferença entre as características de duas imagens. Para o caso deste trabalho, em particular, as imagens serão screenshots de GUIs de aplicações em teste. Para o funcionamento adequado de uma função de similaridade no O-FIm, é exigido que a ela sejam "adicionados" um ou mais extratores. Para que esse tipo de plugin funcione corretamente, é preciso que o testador crie-o em uma classe que implemente a interface chamada de ISimilarity. Na Listagem 4.2, a interface desse tipo de plugin é apresentada.

Listagem 4.2: Interface Java ISimilarity

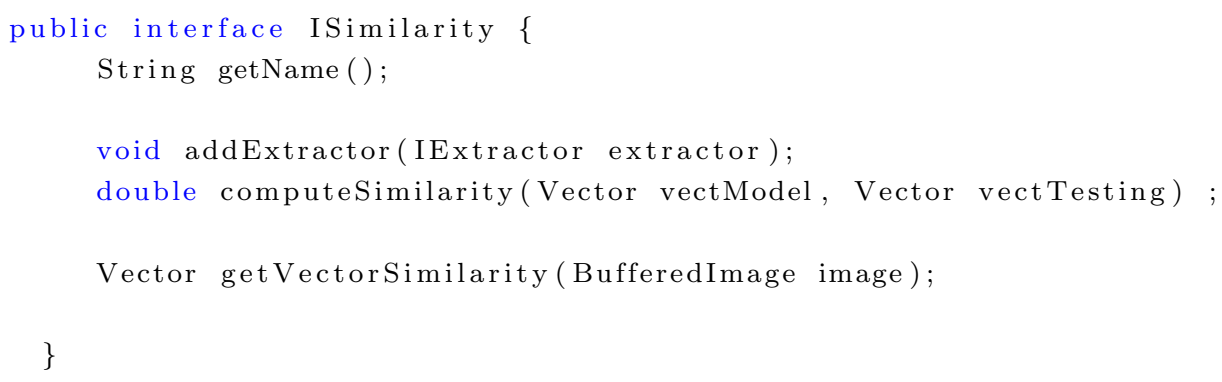

A especificação de cada um dos métodos da interface ISimilarity é descrita a seguir:

- java.lang.String getName(): retorna um objeto do tipo java.lang.String com o nome atribuído à função de similaridade;

- void addExtractor(IExtractor): uma função de similaridade utiliza um ou mais extratores. Esse método permite adicionar um extrator à função de similaridade ajustada em determinado oráculo;

- IExtractor [] getExtractors(): retorna um objeto que represente a lista de extratores que fazem parte da função de similaridade; 
- double[] computeValues (java.awt.image.BufferedImage): calcula o valor de cada um dos extratores para uma dada imagem em teste;

- double computeSimilarity(double [], double []): computa o valor da função de similaridade aplicada a dois vetores de números, em geral, retornados da aplicação dos extratores de características em duas imagens distintas.

Na Figura 4.3 é expressa a relação entre as duas interfaces para instalação de plugins no framework O-FIm. A despeito do fato de serem simples e intuitivas, as duas interfaces são suficientes para que sejam configurados oráculos de teste para diferentes sistemas com saídas gráficas. Para tanto, conforme pode ser visualizado na referida figura, há uma relação direta entre funções de similaridade e extratores de característica de imagens ocorrida durante a criação de um oráculo. Mais precisamente, durante a instanciação de um objeto do tipo ISimilarity são adicionados um ou mais extratores para a configuração de um oráculo teste.

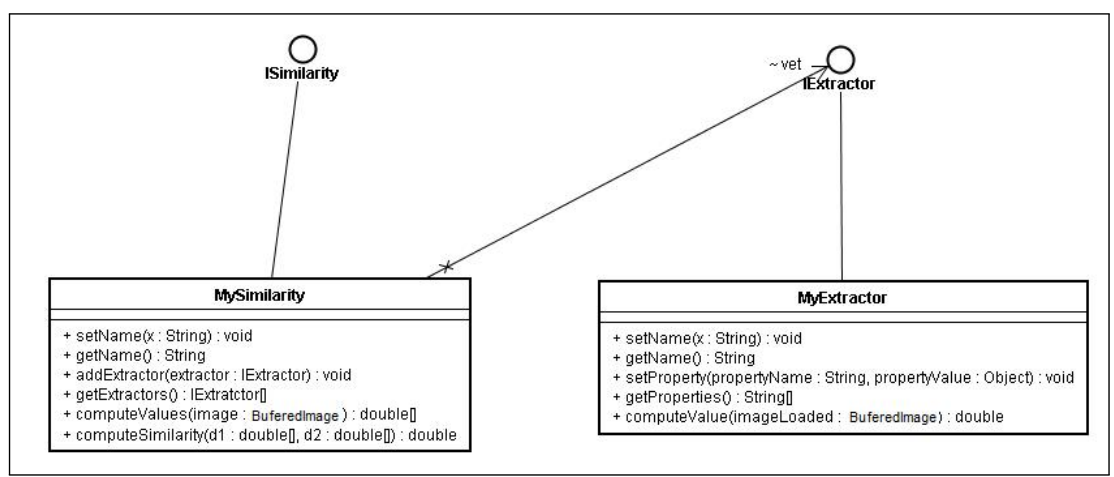

Figura 4.3: Estrutura de classes para extratores e funções de similaridade (adaptado de Delamaro et al. (2011))

\subsection{Núcleo}

Todas as atividades realizadas pelo framework O-FIm são gerenciadas, direta ou indiretamente, por um módulo identificado na Figura 4.1 como núcleo. Para o contexto deste trabalho de mestrado, o núcleo da ferramenta foi ajustado para realizar funcionalidades fundamentais como, por exemplo, instalação ou remoção de plugins e criação de estrutura de dados descritas pelos oráculos ajustados. É importante destacar que o núcleo constitui uma API que é suficiente para um testador criar classes de teste capazes de executar oráculos para diferentes domínios. Para instalar e remover plugins, o núcleo provê um programa que pode ser invocado diretamente na linha de comando. Por exemplo, para instalar um plugin pode-se executar um comando do seguinte tipo: 
java br.oraculos.Main install MyExtractor

/home/rafael/myextractor br.extractors.MyExtractor

Para esse caso, em particular, os argumentos expressados por linha de comando representam:

- install: indica que uma operação de instalação de plugin deve ser realizada;

- MyExtractor: indica para o O-FIm o nome a ser dado ao plugin. O núcleo irá associar esse nome às classes que representam o plugin por meio de uma estrutura XML. Este será o nome que deve ser utilizado quando for necessário configurar oráculos utilizando esse plugin;

- /home/rafael/myextractor: representa o nome do diretório do arquivo ".jar" ou, então, das classes que contêm o extrator ou função de similaridade em instalação;

- br.extractors. MyExtractor: indica o nome da classe que implementa a interface dentro do diretório raiz do plugin em instalação. O núcleo, então, identifica automaticamente qual o tipo de plugin, verificando quais interfaces ele implementa. Isso, internamente, determina a forma como a classe pode ser usada - como um extrator, como uma função de similaridade ou, ainda, como ambos. Posteriormente, durante a realização de um teste, essa classe será usada para instanciar o plugin quando um oráculo necessitá-lo.

\subsubsection{API do framework}

Para facilitar a operação do núcleo do O-FIm, implementou-se durante este trabalho uma API. Em linhas gerais, tal API permite, de forma pragmática, a criação de um oráculo com classes pré-estabelecidas. Entretanto, caso o testador considere necessário, tal funcionalidade é provida de modo mais intuitivo por meio da interface gráfica do wizard, descrito com detalhes na Seção A. Na Figura 4.1, a criação de um oráculo por meio da utilização dessa API é representada pela aplicação do testador que acessa os métodos da API do núcleo. As principais funções fornecidas pelo núcleo estão na classe br.oraculos. Oracle que implementa:

- static Oracle createOracle(): criação de uma instância de um oráculo vazio;

- static Oracle createOracle(java.io.InputStream): cria um oráculo baseado numa descrição completa dada por meio de java.io.InputStream. Essa descrição constitui o que nesta dissertação é chamado de oráculo gráfico. Detalhes das especificações necessárias para a configuração de um oráculo gráfico são apresentadas na Seção 4.5.1 deste capítulo; 
- void setSimilarityFunction(ISimilarity): determina qual função de similaridade é usada pelo oráculo;

- ISimilarity getSimilarityFunction(): retorna um objeto do tipo ISimilarity que representa a função de similaridade utilizada em um oráculo;

- void setPrecision(double): determina qual é a precisão ou limiar (threshold) usada pelo oráculo. Desse modo, esse será o valor a partir do qual determinado oráculo deverá definir se as diferenças entre duas imagens (screenshots) é considerada aceitável, ou não. Caso o valor retornado pelo método computeDistance seja inferior a esse valor, as imagens são consideradas similares e, caso contrário, são consideradas diferentes;

- double getPrecision(): método responsável por retornar o valor da precisão sendo utilizada;

- double computeDistance(BufferedImage, BufferedImage): tal método é responsável por calcular a "diferença" ou distância entre duas imagens, usando a função de similaridade definida e os extratores por ela utilizada;

- boolean compare(BufferedImage, BufferedImage): retorna verdadeiro se a distância entre as imagens é inferior ou igual à precisão definida. Retorna falso caso contrário.

Detalhes adicionais acerca da arquitetura, parser e núcleo do framework O-FIm podem ser encontrados em Oliveira et al. (2009a). Na próxima seção é apresentado o modo como o framework O-FIm permite que oráculos de teste sejam especificados para o uso em domínios particulares.

\subsection{Oráculos Gráficos}

Existem diferentes fontes de informações para que sejam definidos oráculos de teste: modelos, especificações, estruturas de dados complexas etc. Entretanto, o presente trabalho de mestrado é baseado em uma estratégia que utiliza screenshots de sistemas em teste como fonte de informação. Em trabalhos anteriores (Delamaro et al., 2011; Oliveira et al., 2010), definiu-se uma maneira alternativa para automatizar oráculos de teste - o método Gr-O. Em linhas gerais, o termo Gr-O (oráculo gráfico) refere-se exatamente à especificação do modo como um oráculo ajustado pelo framework O-FIm deve se comportar para a realização de determinado teste. Aspectos técnicos a respeito de oráculos gráficos para o contexto do framework O-FIm são apresentados nas próximas seguintes. 


\subsubsection{Descritores de Oráculos}

Para construir um oráculo totalmente por meio de um programa, de modo pragmático, um testador precisaria executar alguns passos como: 1) criar os extratores, definir suas propriedades e instalá-los no framework O-FIm ; 2) criar uma função de similaridade e instalá-la no framework; 3) adicionar os extratores à função de similaridade; 4) criar um oráculo; 5) adicionar a função de similaridade ao oráculo; 6) estabelecer o valor da precisão a ser utilizada; 7) definir uma aplicação que execute o teste, ajustando uma imagem como modelo e diversas outras imagens a serem comparadas.

Para simplificar essa tarefa, o testador pode definir a estrutura de um oráculo por meio de um arquivo texto simples. Este arquivo deve ser reconhecido pelo parser da ferramenta O-FIm e nele podem ser estabelecidas todas as características desejadas como extratores e suas propriedades, função de similaridade e precisão. Para generalizar o modo como um oráculo gráfico é definido, estabeleceram-se regras gramaticais de formação de um descritor de oráculo no formato BNF (Backus-Naur Form), apresentadas na Figura 4.4.

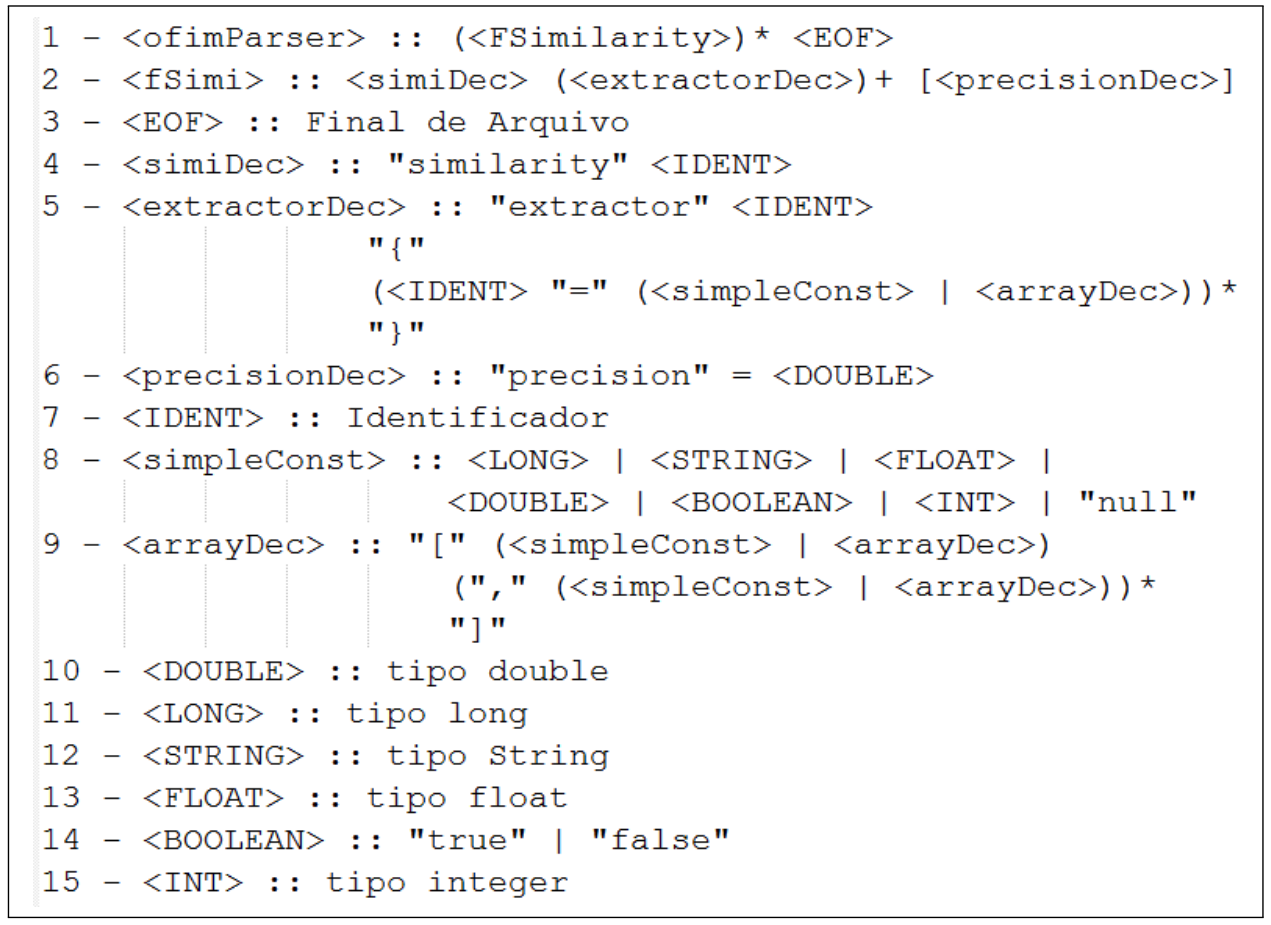

Figura 4.4: Gramática de oráculos gráficos no formato BNF

Por meio das regras gramaticais estabelecidas, um testador pode especificar e armazenar oráculos a serem úteis para domínios específicos. A Figura 4.5 mostra um exemplo de definição de oráculo. Nele, um oráculo é criado usando os extratores MyExtractor e OurExtractor. O primeiro possui uma propriedade chamada "color" que será definida com o valor (uma String) "red" e uma propriedade "alpha" cujo valor é um inteiro longo, 
78. O segundo possui uma propriedade "scale" cujo valor será inicializado com o valor double, 1.33. Ambos possuem uma propriedade chamada "rectangle" para a qual um vetor de inteiros deve ser usado.

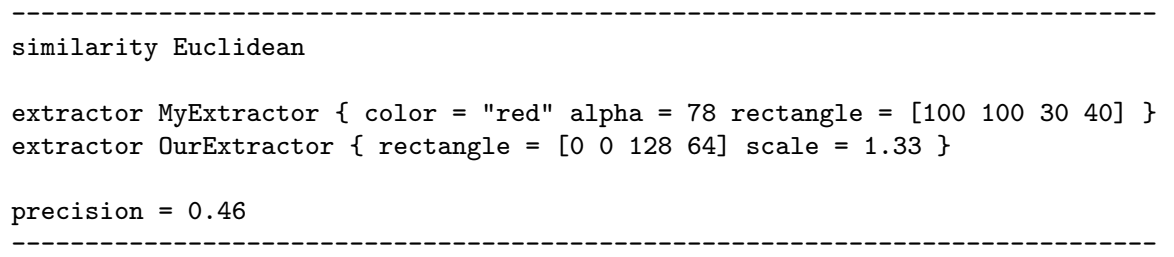

Figura 4.5: Exemplo de um oráculo gráfico para a ferramenta O-FIm

O arquivo exibido na Figura 4.5 é utilizado pelo parser da ferramenta O-FIm e indica para o framework como um oráculo gráfico deve realizar uma comparação durante a execução de determinado teste. Descritores corretos indicam diretamente ao parser quais objetos, previamente instalados, (extratores e funções de similaridades) devem ser instanciados e utilizados. Sendo assim, o testador tem a opção de chamar diretamente o método createOracle(java.io.InputStream) passando como argumento, por exemplo, um arquivo que contenha a descrição do oráculo idêntica à da Figura 4.5.

Por meio do wizard ou por linha de comando, o framework recebe uma descrição textual em forma de arquivo de parâmetro. É importante destacar que uma das funcionalidades adicionadas à ferramenta é a geração, persistência e recuperação de tais arquivos. O reconhecimento e manuseio dos arquivos descritores são funções do parser que, em termos práticos, funciona como um parametrizador. Também é função do parser, durante a análise de uma descrição, indicar ao núcleo quais objetos e parâmetros deverão ser usados pelo oráculo durante um processo de teste. Aspectos operacionais do framework por meio de um wizard são apresentados com mais detalhes no Apêndice A da presente dissertação.

\subsection{Aplicações}

\subsubsection{Apoio ao Teste de Aplicações Web}

Após o estabelecimento da estrutura de um sistema de software capaz de apoiar o teste de sistemas com saídas gráficas, foi possível realizar alguns estudos empíricos que demostrassem a aplicabilidade prática dos oráculos gráficos. Um dos estudos de caso apresentado em Delamaro et al. (2011) tem o objetivo de verificar a correção de uma aplicação Web, baseando-se em aspectos visuais. Desse modo, foram considerados aspectos como, por exemplo, o posicionamento de textos, títulos e fotos. Delamaro et al. (2011) definem que quando há um template para determinada aplicação Web, pode-se verificar a correção de 
diversas outras aplicações utilizando, como fonte de informação, aspectos visuais inerentes ao template.

Diante desse cenário, Delamaro et al. (2011) apresentam uma abordagem na qual a página principal do site brasileiro do $\mathrm{YAHOO}^{3}$ foi assumida como um template a ser seguido por outros doze sites do YAHOO de diferentes nacionalidades. Desse modo, foi configurado um descritor de oráculo que considerava o posicionamento de títulos, fotos e painéis de links do site brasileiro como modelo para os sites de outros países. Para tanto, foram implementados dois extratores de características: "contador de cores" e "razão de pixels escuros pelo número de pixels claros". De um modo pragmático, o primeiro extrator, de simples implementação, é responsável por contar o número de diferentes níveis de cinza em determinada região. O segundo extrator retorna a proporção do número de pixels escuros de uma região pelo número de pixels claros. Para esse estudo, em particular, os pixels com valor abaixo de 128 foram considerados escuros e os demais considerados como pixels claros. É importante destacar que tais extratores foram aplicados aos screenshots das aplicações Web transformadas em níveis de cinza (8 bits, níveis de 0 a 255).

Diante desse cenário, o estudo empírico explorou dois oráculos gráficos aplicados em diferentes regiões da imagem das aplicações Web. Os resultados apontaram que a produtividade e objetividade da abordagem permitiu que características visuais entre aplicações fossem comparadas por meio do O-FIm. Além disso, algumas métricas estáticas como, por exemplo, linhas de código e tamanho (número de bytecodes por instrução) dos extratores têm baixa complexidade e pouco esforço é necessário para sua implementação. Isso se dá pelo fato da literatura estar repleta de técnicas de processamento de imagem firmadas e conhecidas. Além disso, o uso do framework O-FIm e seu wizard e, consequentemente, do método Gr-O para automatização do teste promovem um modo flexível de criação de oráculos e, assim, cada alteração nas aplicações testadores e nos descritores de oráculos puderam ser realizadas de modo simples e rápido.

\subsubsection{Apoio ao Teste de Esquemas CAD}

Sistemas CAD podem ser considerados métodos computacionais a partir dos quais radiologistas conseguem uma segunda opinião para apoiar a elaboração de um diagnóstico qualquer (Giger, 2000). Outro estudo de caso fornecido em Delamaro et al. (2011) explora, exatamente, funcionalidades oferecidas por um esquema CAD para averiguar a aplicabilidade dos oráculos de teste do framework O-FIm. Tal esquema CAD contribui para o diagnóstico precoce do câncer de mama. Para tanto, um dos módulos do CAD deve fazer a segmentação de uma imagem mamográfica, pintando com pixels pretos o fundo de uma

\footnotetext{
3 acesse: http://br.yahoo.com/
} 
mamografia qualquer. Entretanto, um erro de segmentação pode prejudicar os algoritmos de análises do esquema CAD.

Nesse contexto, o estudo de caso consistiu em aplicar as técnicas de geração de oráculos de teste oferecidas pelo framework O-FIm, como forma de evidenciar possíveis erros de segmentação no sistema CAD. Um conjunto de 30 imagens mamográficas foi segmentado manualmente por dois profissionais especializados. Para esse objetivo, em particular, foi utilizado um notebook com tela sensível ao toque e um sistema desenvolvido especificamente para este estudo experimental. Tal sistema tem como funcionalidade principal a exibição de uma imagem mamográfica em uma GUI que permite que o usuário marque com uma caneta a região mamária na imagem sendo exibida. Feito isso, o programa automaticamente remove o fundo da imagem e salva a imagem segmentada em disco.

Para a configuração do oráculo gráfico, no caso deste estudo particular, foram implementados três extratores de características de imagem e uma função de similaridade. O primeiro extrator desenvolvido, denominado extrator de área, tem como funcionalidade contar o número de pixels correspondente à mama em uma imagem mamográfica. Sendo assim, como os extratores são aplicados às imagens segmentadas, ele conta o número de pixels não pretos em uma imagem mamográfica. Outro extrator implementado é responsável por calcular o perímetro de uma mama segmentada. Sendo assim, o algoritmo é capaz de identificar e somar o número de pixels localizados na região de borda entre a mama e o fundo da imagem. O último extrator implementado, chamado de extrator de assinatura, tem a função de identificar o formato do contorno de uma região mamária, identificando sua regularidade. Para isso, o algoritmo implementado no extrator é capaz de identificar o pixel central da mama na última coluna da imagem e medir a distância entre esse pixel e determinados pixels da borda da mama. Assim, o extrator consegue aferir bordas irregulares na mama. Por fim, a função de similaridade Euclidiana, conhecida na literatura por medir a distância entre dois pontos, foi implementada e instalada como plugin.

Os resultados e as conclusões obtidas a partir do experimento foram baseadas na comparação entre as 30 imagens mamográficas segmentadas manualmente e as mesmas 30 imagens segmentadas pelo sistema CAD. As imagens segmentadas manualmente foram utilizadas como imagens modelo. Resultados quantitativos apresentados em Delamaro et al. (2011) evidenciaram que o uso de oráculos gráficos pode servir como alternativa para os testes utilizando análises humanas em imagens mamográficas segmentadas. Adicionalmente, a utilização do método Gr-O serviu para identificar situações nas quais o algoritmo de segmentação do sistema CAD não segmentava a imagem mamária corretamente, prejudicando o apoio ao diagnóstico do médico. 


\subsection{Considerações Finais}

Nesse capítulo apresentaram-se os principais aspectos técnicos relacionados à estrutura do núcleo e implementação de funcionalidades adicionais para que o framework O-FIm apoiasse o teste de sistemas com GUIs. Observa-se que a complexidade da automatização de mecanismos de oráculos é diretamente proporcional à complexidade da saída do programa em teste. Dessa forma, quando a saída de processamento é complexa, em particular, no formato gráfico, sua automatização também será complexa. Em relação a esse cenário, ainda esperam-se contribuições do framework O-FIm, que teve algumas das suas funcionalidades implementadas durante a realização deste trabalho de mestrado. No Capítulo 5 são especificados os extratores de características implementados especificamente para componentes de GUIs implementadas com os recursos oferecidos pela biblioteca gráfica Swing. 



\section{Insumos para Oráculos Gráficos em}

\subsection{Considerações Iniciais}

O uso de oráculos gráficos (método Gr-O) em diferentes domínios necessita de contribuições do testador. Essas contribuições são exatamente implementações de plugins (extratores e funções de similaridade) capazes de apoiar o método Gr-O durante a realização de testes. Uma das contribuições deste trabalho de mestrado é o fornecimento de uma base de insumos e recursos para a utilização do método Gr-O no teste de sistemas computacionais com interfaces gráficas. Foi implementado um conjunto de plugins que pode ser aplicado diretamente no teste de GUIs escritas usando a biblioteca Swing ou adaptados para outras bibliotecas que implementem componentes semelhantes, uma vez que baseiam-se na análise de aspectos visuais desses componentes.

Neste capítulo são apresentadas as especificações e são descritos os principais aspectos técnicos de cada um dos plugins implementados. Adicionalmente, é apresentado um estudo que foi conduzido visando a estabelecer uma comparação entre o uso do método Gr-O e de duas técnicas de teste tradicionais para sistemas com GUIs. É importante salientar que todos os plugins apresentados são disponibilizados como software livre e podem ser baixados e alterados para serem explorados em domínios particulares ${ }^{1}$.

\footnotetext{
${ }^{1}$ o link de acesso para os extratores é: http://www.icmc.usp.br/ rpaes/Gr-0SwingPlugins.rar
} 


\subsection{Extratores de Características}

Esta seção visa a apresentar uma das contribuições fornecidas por este trabalho de mestrado: tratam-se de extratores de características de imagens implementados e testados em domínios de GUIs implementadas com a biblioteca gráfica Swing. Com o intuito de viabilizar a utilização da técnica proposta, aumentando o valor do método Gr-O para o contexto de sistemas com GUIs, são apresentadas as características essenciais para instalação e utilização de cada extrator durante a automatização de oráculos de testes. Para cada um dos extratores desenvolvidos, apresentam-se nome (utilizado para a definição de descritores de oráculos e para instalações do plugin), classe principal (corresponde à classe Java que implementa a interface de instalação), parâmetros (utilizados para indicar especificidades em cada extrator) e, por fim, uma especificação que serve como apoio aos testadores e pesquisadores que queiram utilizar a técnica em seus projetos. Os extratores desenvolvidos foram:

\section{- Extrator de Cores:}

- especificação: é capaz de calcular a soma da média ponderada de cada pixel de uma imagem RGB (com pesos 1 para a banda Red, 2 para a banda Green e 3 para a banda Blue). Após isso, é feita uma normalização dessa soma pelo máximo valor que pode ter um pixel da região ajustada no parâmetro rectangle. Na Listagem 5.1 é apresentado o método principal do extrator de cores. Para o bom funcionamento do extrator, é importante destacar que ele pode ser utilizado em qualquer componente Swing que tenha uma cor bem definida

- nome: "colorExtract"

- classe principal: br.extractor.swing. ColorExtract

- parâmetros: int [4] rectangle: serve para ajustar a região na qual o extrator deverá ser aplicado na imagem. As duas primeiras posições do vetor representam o pixel inicial e as duas últimas posições do vetor representam largura e altura, respectivamente. Na Listagem 5.2 é apresentado o método que ajusta os parâmetros para o extrator de cores

Listagem 5.1: Método principal do extrator de cores

\footnotetext{
public double computeValue(Image image) \{

BufferedImage bufferImage $=$ (BufferedImage) image;

PlanarImage pI = PlanarImage $\cdot$ wrapRenderedImage (bufferImage );

int pow $=($ bufferImage $\cdot$ getColorModel ()$\cdot g$ etPixelSize () $/$ pI $\cdot \operatorname{getNumBands}())$;

//captura o numero de bits da imagem, na maioria dos casos 8 bits por pixel
} 




Listagem 5.2: Método que ajusta propriedades do extrator de cores para componentes Swing

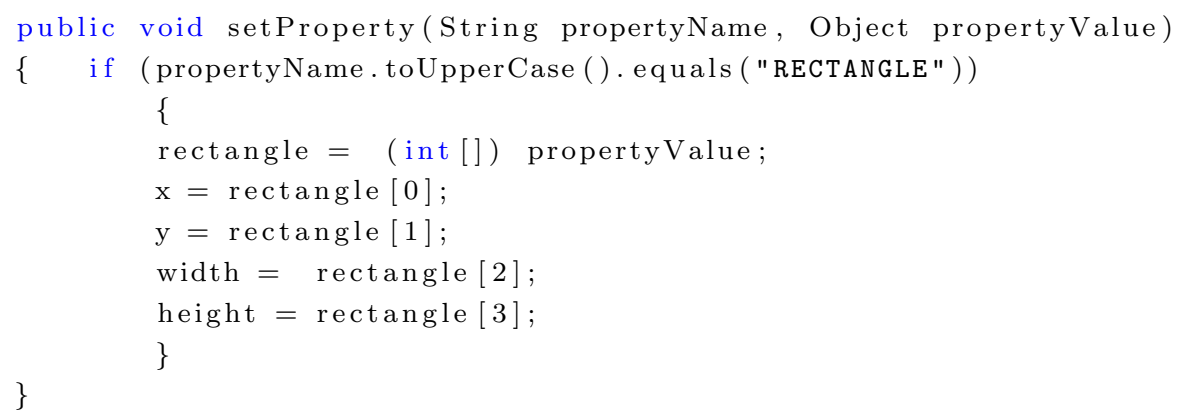

\section{- Extrator para CheckBox:}

- especificação: o extrator tem a funcionalidade de definir se um componente do tipo checkBox do Swing está marcado ou não. O extrator faz como pré-processamento a binarização dos pixels da região ajustada. Após isso, é verificada a média de pixels pretos da área. No caso dessa média representar maior do que $20 \%$ do total dos pixels da área, o extrator considera a área como sendo um checkBox Swing selecionado e retorna o valor 1.0. Caso contrário, o extrator considera a área como não marcada, retornando o valor 0.0. É importante destacar que a lógica do extrator foi testada, tendo resultados válidos em diversos L\&Fs

- nome: "checkBoxExtractor"

- classe principal: br.extractor.swing. CBExtract

- parâmetros: int [4] rectangle 


\section{- Extrator para RadioButtons:}

- especificação: é similar ao extrator para checkBox, com a diferença de ter sido implementado para o componente Swing radioButton. Devido a algumas diferenças visuais entre os componentes, alterações de código foram necessárias. Por isso, após um pré-processamento para binarizar a região considerada, o extrator define um radioButton como selecionado em casos nos quais a média do número de pixels pretos da área ajustada for maior que $50 \%$ do total. Consequentemente, em outros casos, o extrator considera o radioButton como não selecionado

- nome: "radioButton"

- classe principal: br.extractor.swing.RBExtract

- parâmetros: int [4] rectangle

\section{- Extrator para Label:}

- especificação: o extrator definido para o componente Swing do tipo label visa a quantificar aspectos visuais do componente, a partir de uma imagem em níveis de cinza. O extrator computa a média dos valores dos pixels de determinada região pré-ajustada. Tal média é normalizada pelo valor máximo de um pixel -255

- nome: "label"

- classe principal: br.extractor.swing. JLextract

- parâmetros: int [4] rectangle; int $\mathrm{x}$; int $\mathrm{y}$; int width; e int height

\section{- Extrator para TextArea:}

- especificação: o extrator desenvolvido para o componente Swing textArea tem como pré-processamento um recurso que binariza a região especificada pelo parâmetro rectangle. Após isso, são somados os pixels pretos da região e, assim, o retorno do extrator é a soma desses pixels pretos normalizados pela área da região na qual ele foi aplicado. A estratégia se mostra eficiente para quantificar componentes textArea em diferentes L\&Fs

- nome: "textArea"

- classe principal: br.extractor.swing. JLextract

- parâmetros: int [4] rectangle; int $\mathrm{x}$; int $\mathrm{y}$; int width; e int height

\section{- Extrator para ProgressBar:}


- especificação: esse extrator considera o valor ajustado para o parâmetro $p i$ xelColor e utiliza uma heurística que conta os pixels de cores similares e os considera como sendo parte de um componente do tipo ProgressBar que esteja preenchido. Para considerar pixels como sendo de cores similares, o extrator leva em conta todas as bandas da imagem. Por fim, o retorno do extrator é normalizado pela área da região ajustada em rectangle.

- nome: "progressBar"

- classe principal: br.extractor.swing.ProgressBarExtractor

- parâmetros: int [4] rectangle; int $\mathrm{x}$; int $\mathrm{y}$; int width;int height e double[] pixelColor: parâmetro que pode ser utilizado para representar a cor dos pixels a serem considerados como sendo pertencentes à área preenchida em um componente ProgressBar

\section{- Extrator para ComboBox:}

- especificação: esse extrator de características utiliza um filtro de imagens do tipo Sobel horizontal para quantificar as arestas verticais em uma região que represente um componente Swing do tipo ComboBox. Algoritmos para filtros do tipo Sobel são bem representados e firmados pela literatura. Desse modo, o retorno do extrator é o número de arestas verticais identificadas normalizado pela altura da região ajustada em rectangle

- nome: "cBox"

- classe principal: br.extractor.swing.cBoxExtractor

- parâmetros: int [4] rectangle; int $\mathrm{x}$; int $\mathrm{y}$; int width; e int height

\section{- Extrator Sobel Vertical:}

- especificação: para a especificação deste extrator de características foram utilizados os recursos da API JAI (Java Advanced Image). Essa API de processamento de imagem oferece operadores capazes de detectar diversas informações visuais de imagens sendo processadas. Um dos recursos da JAI, por exemplo, é a disponibilização de filtros pré-definidos. Esse extrator utiliza os operadores JAI que configuram um filtro Sobel vertical para identificar arestas verticais em um screenshot. Portanto, o extrator conta o número de pixels pertencentes a arestas verticais de uma região e retorna essa soma normalizada pela área da região definida pelo parâmetro rectangle. O extrator "sobelVfilter" pode ser útil, por exemplo, para identificar arestas um conjunto de botões

- nome: "sobelVfilter" 
- classe principal: br.extractor.swing. SobelVextractor

- parâmetros: int [4] rectangle; int $\mathrm{x}$; int $\mathrm{y}$; int width; e int height

\section{- Extrator Sobel Horizontal:}

- especificação: os conceitos relacionados a este extrator são iguais aos apresentados para o extrator Sobel Vertical. A única diferença que merece ser citada é que o extrator quantifica, utilizando recursos da JAI, as arestas horizontais de determinada região especificada pelos parâmetros do usuário. Pode ser útil para o mesmo contexto descrito no extrator Sobel vertical

- nome: "sobelHfilter"

- classe principal: br.extractor.swing. SobelHextractor

- parâmetros: int [4] rectangle; int $\mathrm{x}$; int $\mathrm{y}$; int width; e int height

\section{- Extrator de Componentes Conexos:}

- especificação: no trabalho apresentado por Gonzalez e Woods (2006), são demonstradas algumas aplicações que utilizam a contagem de componentes visuais conexos em uma determinada imagem. Muito pelo fato deste trabalho ter interesse em componentes apresentados em uma GUI, implementou-se esse extrator de características. Em termos gerais, o algoritmo seguido para a implementação é o mesmo apresentado por Gonzalez e Woods (2006) e utiliza a rotulação de pixels com o intuito de definir o número de componentes conexos (ligados) em uma GUI implementada com recursos da biblioteca Swing. Por fim, o retorno do extrator é o número de componentes conexos identificados normalizado pelo perímetro do região considerada. O extrator é útil para analisar GUIs, completas ou apenas em regiões particulares, de forma que informações sobre o número de componentes presentes sejam oferecidas

- nome: "connectedComp"

- classe principal: br.extractor.swing. CComponents

- parâmetros: int [4] rectangle; int $\mathrm{x}$; int $\mathrm{y}$; int width; e int height

\subsection{Funções de Similaridade}

Diversas funções de similaridade são apresentadas na literatura. Em geral, essas funções são utilizadas em diversas áreas e em diferentes contextos como, por exemplo, processamento de áudio ou processamento de imagens. Dependendo do contexto, uma função 
de similaridade pode ser mais eficiente do que outra. Diversos estudos tentam comparar e explorar, exatamente, características, vantagens e desvantagens do uso de funções de similaridade. Em Gonçalves et al. (2011) diversas funções de similaridade são descritas e avaliadas no contexto do método Gr-O.

Para o caso deste trabalho, em particular, foram implementadas duas funções de similaridade descritas a seguir:

\section{- Função Euclidiana:}

- especificação: corresponde à função que mede a distância entre dois vetores de tamanho $n$. De fácil implementação e muito eficiente para estudos empíricos como os apresentados nesta dissertação, essa função permite quantificar numericamente quão distante estão dois conjuntos de valores. O retorno 0.0 representa a similaridade máxima. É a função de distância mais encontrada na literatura e em estudos relacionados a CBIR por ter simples implementação. Na Equação 5.1 é apresentada a fórmula genérica definida pela função de similaridade Euclidiana, considerando dois vetores de características $x$ e $y$, de tamanho $n$, em que os elementos são denominados $x_{i}$ e $y_{i}$, respectivamente. Na Listagem 5.3 é apresentado, em código Java, uma possível implementação da função de similaridade euclidiana :

- nome: "euclidean"

- classe principal: br.similarity.swing.Euclidean;

$$
E D(x, y)=\sqrt{\left(x_{1}-y_{1}\right)^{2}+\left(x_{2}-y_{2}\right)^{2}+\ldots+\left(x_{n}-y_{n}\right)^{2}}
$$

Listagem 5.3: Método Java que implementa a função Euclidiana

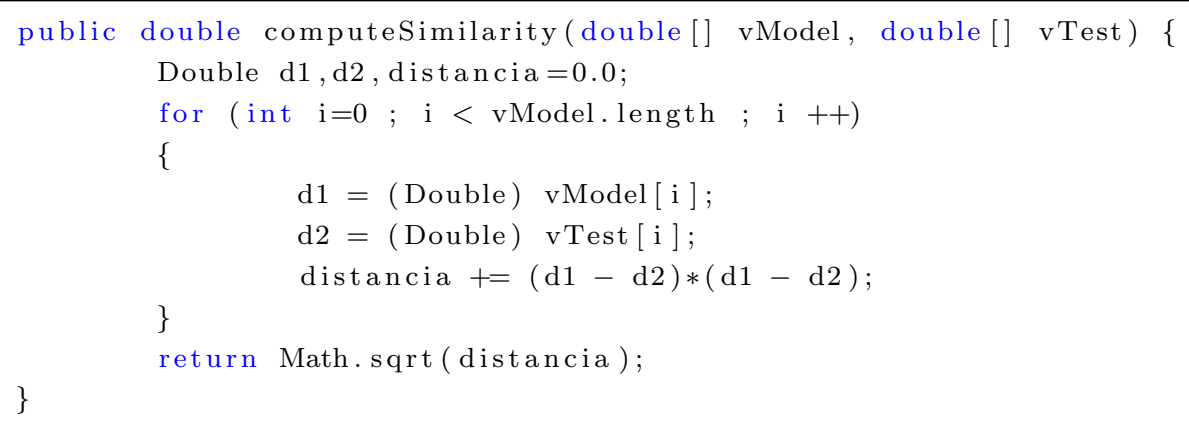

\section{- Função Identical:}

- especificação: é uma função de similaridade definida para casos nos quais é necessário verificar características idênticas em imagens. Ela é utilizada para 
definir casos nos quais são utilizados extratores determinísticos. A função implementada compara elemento por elemento dos vetores de características e retorna 0.0 para os casos em que todos eles sejam iguais e 1.0 caso contrário

- nome: "identical"

- classe principal: br.identical.Identical;

\subsection{Oráculos para sistemas com GUls: Método Gr-O ver- sus Métodos Tradicionais}

Conforme foi observado nos resultados da RS apresentada nesta dissertação (Seção 3.2.3), os principais métodos e técnicas de apoio a sistemas com GUIs encontrados na literatura exploram estruturas internas e transições entre estados de GUIs para a definição de oráculos de teste. Tais técnicas têm como limitação o fato de não serem capazes de verificar falhas visuais e aparentes ao usuário finais por meio da GUI da aplicação. Por isso, em geral, organizações utilizam oráculos humanos para a verificação desses possíveis problemas.

Uma GUI é composta de diversos componentes cujo comportamento, conhecido pelos usuários, indica a correção, ou não, da execução do programa. Por exemplo, uma área preenchida numa barra de progresso (ProgressBar) ou uma caixa de seleção (CheckBox) marcado determinam se o resultado esperado foi ou não alcançado. Por outro lado, existem diversos fatores que podem fazer com que a representação gráfica de duas execuções com o mesmo resultado não seja exatamente a mesma. Por exemplo, quando as duas execuções - a que produz a imagem de referência e a que se deseja analisar - são utilizadas em ambientes diferentes, com L\&Fs diversos.

Situações como essa são cada vez mais comuns, dada a portabilidade alcançada por meio de algumas linguagens de programação ou se considerarmos aplicações WEB cuja aparência para o usuário final depende, também, do cliente (navegador ou WEB browser) utilizado (Delamaro et al., 2011). A Figura 5.1 mostra o resultado de duas execuções que apresentam o mesmo comportamento e, portanto, deveriam ser consideradas "iguais" do ponto de vista de um oráculo de teste. No detalhe, pode-se notar que a comparação pixel-a-pixel para os componentes checkbox no lado esquerdo da figura produziria o resultado incorreto sob essa perspectiva.

Nos dois casos citados (GUIs e aplicações Web), o problema que se tem é o de utilizar uma imagem de referência que pode não corresponder exatamente ao resultado esperado e pode haver mais de um resultado aceitável. Ou, ainda, de se ter apenas uma aproximação do resultado (imagem) esperado. A utilização dos conceitos de CBIR, por meio 


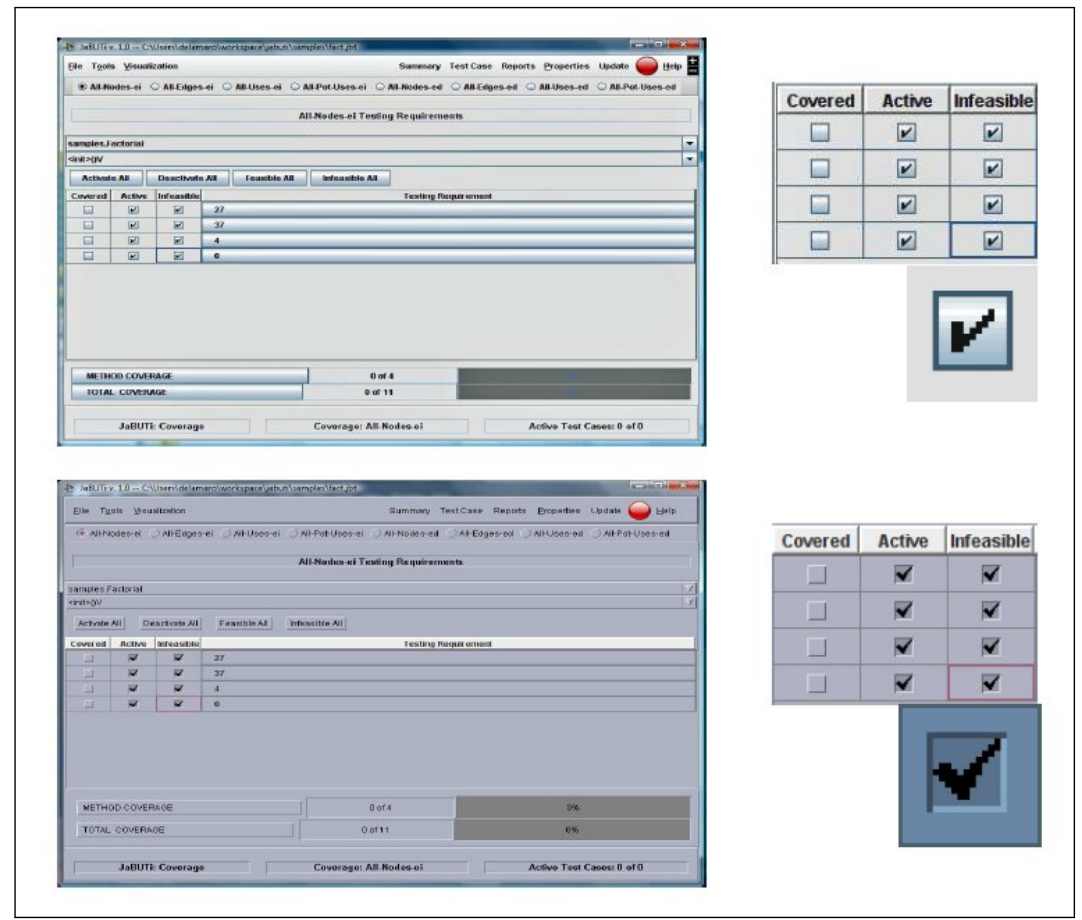

Figura 5.1: GUIs com diferentes look and feel (adaptado de Delamaro et al. (2011))

do método Gr-O, contrasta com as técnicas de teste tradicionais para sistemas com GUIs e pode ajudar nesse contexto à medida que permite que sejam extraídas das imagens as características relevantes para a comparação. Por exemplo, a área e o perímetro de uma região de interesse em uma GUI podem ser comparadas com as mesmas características de um screenshot de referência. Embora o resultado da comparação não seja, em geral, exatamente igual, resultados similares devem indicar se a aplicação em teste tem o comportamento esperado.

\subsubsection{Estudo Empírico Comparativo}

Para aumentar a qualidade de avaliações empíricas, quando se trata de um novo processo de Engenharia de Software, é necessária a realização de estudos empíricos comparativos entre novos métodos e os métodos tradicionais. Tais comparativos visam à criação de argumentos válidos acerca do que está sendo proposto e avaliado diante dos processos ou métodos tradicionais. Para tanto, a execução de projetos paralelamente, utilizando técnicas diferentes, é uma prática comum que configura um meio para que estudos comparativos sejam definidos de modo mais seguro. Neste trabalho é apresentado um estudo empírico comparativo entre métodos que envolvam oráculos para sistemas com GUIs.

Visando ao estabelecimento de dados quantitativos e qualitativos acerca da utilização do método Gr-O e definindo padrões comparativos, este estudo descreve as experiências e resultados obtidos por meio do desenvolvimento de um teste para um sistema com GUI, 
utilizando três diferentes métodos: exploração dos recursos da ferramenta de apoio ao teste de sistemas com GUIs FEST Swing (1), utilização da ferramenta de captura/reprodução Window Tester Pro (2) e a utilização dos oráculos gráficos por meio do métodos Gr-O (3). A escolha da FEST Swing e da Window Tester se justifica pela fato de elas utilizarem estruturas internas da GUIs e técnicas de captura e reprodução, respectivamente, para testar aplicações com GUIs. Essas duas técnicas são as mais encontradas na literatura e, por isso, mereceram ser investigadas nesse estudo.

A aplicação escolhida para ter sua GUI e suas funcionalidades exploradas no estudo foi uma calculadora. Na Figura 5.2 são ilustradas diversas GUIs da calculadora a ser estudada. A calculadora contém um botão (widget) para representar cada um do algarismos (dígitos) a serem aproveitados. Além disso, a interface tem um botão para cada um dos operadores aritméticos e uma área de texto para exibir os resultados das operações. Adicionalmente, a referida interface conta com uma Barra de Títulos, uma Barra de Menus com alguns menus (File, Help), um campo texto e diversos botões.

Como estratégia para o estudo utilizou-se um teste simples na aplicação, entretanto, suficiente para que diversos aspectos comparativos fossem levantados. O teste a ser automatizado pelas três técnicas foi o seguinte: partindo do estado inicial da aplicação (display exibindo o número 0 - Figura 5.2a) é simulado que um usuário dispare um evento no botão que representa o dígito " 9 " (Figura 5.2b), seguido de um evento no botão "sqrt" que representa a raiz quadrada (Figura 5.2c) e, por fim, um evento deve acionar o botão "C" que é responsável por colocar a calculadora em seu estado inicial novamente com o display exibindo o número 0 (Figura 5.2d). Para os casos em que, após o disparo de todos os eventos, o display mostrar qualquer valor diferente de 0 , o teste deve ser reprovado.

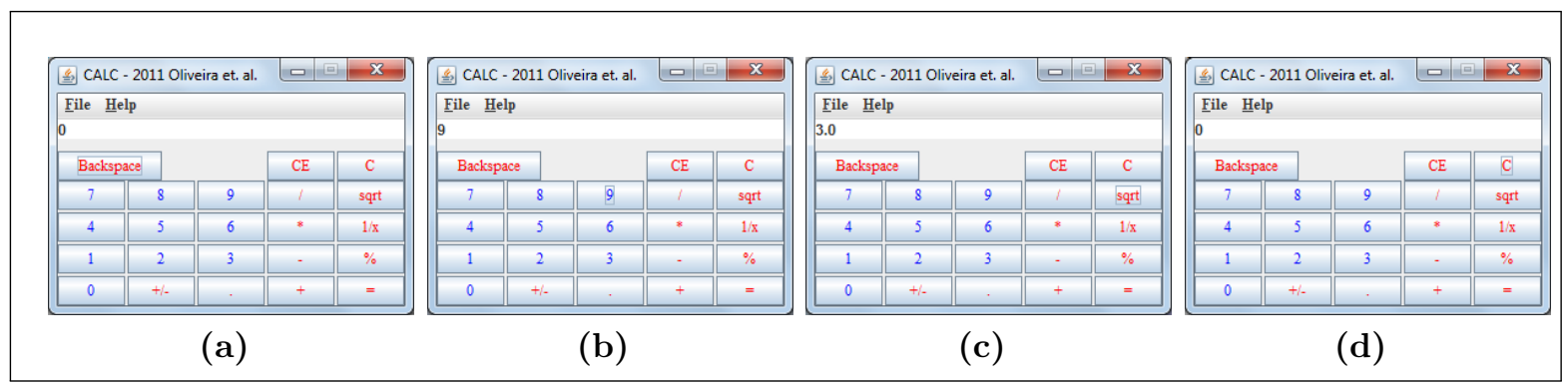

Figura 5.2: Calculadora Swing utilizada para o estudo empírico - a)estado inicial da calculadora; b)após um evento no botão "9"; c)após um evento no botão "sqrt"; d)após um evento no botão "C"

\subsubsection{Condução Paralela dos Projetos}

Para a realização do estudo, os três projetos foram conduzidos paralelamente. Para o caso da automatização do teste projeto utilizando a ferramenta FEST Swing foi neces- 
sário alterar o código da aplicação e nomear todos os componentes por meio do método setName(String name) como, por exemplo, jbnButtons [17].setName("sqrt"). Em seguida, após a familiarização com a API da ferramenta, o teste pôde ser automatizado sem maiores dificuldades. Na Listagem 5.4 é apresentado o código principal escrito, especificamente, para a realização do estudo.

Listagem 5.4: Automatização do teste com a ferramenta FEST Swing

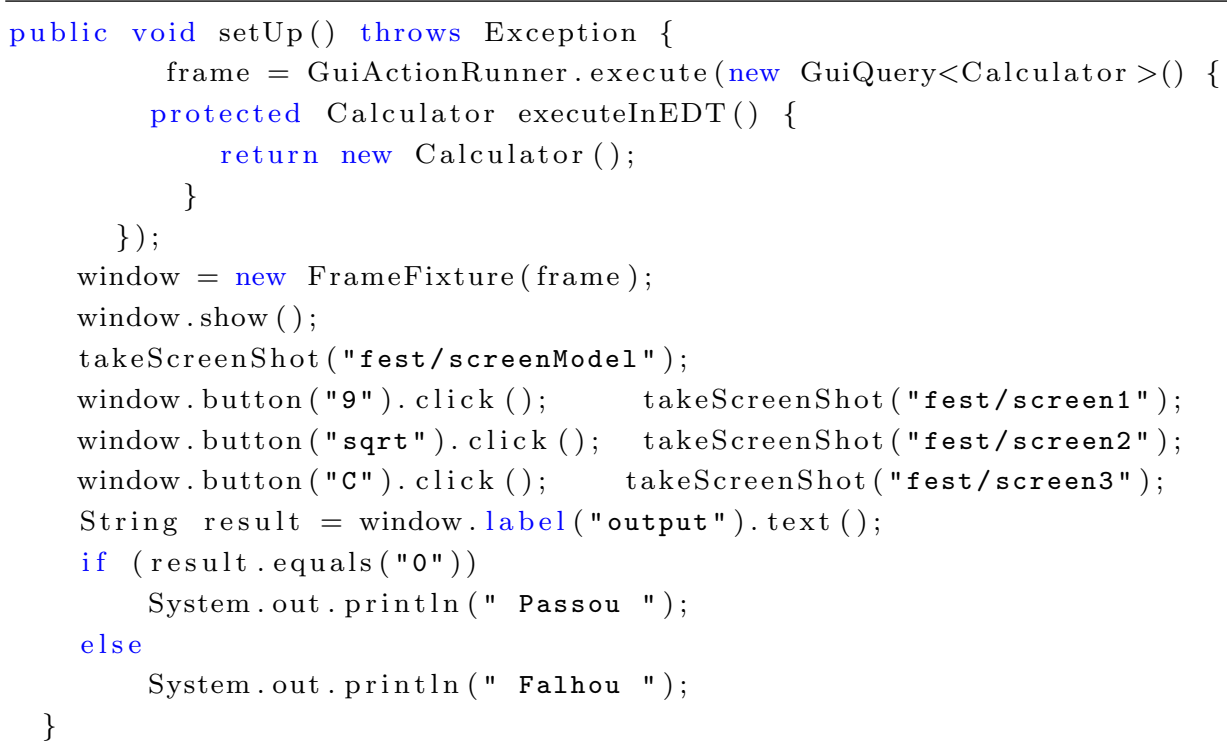

No caso da automatização do teste utilizando a biblioteca WindowTester Pro, foi utilizado o plugin nativo que a ferramenta oferece para a IDE Eclipse. Assim, foi necessário ajustar a funcionalidade de captura da ferramenta, operar a GUI da aplicação de acordo com o teste desejado e, por fim, ajustar o código gerado para fazer a verificação da última tela da aplicação após a execução. Após isso, a reprodução do teste pôde ser executada. É importante salientar que o código gerado pela ferramenta WindowTester, após a captura, oferece a reprodução dos testes compatíveis com formato JUnit, o que facilita sua visualização. Para o caso deste estudo, em particular, após os passos descritos anteriormente, a ferramenta gerou uma classe para reprodução bem simples e intuitiva, na Listagem 5.5 é apresentado o principal método da classe de reprodução gerada.

Listagem 5.5: Código de automatização do teste gerado com a ferramenta Window Tester

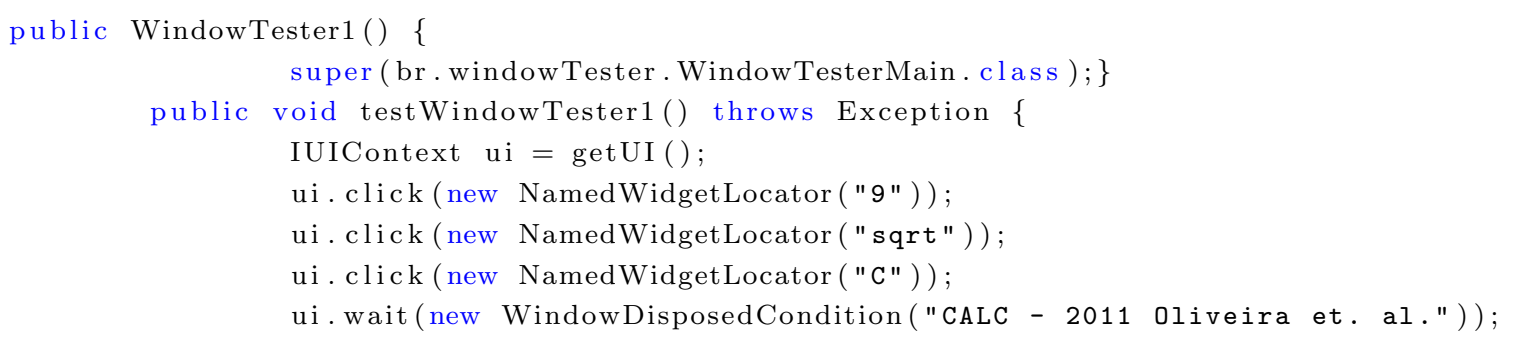


Por fim, a automatização do teste proposto utilizando os oráculos gráficos do método Gr-O foi feita utilizando apenas um extrator de característica específico para componentes do tipo TextArea, a ser aplicado na região correspondente ao display da GUI, e a função de similaridade Identical, especificada na Seção 5.3. Tal extrator tem implementação simples e consiste apenas da contagem dos pixels pretos de uma determinada região de um screenshot binarizado. Para a normalização do retorno, é utilizado o valor da área ajustada em rectangle. É importante destacar que, para o contexto do comparativo realizado, considerou-se que os plugins já estavam implementados, sendo apenas utilizados pelo testador para a configuração de seus testes. Sendo assim, um oráculo gráfico foi ajustado por meio do framework O-FIm e o teste pode ser realizado. Na Listagem 5.6 é apresentado o código principal para a execução do teste proposto com o método Gr-O.

Listagem 5.6: Automatização do teste com o método Gr-O

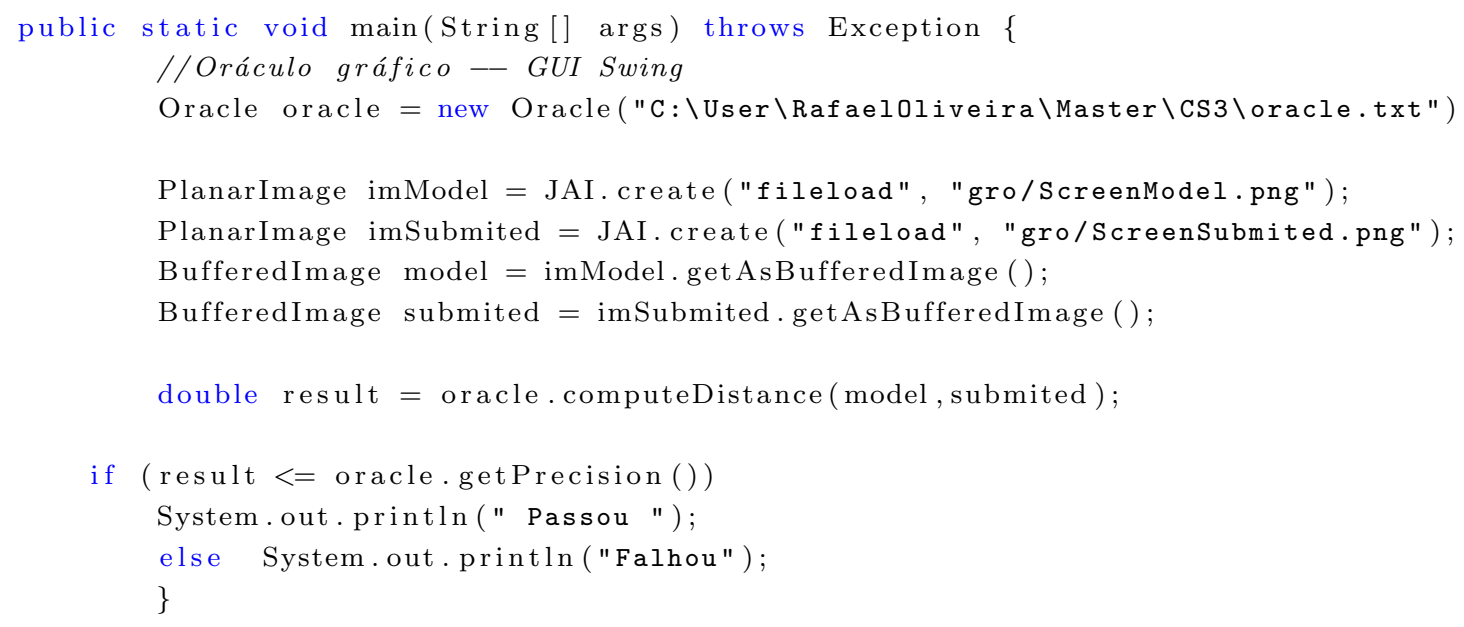

\subsubsection{Comparativo}

É importante salientar que, para as comparações apresentadas nesta seção, foram desconsiderados fatores particulares e pré-requisitos necessários para cada uma das abordagens. Por exemplo, necessidade da IDE Eclipse para o método Window Tester, necessidade de conhecimento das especificações API Fest e de métodos estáticos para o caso da Fest Swing e, por fim, necessidade da disponibilidade de um método de captura de screenshot para o Gr-O. Considera-se que, por se tratarem de métodos distintos, não é interessante estabelecer parâmetros comparativos para pré-requisitos inerentes a cada método.

Algumas medidas foram assumidas como forma de levantar dados que exponham e representem quantitativamente a experiência em utilizar o método Gr-O. Entre elas destacam-se medidas objetivas, diretas, indiretas e subjetivas. Como exemplo de medidas 
objetivas, consideraram-se os números de linhas de código das aplicações (LOC - do inglês Lines Of Code), tempo de execução dos testes e a complexidade ciclomática (CC) de classes principais de cada método. Para o contexto desta seção, em particular, denominam-se classes principais aquelas responsáveis por ajustar, executar e reexecutar os testes. Em termos gerais, CC mede a quantidade de caminhos de execução de um sistema independente a partir de seu código. Por fim, aspectos subjetivos sobre a experiência em utilizar a técnica Gr-O também foram definidos. Na Tabela 5.1 são apresentadas as métricas para cada uma das técnicas estudadas.

Tabela 5.1: Tabela de comparativo de métricas entre as técnicas

\begin{tabular}{|c|c|c|c|}
\hline \multicolumn{4}{|c|}{ Comparativo de Métricas } \\
\hline técnica & $\mathrm{LOC}$ & Tempo $10_{\text {seg. }}^{-3}$ & $\mathrm{CC}$ \\
\hline FEST Swing & 47 & 2164 & 3 \\
\hline Window Tester Pro & 15 & 1805 & 1 \\
\hline Gr-O & 28 & 1206 & 2 \\
\hline \multicolumn{4}{|c|}{$\begin{array}{l}\text { LOC, total de linhas de código executáveis } \\
\text { Tempo, total de tempo de execução em milissegundos } \\
\text { CC, complexidade ciclomática da classe principal }\end{array}$} \\
\hline
\end{tabular}

É importante destacar que, além de métricas apresentadas na Listagem 5.1, para que o método Gr-O caso seja mais bem avaliado, são necessárias informações qualitativas a respeito da utilização e eficiência de cada técnica em projetos reais. Com o intuito de contribuir com dados desse tipo, algumas características particulares de cada uma das técnicas foram observadas e definidas durante a condução deste estudo empírico.

Como pode ser observado na Tabela 5.1, a técnica que utiliza a ferramenta de captura e reprodução configurou as classes de teste com o menor número de linhas de código e menor complexidade ciclomática. Apesar da diferença de complexidade não ter sido muito significativa, tal técnica pode ser considerada a que menos exige esforços do testador. Isso pode ser justificado pelo fato de que a classe considerada no comparativo é gerada, automaticamente, durante uma operação de captura e pode se executada pelo framework JUnit. Na Tabela 5.2 são resumidos aspectos qualitativos definidos a partir da experiência do uso da ferramenta neste estudo. Vantagens e desvantagens do uso de captura e reprodução são apresentadas.

O processo de teste utilizando os oráculos gráficos avaliados no presente trabalho, conforme pode ser observado na Tabela 5.1, disponibilizou o resultado dos testes em menor tempo que as outras duas técnicas. O oráculo de teste pode ser definido de modo simples e intuitivo. Nas Tabelas 5.2 e 5.3 são apresentadas as principais vantagens e desvantagens observadas durante a condução do estudo.

Por fim, a técnica que utiliza estruturas internas da GUIs, implementada neste estudo por meio da ferramenta FEST Swing, pode ser considerada a mais custosa diante das métricas observadas. Conforme aponta a Tabela tab:comparaTecnicas, em linhas gerais, 
Tabela 5.2: Aspectos negativos e positivos acerca do uso do uma técnica de captura e reprodução

\begin{tabular}{|c|c|}
\hline Vantagens & Desvantagens \\
\hline $\begin{array}{l}\text { *a reprodução das classes por meio do J- } \\
\text { Unit permite uma melhor visualização dos } \\
\text { resultados na prática } \\
\text { *pode facilitar muito a definição e re- } \\
\text { execução de classes de teste para GUIs } \\
\text { complexas } \\
\text { *facilita a manutenção em classes de tes- } \\
\text { te após alterações na GUI }\end{array}$ & $\begin{array}{l}\text { *para testes de mais qualidade é neces- } \\
\text { sária destreza para operar a ferramenta } \\
\text { de captura e reprodução } \\
\text { *sua utilização sem uma IDE é complexa } \\
\text { e toma valioso tempo com ajustes e ins- } \\
\text { talações de bibliotecas } \\
\text { *depende do JUnit para a reprodução das } \\
\text { classes geradas durante a captura } \\
\text { *exige que o testador tenha conhecimen- } \\
\text { tos de testes utilizando o JUnit } \\
\text { *não oferece funcionalidade para a cap- } \\
\text { tura de screenshots }\end{array}$ \\
\hline
\end{tabular}

Tabela 5.3: Aspectos negativos e positivos acerca do uso do método Gr-O

\begin{tabular}{|c|c|}
\hline \multicolumn{2}{|c|}{ Método Gr-O } \\
\hline Vantagens & Desvantagens \\
\hline $\begin{array}{l}\text { *dentre as técnicas estudadas foi a que } \\
\text { apresentou a maior flexibilidade e pos- } \\
\text { sibilita replicação em outros domínios } \\
\text { *é independente da linguagem de progra- } \\
\text { mação da aplicação em teste } \\
\text { *após a definição do oráculo gráfico, a } \\
\text { execução dos teste é trivial }\end{array}$ & $\begin{array}{l}\text { *depende, obrigatoriamente, do screen- } \\
\text { shots como fonte de informação do tes- } \\
\text { te } \\
\text { *exige conhecimentos básicos de técni- } \\
\text { cas de processamento de imagens } \\
\text { *extratores e funções de similaridades } \\
\text { podem conter erros ou viéses } \\
\text { *a captura automatizada de screenshots } \\
\text { deve ser implementada ou viabilizada } \\
\text { por meio de outra ferramenta } \\
\text { *necessita do ajuste de oráculos grá- } \\
\text { ficos para a definição dos testes }\end{array}$ \\
\hline
\end{tabular}

o uso dessa técnica exige muito conhecimento de detalhes delicados de código como, por exemplo, a identificação do local ideal para nomear os componentes a serem utilizados no teste. Por isso, a impressão deixada pela experiência descrita neste estudo é que a técnica pode ser valiosa e poderosa quando aplicada em organizações nas quais a comunicação entre equipes de desenvolvimento e teste acontecerem de modo eficiente. Na Tabela 5.4, os aspectos qualitativos observados são especificados.

É preciso destacar que, entre as avaliações apresentadas nesta seção, não foram definidos dados comparativos como, por exemplo, tempo e esforços necessários para a implementação dos testes, ou, então, facilidade de uso de cada uma das técnicas. Omitiram-se dados desse tipo por conta de que sua apresentação poderia caracterizar a presença de fatores de confusão para o estudo empírico. Um fator de confusão para um estudo de caso, por exemplo, pode ser definido como sendo um aspecto que inviabilize a distinção entre fatores do estudo. Pelo fato de que a equipe que conduziu o estudo de caso era, 
Tabela 5.4: Aspectos negativos e positivos acerca de uma técnica que explore estruturas

\begin{tabular}{|c|c|}
\hline \multicolumn{2}{|c|}{ FEST Swing } \\
\hline ens & Desvantagens \\
\hline $\begin{array}{l}\text { *depois de instalado e, após a leitura do } \\
\text { manual, é bem simples e intuitivo para } \\
\text { executar; } \\
\text { *oferece método nativo para captura de } \\
\text { screenshots de erros; } \\
\text { *reexecuções permitem a visualização da } \\
\text { GUI sendo operada por um robô }\end{array}$ & $\begin{array}{l}\text { *a necessidade em nomear todos os compo- } \\
\text { nentes da intercafe gráfica inviabiliza } \\
\text { seu uso em GUIs complexas; } \\
\text { *são necessárias diversas chamadas a méto- } \\
\text { dos e ajustes específicos para a reexecu- } \\
\text { ção dos testes; } \\
\text { *a necessidade de diversos ajustes torna a } \\
\text { leitura da especificação da biblioteca in- } \\
\text { dispensável; e } \\
\text { *a manutenção em clases de teste pode ser } \\
\text { complexa em projetos grandes. }\end{array}$ \\
\hline
\end{tabular}

exatamente, a mesma que propôs o método Gr-O, muitos dados subjetivos poderiam ser um fator de confusão.

\subsection{Considerações Finais}

Neste capítulo foram apresentados insumos que contribuem com a utilização do método Gr-O para a definição de oráculos para sistemas com GUIs. Adicionalmente, um estudo comparativo entre o uso do método Gr-O e as técnicas tradicionais de teste para sistemas com GUIs foi descrito. Tal estudo comparativo serve como forma de apoio ao Capítulo 6, no qual a condução de um estudo empírico mais complexo é descrita. Por meio do estudo de caso a serem apresentados, algumas características do uso de Gr-O para o contexto sistemas com GUIs puderam ser observadas e discutidas no capítulo conclusivo deste trabalho (Capítulo 7). 



\section{Gr-O e Sistemas com GUls: Estudos de \\ Caso}

\subsection{Considerações Iniciais}

Foi conduzido um estudo empírico que visa a apoiar o estabelecimento de processos de teste alternativos (método Gr-O) para sistemas com GUIs. O uso de técnicas de processamento de imagem como estratégia de automatização de oráculos de teste para sistemas com GUIs não foi encontrado na literatura pesquisada. Por isso, espera-se que o estudo apresentado pelo presente capítulo, além de apoiar o desenvolvimento de sistemas de software de qualidade, configure parte da validação de um método de teste incremental, flexível e de baixocusto.

As implementações do framework O-FIm, descrito no Capítulo 4, e dos plugins descritos no Capítulo 5, possibilitaram que um método diferente das técnicas de teste tradicionais para sistemas com GUIs pudesse ser utilizado e, assim, avaliado empiricamente. Para a proposição de alterações e alternativas em processos de Engenharia de Software, é indispensável a realização de estudos empíricos que visem a sua validação. Apesar do fato de não serem muito explorados na literatura, estudos empíricos são valiosas ferramentas para pesquisadores e profissionais da indústria tomarem decisões importantes de projetos. Muitas vezes, escolhas de tecnologias, ferramentas e processos são fatores críticos para que 
a solução de um problema possa ser implementada por meio de um sistema computacional (Wohlin et al., 2000).

\subsection{Materiais e Métodos}

O estudo de caso descrito no presente capítulo foi elaborado com o objetivo de criar um meio para estabelecer controles, definições de predições, identificações de limitações e vantagens oferecidas pelo método Gr-O. Diferentemente de surveys e experimentações, um estudo de caso é conduzido para identificar a validade de uma entidade ou fenômeno em um espaço de tempo específico (Wohlin et al., 2000).

Outro objetivo do estudo é o estabelecimento e execução de um processo de avaliação empírica mais rigoroso. É interessante destacar que trabalhos dessa modalidade são valiosos pelo fato de que a indústria de software tem grande volatilidade e muda rapidamente. Sendo assim, muitas empresas não têm tempo de investir em técnicas e processos de Engenharia de Software que não tenham sido experimentados e validados de modo adequado, com critério e rigor. Por meio de estudos empíricos pode-se obter informações relevantes para evidenciar consequências e benefícios do uso de novos métodos.

\subsubsection{Estratégia de Estudo Empírico}

Os efeitos da aplicação de um novo método não podem ser aferidos imediatamente (Wohlin et al., 2000). Para obter informações a respeito dos efeitos positivos de uma ferramenta que aumente a confiabilidade do uso de sistemas com GUIs, por exemplo, é necessário esperar sua distribuição e utilização prática para que se acesse essas informações de modo preciso. Entretanto, estudos empíricos bem elaborados contribuem para que propostas de métodos em Engenharia de Software sejam adotados na prática.

Um estudo empírico deve seguir alguma estratégia que vise a evitar possíveis viéses em seus resultados. Para o caso do presente projeto de mestrado além de buscar a validade interna da proposta, a estratégia estabelecida para o estudo de caso foi definida com o intuito de constituir uma base de acesso a resultados empíricos. Para tanto, a estratégia adotada consistiu do planejamento, definição e implementação de dois estudos diferentes:

Primeiro estudo: buscou-se validar a proposta do uso do método Gr-O para um domínio específico, avaliando a flexibilidade da técnica proposta;

Segundo estudo: proposto com o intuito de avaliar pontos positivos e negativos do método Gr-O em interfaces gráficas complexas implementadas com a biblioteca Swing;

A realização dos estudos é complementar à analise comparativa apresentada por meio da Seção 5.4 (Capítulo 5). A análise dos estudos, apresentados com mais detalhes nas seções 
seguintes, tem a função de servir como meio para a definição de possíveis consequências da utilização do método Gr-O como forma de automatizar oráculos capazes de verificar funcionalidades específicas de sistemas com GUIs.

\subsection{Primeiro Estudo: GCalcTool}

Este primeiro estudo visa a averiguar a aplicabilidade do uso do método Gr-O como apoio ao teste de domínios específicos de sistemas com GUIs. Busca-se enfatizar o uso do framework O-FIm, do método Gr-O e de seus atributos para o aumento da produtividade e eficiência em atividades de teste. Para tanto, realizaram-se testes para verificar a operabilidade da ferramenta GCalctool $^{1}$, por meio de sua interface gráfica, em diferentes resoluções de tela e tamanhos distintos. Tal aplicativo consiste de uma calculadora, distribuída como software livre e compatível com a maioria dos sistemas operacionais Unix. Na Figura 6.1a é apresentada uma interface gráfica da ferramenta GCalctool.

É comum que sistemas de software que contenham GUIs sejam implementados e testados em determinada resolução específica. Entretanto, quando o produto é distribuído, o usuário pode configurar a interface do sistema para resoluções e tamanhos diferentes. Isso pode fazer com que falhas inesperadas surjam. Supondo que uma organização que desenvolva e teste suas aplicações utilizando uma resolução 1024x768 pixels, devido aos múltiplos dispositivos e plataformas existentes, é desejável que o produto seja disponibilizado para ser utilizado em diferentes resoluções de vídeo.

A GCalctool possui cinco GUIs diferentes e cada uma delas representa um tipo de calculadora. Na Figura 6.1 são apresentados todos os possíveis formatos que a ferramenta pode assumir: "básica" (Figura 6.1a), "avançada" (Figura 6.1b), "financeira" (Figura 6.1c), "científica" (Figura 6.1d), e, por fim, "programável" (Figura 6.1e)².

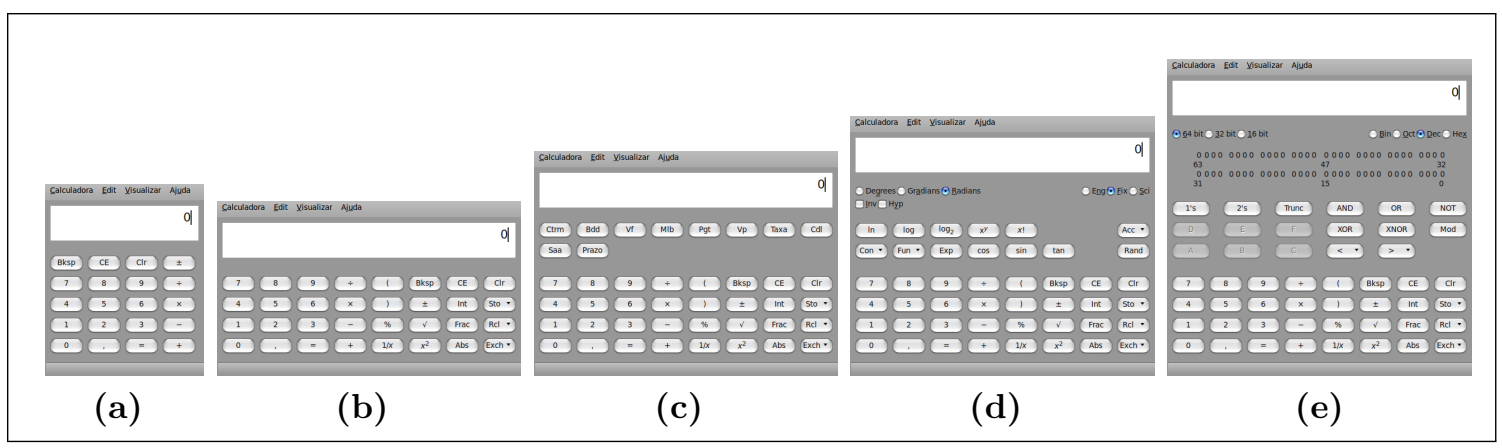

Figura 6.1: GCalctool-a) básica; b) avançada; c) financeira; d) científica; e) programável

\footnotetext{
${ }^{1}$ acesse: http://live.gnome.org/Gcalctool

2 As GUIs foram capturadas a partir do sistema operacional Ubuntu, sendo executado com o tema Mac4Lin
} 
Para a condução do presente estudo empírico, cada um dos possíveis formatos de GUI da GCalctool foi capturado como screenshots, em cinco diferentes resoluções e em dois tamanhos diferentes: normal, que é o tamanho definido para inicialização da GUI e maximizado. Desse modo, foram obtidas cinco interfaces em cinco resoluções diferentes e em dois tamanhos diferentes. As resoluções de tela utilizadas no estudo foram: 640x400, 720x400, 800x600, 1024x768 e 1280x800 pixels. Portanto, 50 screenshots da GCalctool, como aqueles representados por meio da Figura 6.1, foram utilizados como fonte de informação para a realização dos testes. Os cinco screenshots com uma resolução de tela de 1024x768, um de cada tipo, capturados em tamanho normal foram utilizados como modelo do estudo. Isso se deu pelo fato de que essas configurações são suficientes para a garantia da operabilidade da GCalctool.

O critério para definir a correção das GUIs da GCalctool no teste realizado foi o número de botões presente visíveis entre screenshots do modelo. Por isso, o extrator implementado para o teste tem como funcionalidade retornar o número de botões identificados em um screenshot da GCalcTool. É comum, após algum redimensionamento ou alterações de resolução, que componentes de interfaces gráficas fiquem ilegíveis ou, então, tornem-se inoperáveis. Para ilustrar esse tipo de problema, na Figura 6.2 podem ser visualizados dois screenshots da GCalctool. Uma GUI da GCalctool é considerada operável quando seus botões estão legíveis e habilitados. Por exemplo, a Figura 6.2a, que é totalmente operável, é a representação de um screenshot capturado em uma resolução de tela de 1024x768 pixels. Entretanto, a mesma GUI sendo executada em uma tela com resolução de 720x400 pixels (Figura 6.2b) não é totalmente operável e, inclusive, têm alguns botões parcialmente visíveis.

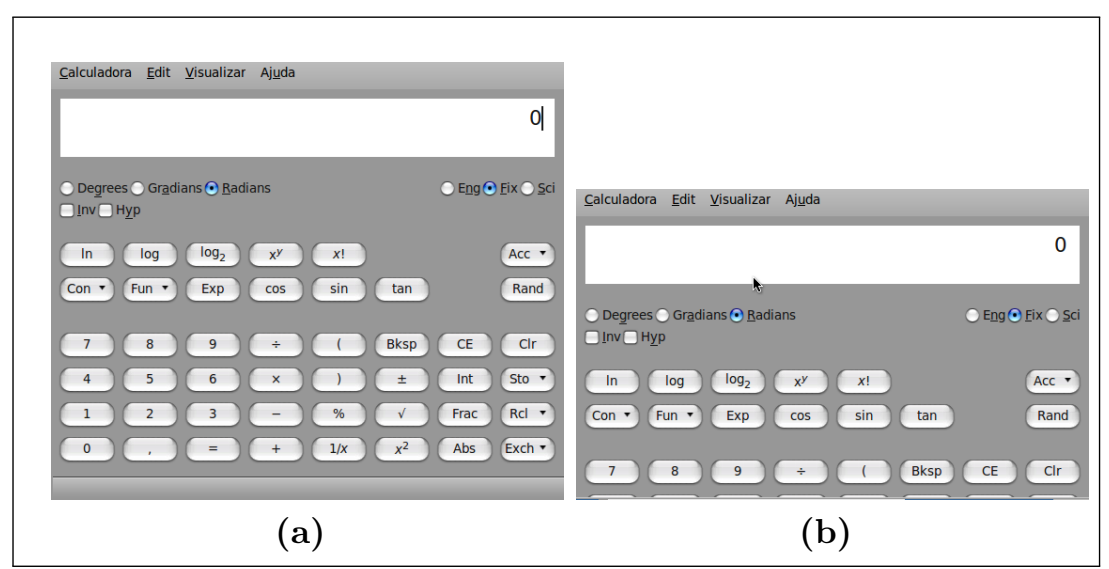

Figura 6.2: Comparativo entre GUIs operáveis e não operáveis - a) GCalctool com a resolução de 1024x768 pixels (operável); b) A GCalctool com a resolução de 720x400 pixels (não operável) 
O estudo foi realizado para avaliar o comportamento do método Gr-O para a automatização de oráculos de teste capazes de identificar problemas como o apresentado na Figura 6.2. Os plugins desenvolvidos com esse objetivo foram:

- Função de similaridade Identical: conforme descrito no Capítulo 5, essa função apenas compara elemento por elemento dos vetores de características e, retorna 0.0 para os casos em que todos eles sejam iguais e 1.0 caso contrário

- Extrator de número de botões ${ }^{3}$ : o extrator de características denominado CountButtons foi implementado especialmente para identificar o número de botões ativos em um screenshot da GCalctool. Aplicado em toda a área de um screenshot como, por exemplo, o representado pela Figura 6.1a, o CountButtons retorna o valor 20.0. As etapas necessárias para seu desenvolvimento, incluindo o pré-processamento, seguiram a seguinte ordem:

1. Transformação de imagem do screenshot do modelo de cores RGB (Red, Green e Blue) para uma imagem em equivalente em 256 níveis de cinza. Na Figura 6.3a pode ser visualizado um screenshot da GCalctool em níveis de cinza;

2. Aplicação de um algoritmo com um limiar que distingua pixels com alta intensidade de brilho dos pixels mais escuros. Esse limiar é suficiente para a identificação de aglomerações que, visualmente, são a representação de um botão. Por isso, o algoritmo de pré-processamento é responsável por ajustar tais aglomerações com o valor 255 (branco) e os demais pixels com 0 (preto). Na Figura 6.3b pode ser visualizada a GUI da GCalctool após essa etapa do pré-precessamento;

3. Após a execução da etapa anterior, pode ser que alguns ruídos estejam presentes na imagem a ser analisada, fato que prejudica a análise do CountButton. Para a eliminação desses ruídos, nessa etapa do pré-processamento, é aplicado um filtro de mediana no screenshot da GUI. Tal filtro consiste de um algoritmo de filtro não-linear capaz de remover ruídos em imagens avaliando os valores dos pixels vizinhos de uma região ruidosa (Gonzalez e Woods, 2006). Na Figura 6.3c pode ser visualizada uma GUI com ruídos removidos; e

4. Por fim, para a contagem do número de botões é aplicada uma técnica conhecida como transformação área-ponto (Nunes, 1997). Tal técnica é capaz de transformar áreas conectadas em um único ponto. Aplicada à Figura $6.3 \mathrm{c}$, a técnica faz com que cada aglomerado de pixels brancos seja transformado em um único pixel, viabilizando a contagem do número de botões da GUI computacionalmente.

\footnotetext{
${ }^{3}$ Diversos aspectos de implementação desse e de outros extratores de características apresentados neste capítulo utilizam recursos da API JAI (Java Advanced Image) (acesse: http://bit.1y/JJymQ)
} 
CAPÍTULO 6. GR-O E SISTEMAS COM GUIS: ESTUDOS DE CASO

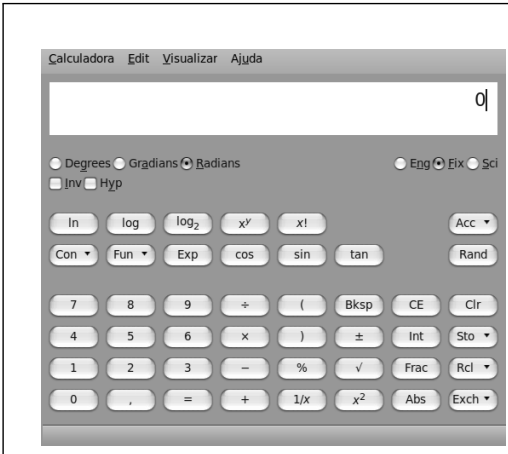

(a)

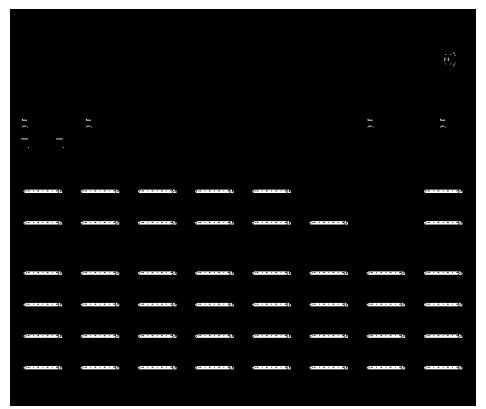

(b)

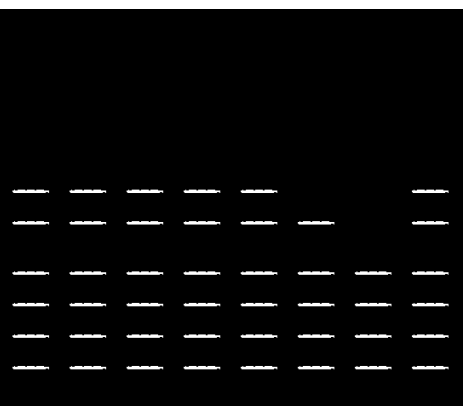

(c)

Figura 6.3: Etapas do CountButtons - a) Screenshot da GCalctool em 256 níveis de cinza; b) Figura 6.3a após aplicação de um limiar; c) Figura 6.3b após a aplicação de um filtro de mediana

Desse modo, por meio do método Gr-O e do framework O-FIm, pode-se configurar e executar um oráculo de teste capaz de automatizar verificações nas funcionalidades da interface da GCalctool em diferentes resoluções. Na Figura 6.4 pode ser visualizado o oráculo gráfico definido. O critério para estabelecer se o screenshot de uma GUI está de acordo com o esperado é simples: basta que o número de botões ativos da GCalctool em teste seja igual ao número de botões ativos da interface da GCalctool modelo. Por isso, no oráculo gráfico, o campo "precision" é definido com o valor 0.0, o que representa similaridade máxima.

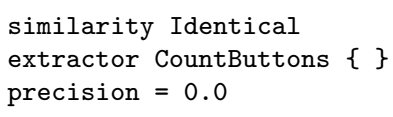

Figura 6.4: Oráculo gráfico definido para o estudo empírico do método Gr-O com a GCalctool

\subsubsection{Resultados}

Por meio da Tabela 6.1 podem ser visualizados os resultados de cada um dos testes realizados. Essa tabela relaciona linhas e colunas nas quais são exibidos o tipo de GUI da GCalctool em análise e o número de botões utilizado pelo oráculo para decidir sobre a correção de cada screenshot em teste. Tal número corresponde ao resultado da aplicação de CountButtons em cada uma das GUIs utilizadas como modelo. Assim, cada associação entre linha e coluna apresenta o resultado de uma teste como por exemplo, a GUI Básica na resolução 640x400 pixels e tamanho maximizado, passou no teste e teve o número de botões ativos iguais ao número da GUI modelo. Por isso, informações como resoluções e tamanho são apresentadas na tabela. 
Tabela 6.1: Resultados estudo de caso do método Gr-O com a GCalctool

\begin{tabular}{|c|c||c|c|c|c|c|c|c|c|c|c|}
\hline \multirow{2}{*}{ Tipo de GUI } & \multirow{2}{*}{ Botões } & \multicolumn{3}{|c|}{$640 \times 400$} & \multicolumn{2}{c|}{$720 \times 400$} & \multicolumn{2}{c|}{$800 \times 600$} & \multicolumn{2}{c|}{$1024 \times 768$} & \multicolumn{2}{c|}{$1280 x 800$} \\
& & norm. & max. & norm. & max. & norm. & max. & norm. & max. & norm. & max. \\
\hline \hline Básica & 20 & Passou & Passou & Passou & Passou & Passou & Passou & Passou & Passou & Passou & Passou \\
\hline Avançada & 32 & Passou & Passou & Passou & Passou & Passou & Passou & Passou & Passou & Passou & Passou \\
\hline Financeira & 42 & Falhou & Falhou & Falhou & Passou & Passou & Passou & Passou & Passou & Passou & Passou \\
\hline Científica & 45 & Falhou & Falhou & Falhou & Falhou & Passou & Passou & Passou & Passou & Passou & Passou \\
\hline Programável & 43 & Falhou & Falhou & Falhou & Falhou & Passou & Passou & Passou & Passou & Passou & Passou \\
\hline
\end{tabular}

Os resultados do estudo se mostraram condizentes com a situação das aplicações na prática. Verificou-se cada um dos casos e as ocasiões nas quais o oráculo apontou diferenças entre número de botões de screenshot de sistema em teste e screenshot modelo, realmente, por algum motivo de incompatibilidade, a GUI da calculadora não podia ser operada por completo. Para o caso particular da GCalctool, o método Gr-O é capaz de identificar se sua GUI é operável, ou não. Os resultados foram verificados na prática e se mostraram satisfatórios.

Adicionalmente, observaram-se informações interessantes como, por exemplo, o funcionamento ideal da GCalctool na resolução 720x400 pixels somente é obtido com sua GUI maximizada. Claramente, verificar a operabilidade de uma GUI é uma tarefa trivial para um oráculo humano. Entretanto, considerando que foi necessária a conferência da operabilidade de 50 GUIs, este trabalho poderia ser tedioso, demorado e propenso a erros se tivesse de ser realizado por um testador manualmente.

Uma descrição mais detalhada de aspectos técnicos do estudo empírico descrito nesta seção pode ser obtida no artigo apresentado por Oliveira et al. (2010). Em tal trabalho são apresentados detalhes técnicos do extrator CountButtons e é levantada uma discussão mais detalhada a respeito dos resultados.

\subsection{Segundo Estudo: Ferramenta JaBUTi}

O segundo estudo empírico realizado durante este projeto de mestrado teve como objetivo verificar a aplicabilidade dos oráculos gráficos para o apoio do teste de sistemas com GUIs consideradas complexas, caracterizadas por um alto número de componentes e pela grande dependência de análises visuais. A ferramenta JaBUTi (Java Bytecode Understanding and Testing) (Vincenzi et al., 2003), desenvolvida pelo grupo de pesquisa em Engenharia de Software do ICMC-USP, tem como principal característica a disponibilidade de uma GUI completa, desenvolvida em Swing, para o acompanhamento das atividades de teste estrutural de programas escritos na linguagem Java. A ferramenta oferece interfaces gráficas que apresentam a cobertura de comandos ou de desvios, informações sobre fluxo de dados e sobre cobertura de métodos, classes ou critérios de teste. Na Figura 6.5 pode ser visualizada uma das GUIs da ferramenta JaBUTi. 


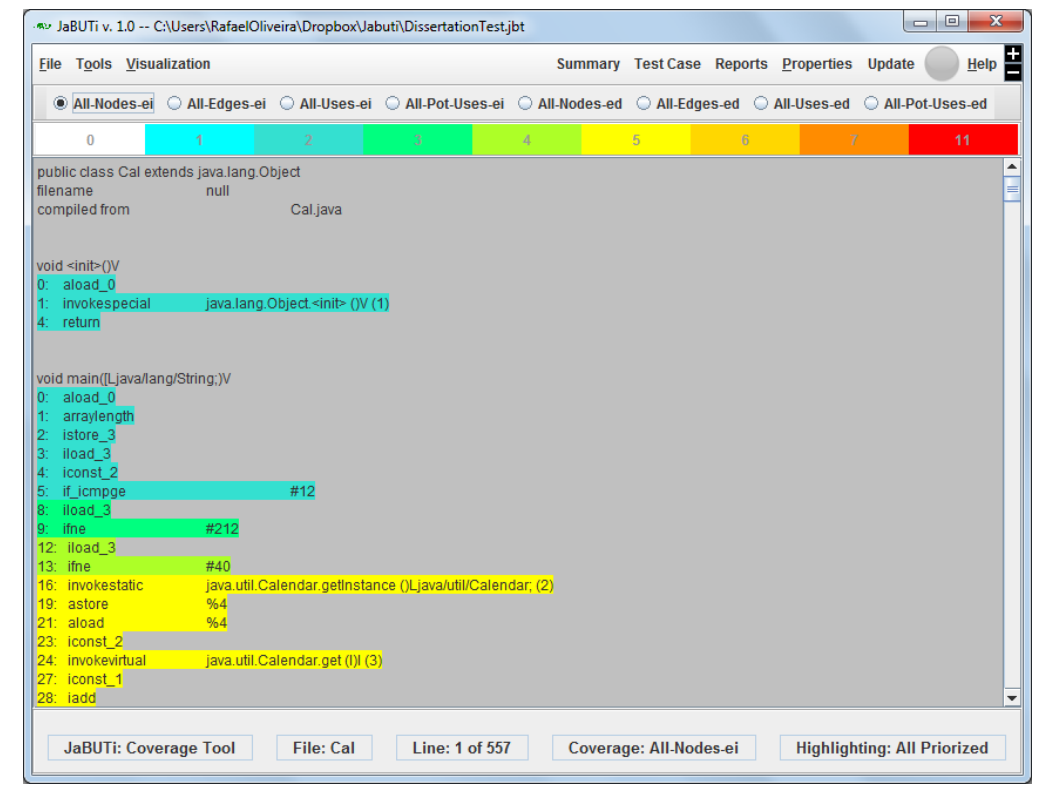

Figura 6.5: GUI da ferramenta JaBUTi

Por ser considerada uma ferramenta que tem sua GUI como um diferencial de sua utilização, ela foi selecionada para ser explorada no presente estudo. Alguns passos básicos seguidos durante a condução do estudo empírico realizado são descritos a seguir:

1. Instrumentação da ferramenta JaBUTi para a captura automática de screenshots: o método Gr-O utiliza imagens como fonte de informação para a realização de testes. Entretanto, a captura manual de screenshots não é interessante para o contexto do estudo empírico a ser realizado. Como solução a isso, um método para a captura de screenshots foi implementado;

2. Implementação de extratores de característica: foram implementados extratores de características específicos para a identificação de informações básicas na GUI implementadas em Swing (biblioteca gráfica da ferramenta JaBUTi). Aspectos particulares de cada extrator são apresentados nas seções seguintes;

3. Configuração de oráculos gráficos por meio do framework O-FIm : utilizando o wizard do framework O-FIm, os oráculos gráficos utilizados nesta seção puderam ser ajustados, viabilizando a execução dos testes.

\subsubsection{Automatização da captura de screenshots da JaBUTi}

Com o intuito de facilitar a obtenção e acesso às fontes de informações para os testes a serem realizados, foi implementado um mecanismo que permite a captura automatizada de screenshots da ferramenta JaBUTi durante sua operação. Tal mecanismo é simples, pode ser replicado em outros estudos e explora classes pré-definidas da linguagem Java como, por exemplo, java.awt.Graphics, java.awt.image.BufferedImage e javax. imageio. ImageIO. Na Listagem 6.1 pode ser visualizado o método que permitiu 
a captura automática de screenshots. Nele, por meio do acesso à estrutura de dados que promove os efeitos visuais na GUI, imagens da instância de um determinada GUI implementada em Swing podem ser salvas em disco e utilizadas como fonte de informação em testes.

Para a realização desse segundo estudo empírico, em particular, a classe principal da interface gráfica da JaBUTi foi alterada. Nela foram introduzidas chamadas ao método que captura seus screenshots após o disparo de alguns eventos específicos por parte do usuário. Entre esses eventos, destacam-se mudanças de L\&F alterações na visualização de análise de cobertura (por critério, por classe, por método), após alterações de visões (bytecode, código fonte e elementos requeridos) e, por fim, após cada mudança de critério de teste estrutural.

Listagem 6.1: Código para automatização de captura de screenshots da ferramenta JaBUTi

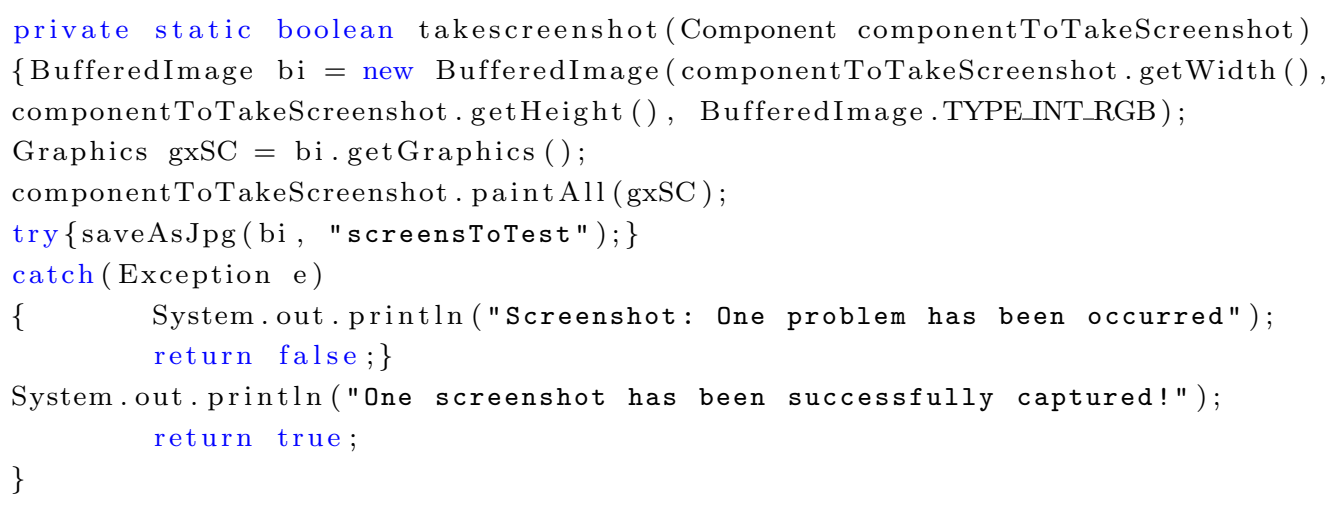

Adicionalmente, para otimizar os processos de teste do método Gr-O e promover mais eficiência na reexecução dos testes, foi utilizada a ferramenta de captura e reprodução WindowTester Pro ${ }^{4}$. Tal ferramenta oferece, de modo simples e eficiente, recursos para que as interações em uma GUI sejam gravadas em uma classe para serem reproduzidas posteriormente. A WindowTester Pro possui um plugin nativo para a IDE Eclipse, facilitando sua instalação e a reexecução das interações. Na Listagem 6.2 é apresentado um exemplo de código de captura gerado pela ferramenta após a abertura de um projeto e uma mudança de visão na ferramenta JaBUTi. Por meio da listagem é possível notar o modo intuitivo que a ferramenta gera códigos para a reprodução de eventos em GUIs

Listagem 6.2: Código gerado pela funcionalidade de captura da ferramenta Window-

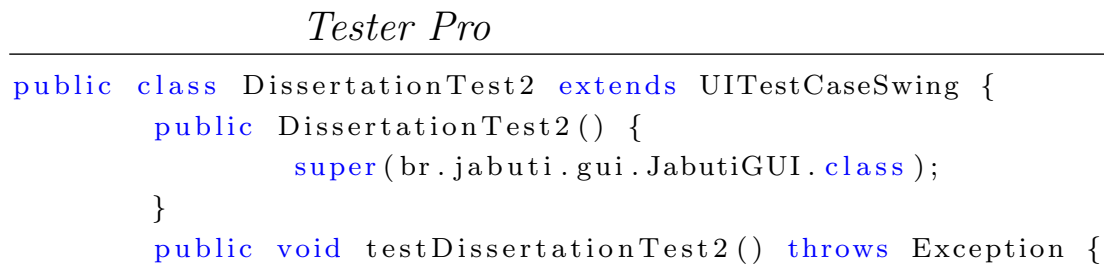

${ }^{4}$ acesse: http://bit.1y/tNRIJL 


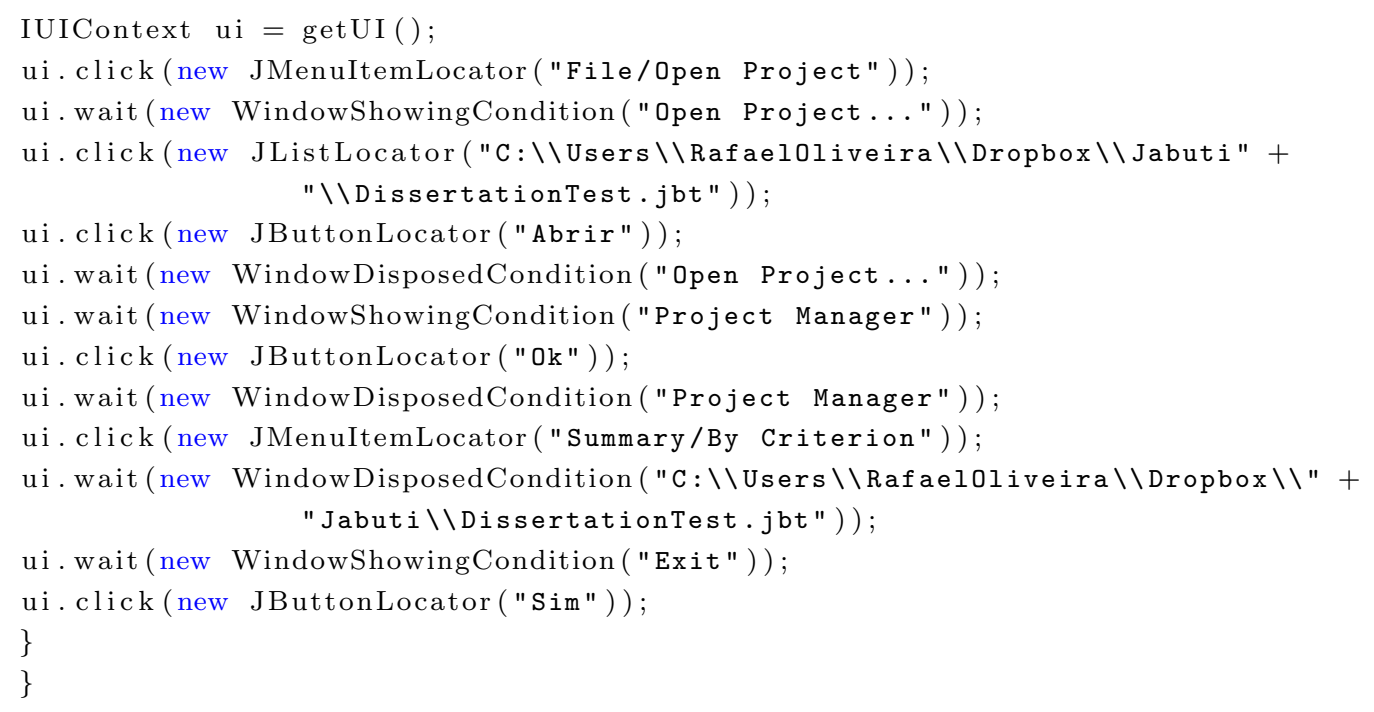

\subsubsection{Oráculo 1}

Uma das funcionalidades da JaBUTi é o oferecimento de diferentes aparências (L\&F - do inglês, look and feels) de interface a serem escolhidas pelo usuário. Um L\&F é responsável por fornecer todos os aspectos gráficos de um componente GUI. A eficiência dessa funcionalidade que permite o uso de diversos L\&Fs na JaBUTi é, exatamente, o que se deseja verificar por meio do oráculo gráfico descrito nesta seção. Deseja-se investigar, utilizando o método Gr-O, se a troca de L\&Fs prejudica a utilização da ferramenta.

Erros decorrentes da troca de L\&Fs são comuns em aplicações que contenham interfaces complexas. Em geral, a alteração de L\&Fs pode mudar a cor e o posicionamento de diferentes componentes em uma GUI. Desenvolvedores podem implementar ou customizar um L\&F como lhe for conveniente e, após isso, disponibilizá-lo para que outros projetistas o utilizem em suas aplicações. Na JaBUTi é disponibilizada uma funcionalidade que permite ao testador a alternância, em tempo de execução, entre L\&Fs.

Vale ressaltar que, um dos diferenciais da ferramenta, é o oferecimento de "dicas" que visam a apoiar os testadores durante a geração de casos de teste e melhorar a cobertura dos testes. A ferramenta oferece a visualização dos bytecodes da aplicação em teste ou, então, de seu código fonte, associados a diferentes cores e pesos. Tais cores e pesos identificam requisitos de teste com maior impacto de cobertura para determinado critério. O peso associado a um determinado requisito serve para identificar o número de requisitos adicionais que serão cobertos quando um caso de teste for capaz de cobrir tal requisito. Intuitivamente, os requisitos de teste com maior peso são apresentados em uma cor mais intensa como, por exemplo, o vermelho. Por meio da Figura 6.6 é possível verificar o modo como o esquema de cores da ferramenta JaBUTi facilita a geração de casos de teste. 


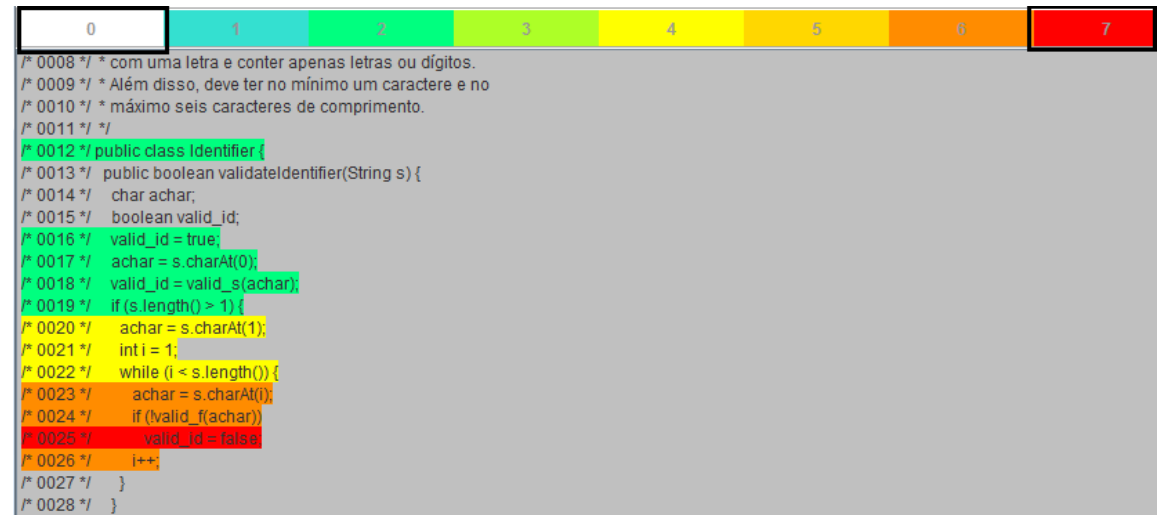

Figura 6.6: Esquema de "dicas" para a geração de casos de teste da ferramenta JaBUTi

A estratégia traçada para definir, utilizando o método Gr-O, se a alternância entre L\&Fs na ferramenta JaBUTi pode provocar erros foi definida do seguinte modo: implementar um oráculo gráfico capaz de verificar se as cores predominantes em regiões específicas de uma GUI da ferramenta JaBUTi eram similares às cores predominantes da mesma GUI executada com o L\&F Metal (screenshot modelo). As regiões específicas correspondem exatamente às indicações de prioridade da ferramenta. Na Figura 6.6, tais regiões são representadas pelos retângulos coloridos na parte superior da interface visualizada. O L\&F metal, que é nativo da biblioteca Swing, foi escolhido como modelo pelo fato de ser a aparência padrão da ferramenta. Por isso, o estudo consistiu em verificar as cores de regiões específicas da GUI da JaBUTi executada em nove diferentes L\&Fs.

O extrator de cores e a função de similaridade euclidiana foram utilizados na composição do oráculo gráfico definido para o teste. os oráculos gráficos foram ajustados por meio do wizard do O-FIm. Assim, as regiões nas quais os extratores deveriam ser aplicados foram definidas. Para os oráculos avaliarem a adequação dos L\&Fs, nesse estudo, em particular, definiram-se duas regiões específicas nas quais os extratores foram aplicados. Tais regiões correspondem às áreas demarcadas com os pesos 0 (cor branca) e 7 (cor vermelha) na Figura 6.6. Na figura, tais áreas estão destacadas em um retângulo em preto. A partir disso, com o apoio do O-FIm, definiu-se o oráculo gráfico apresentado na Figura 6.7. Conforme pode ser observado pelo descritor de oráculo na figura, dois extratores foram ajustados para serem aplicados nas regiões destacadas na Figura 6.6. Como limiar para aceitação, ou não, de um teste, utilizou-se distância obtida entre os L\&Fs Metal(modelo) e Motif. Tal decisão foi baseada na fato de que, apesar de conter cores mais expressivas do que o L\&F Metal, ainda assim, o uso do L\&F Motif não influencia negativamente nas dicas visuais da ferramenta. Na Figura 6.8 são apresentados os screenshots da JaBUTi sendo executada com as aparências do tipo Metal (Figura 6.8a) e Motif (Figura 6.8b), respectivamente. 


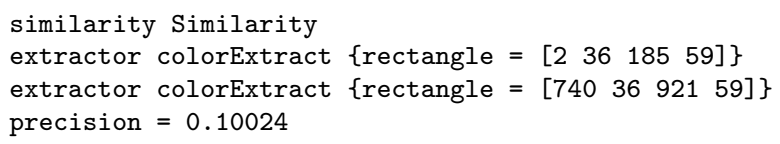

Figura 6.7: Oráculo gráfico (oráculo 1) definido para o estudo empírico com a ferramenta JaBUTi

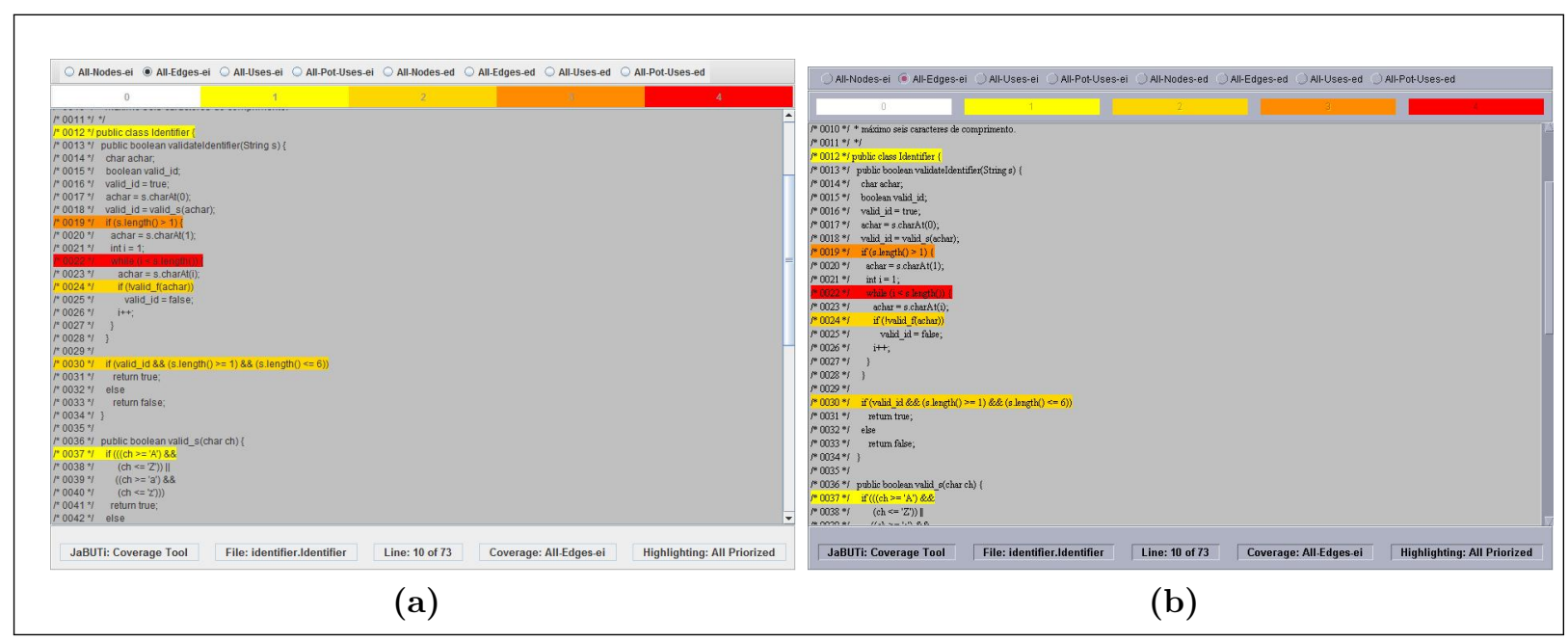

Figura 6.8: GUIs da ferramenta JaBUTi - a)L\&F Metal; b) L\&F Motif

\subsubsection{Resultados}

Por meio da Tabela 6.2 podem ser visualizados os resultados do estudo empírico realizado. Na referida tabela são apresentados os resultados da aplicação do extrator de cor para as duas regiões definidas, o resultado da distância euclidiana entre o screenshot modelo e o screenshot da aplicação em teste e, por fim, o veredicto do oráculo para cada um dos L\&Fs ajustados. Apenas dois, de um total de nove L\&Fs avaliados, passaram no teste. Uma análise visual dos screenshots julgados pelo oráculo como incorretos permite notar que, de fato, determinados L\&Fs prejudicam as funcionalidades de cores da ferramenta JaBUTi. O problema é configurado quando as cores não aparecem ou então, aparecem apenas na margem dos componentes, ou, por fim, aparecem apenas no peso relacionado à cobertura. Situações como essas são comuns em diversos L\&Fs.

Na Figura 6.9 são exibidos dois dos screenshots das aplicações que não foram aceitas pela avaliação do oráculo - L\&F Napkin (Figura 6.9a) e L\&F office2003 (Figura 6.9b), respectivamente. Como pode ser observado, uma vez que o intuito do oráculo gráfico era identificar L\&Fs que prejudicassem o esquema das dicas da JaBUTi, as interfaces ilustradas em 6.8 não disponibilizam as cores que viabilizam tais dicas para a inserção de casos de teste. 
Tabela 6.2: Resultados do segundo estudo de caso - oráculo 1

\begin{tabular}{|c|c||c|c|c|c|c|c|c|c|c|}
\hline & $\begin{array}{c}\text { Metal } \\
\text { model }\end{array}$ & Motif & Windows & Liquid & Tonic & Nimbus & Napkin & office2003 & windowsXP & InfoNode \\
\hline \hline ext.1 & 0.383 & 0.282 & 0.292 & 0.277 & 0.438 & 0.268 & 0.306 & 0.288 & 0.273 & 0.232 \\
\hline ext.2 & 0.013 & 0.009 & 0.059 & 0.053 & 0.015 & 0.052 & 0.306 & 0.057 & 0.055 & 0.046 \\
\hline FS & 0.0 & 0.100 & 0.101 & 0.112 & 0.055 & 0.121 & 0.303 & 0.104 & 0.116 & 0.153 \\
\hline res. & - & passou & falhou & falhou & passou & falhou & falhou & falhou & falhou & falhou \\
\hline
\end{tabular}

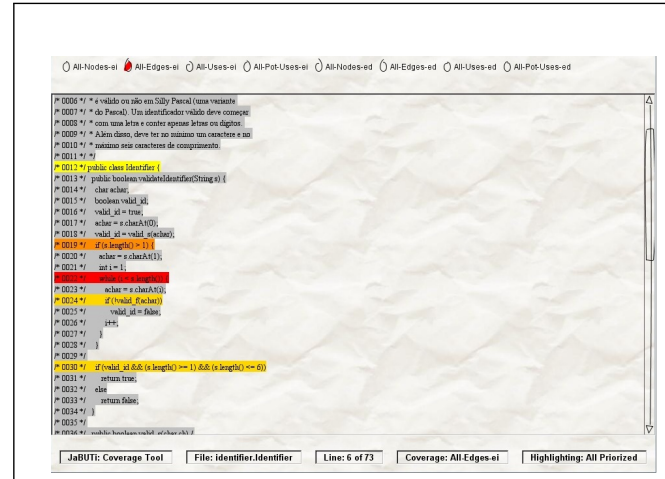

(a)

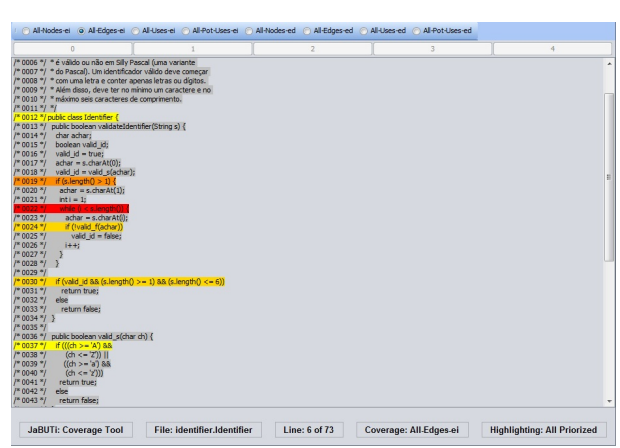

(b)

Figura 6.9: GUIs não aceitas pelo oráculo - a) L\&F Napkin; b)L\&F office2003

Na seção seguinte são apresentados mais duas estratégias de teste para as funcionalidades da ferramenta JaBUTi, utilizando como fonte de informação screenshots de execuções de sua utilização em projetos reais.

\subsubsection{Oráculos}

A ferramenta JaBUTi oferece uma funcionalidade por meio da qual seus usuários podem visualizar diversos elementos requeridos para o teste e a porcentagem de cobertura de classes, métodos e critérios. Quanto aos elementos requeridos de teste, as visualizações são apresentadas por meio de uma GUI com diversos componentes aninhados do tipo checkbox. Por meio da Figura 6.10 é possível verificar uma das GUIs da ferramenta JaBUTi que promovem graficamente a análise dos elementos requeridos para um método de uma classe qualquer.

GUIs complexas, como a da ferramenta JaBUTi, estão sujeitas a erros diversos, principalmente, após alguma manutenção de código ou inclusão de funcionalidades. Em geral, alterações em códigos de funcionalidades específicas podem inserir defeitos no código. E, consequentemente, tais defeitos podem se propagar por meio da interface gráfica da aplicação. No caso da JaBUTi, em particular, isso pode fazer com que a análise de cobertura de um programa seja feita de modo errado, prejudicando a qualidade dos produtos em teste.

Uma possível solução para tal problema é a verificação visual dos elementos requeridos de teste antes de qualquer manutenção. Isso possibilita que valores identificados nos 


\section{CAPÍTULO 6. GR-O E SISTEMAS COM GUIS: ESTUDOS DE CASO}

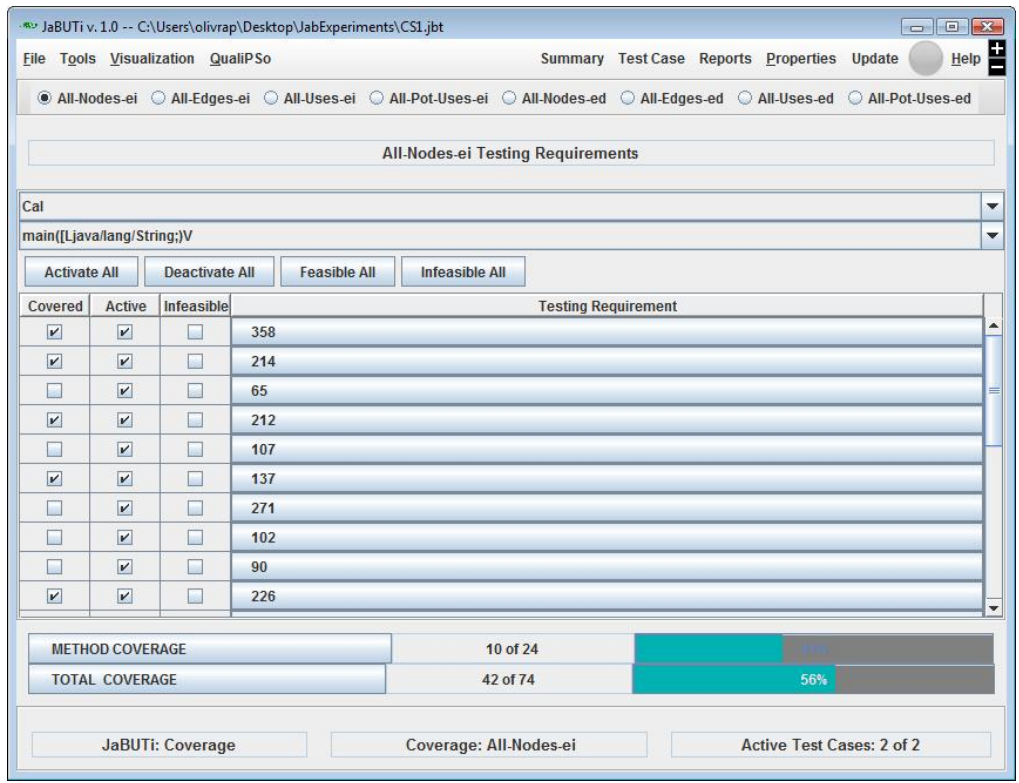

Figura 6.10: Ferramenta JaBUTi na visão de elementos requeridos por método

aspectos visuais possam ser comparados a novos valores após a realização das alterações no sistema. Por isso, com o intuito de servir como um método alternativo para automatizações de testes que verifiquem condições particulares da ferramenta JaBUTi, foram projetadas e avaliadas empiricamente duas estratégias de teste - descritas por meio dos oráculos 2 e 3 , respectivamente.

\subsubsection{Oráculo 2}

O oráculo foi implementado para verificar, por meio de um screenshot, se determinadas regiões indicadas pelo testador por meio do O-FIm, correspondem a componentes checkbox iguais em uma GUI modelo e em uma GUI da aplicação em teste. Como estratégia para o teste, optou-se pela verificação de cinco componentes checkbox em uma GUI modelo, apresentada na Figura 6.11a. Em tal figura, os componentes escolhidos para serem verificados no teste estão destacados por uma seta. Foram incluídos alguns casos de teste no projeto sendo executado na JaBUTi e o screenshot da ferramenta após a atualização da cobertura foi utilizado como fonte de informação para o teste. Tal screenshot é apresentado por meio da Figura 6.11b. Após isso, com o intuito de verificar influências da troca de L\&F, o teste foi replicado para dois L\&Fs diferentes (Motif e Windows), mantendo o screenshot modelo.

Para a composição do oráculo, em relação aos plugins, foram utilizados extratores para checkBox e a função de similaridade identical, especificados no Capítulo 5. Utilizando o framework O-FIm, foi definido um oráculo com cinco extratores de checkbox ajustados para identificar os estados (checado ou não) dos componentes na região destacada na Figura 6.11a. 


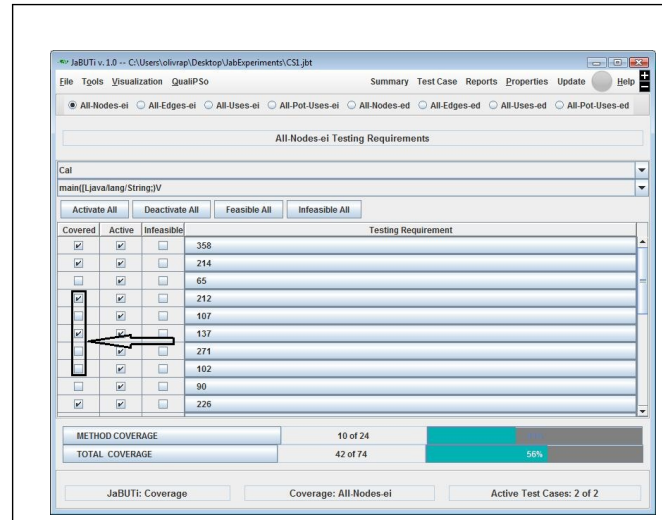

(a)

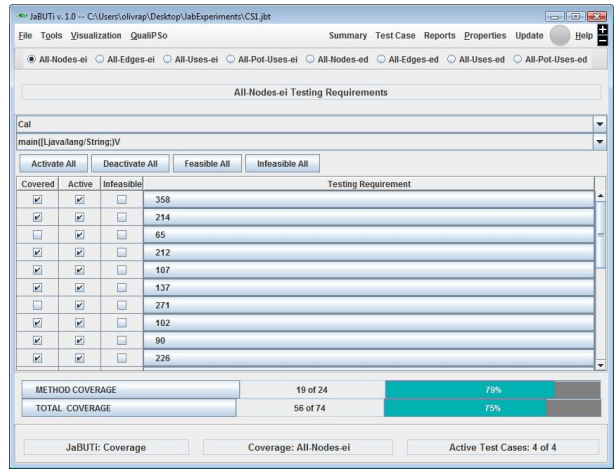

(b)

Figura 6.11: GUIs da ferramenta JaBUTi na visão dos elementos requeridos - a) screenshot da aplicação modelo; b) screenshot da aplicação em teste

\subsubsection{Oráculo 3}

O oráculo 3 foi projetado para detectar possíveis alterações indesejadas na cobertura e nas informações visuais sobre a cobertura apresentada na GUI da ferramenta JaBUTi. Utilizou-se para o teste, a GUI que representa a cobertura do critério de todos os nós em cada um dos métodos da aplicação. Além da cobertura, o oráculo leva em consideração as diversas informações visuais apresentadas em componentes Swing do tipo label.

Na Figura 6.12a é representada a interface considerada como modelo para o teste. Nela pode ser visualizada também, em destaque, os componentes GUI utilizados pelo oráculo como base para as decisões sobre a correção das aplicações em teste. O primeiro desses componentes é do tipo ProgressBar e representa a cobertura de teste de um método, levando em consideração um critério. Os labels considerados apresentam dados sobre cobertura como, por exemplo, o número de nós total e o número de nós cobertos (quando o todo-nós estiver selecionado). Outro dado informado pelos labels é o número de casos de teste ativos considerados na cobertura.

A GUI modelo considerada para o teste capturada com o L\&F Metal apresentava: 92\% de cobertura na barra de progresso considerada, um label informando que 44 de 74 nós estavam cobertos e um caso de teste ativo. A estratégia seguida para o teste consistiu da inclusão de alguns casos de teste e, após a atualização da cobertura, novos screenshots foram capturados. Adicionalmente, verificou-se que a alteração de L\&Fs influenciava nas decisões dos oráculos com a replicação do mesmo teste com diferentes L\&Fs. Desse modo, mais uma vez, os testes foram replicados nos L\&Fs Motif e Windows. Como limiar de decisão para o oráculo utilizou-se o resultado de sua aplicação com o L\&F Metal como modelo e o L\&F Nimbus como aplicação sendo testada. Isso se justifica pelo fato de que apesar de serem bastante distintas em diversos componentes, ambas permitem visualmente a análise de cobertura na ferramenta JaBUTi. 


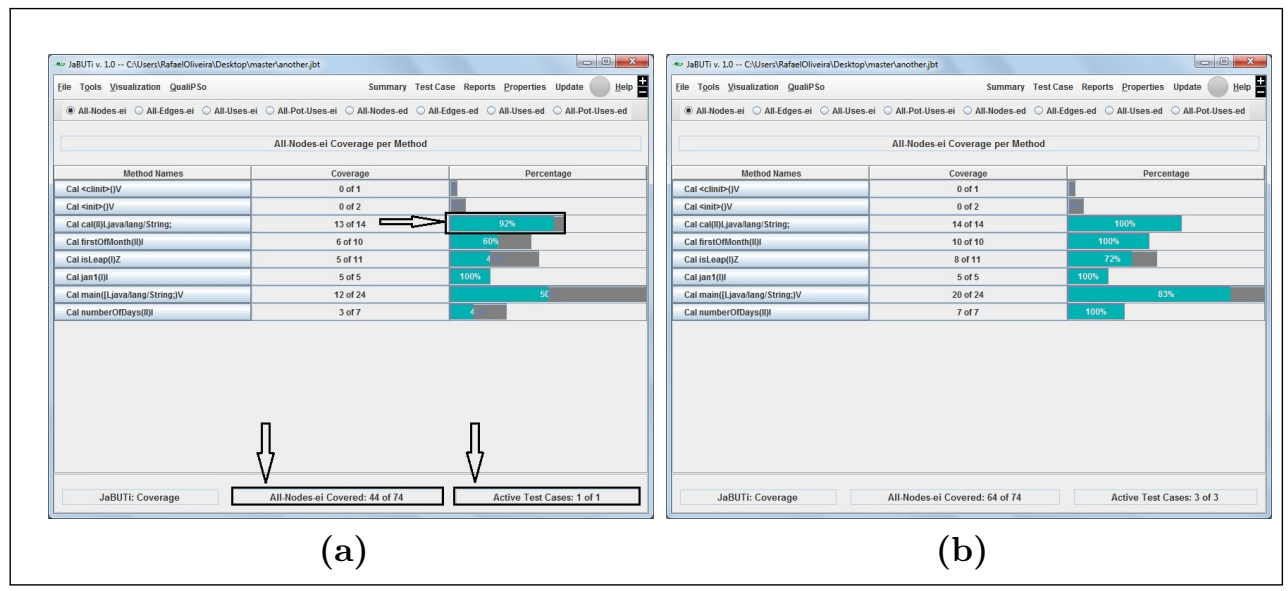

Figura 6.12: GUIs da ferramenta JaBUTi na visão de cobertura do critério todos-nós por métodos - a) screenshot da aplicação modelo; b) screenshot de uma das aplicações em teste

A Figura 6.13 serve como para a visualização do descritor de oráculo gráfico definido pelo Oráculo 3. É possível notar que o teste foi ajustado para não aprovar testes que alterem valores na cobertura representada pela Barra de Progresso ou então, alterem informações nos labels.

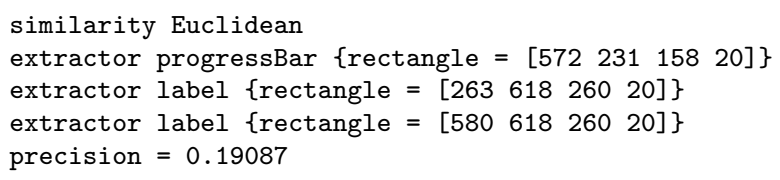

Figura 6.13: Oráculo gráfico (oráculo 3) definido para o estudo empírico com a ferramenta JaBUTi

\subsubsection{Resultados}

Todos os screenshots, considerados aceitos ou não aceitos, foram analisados visualmente por um oráculo humano. Os resultados desses estudos empíricos mostraram-se satisfatórios. Buscou-se investigar a viabilidade da utilização do método Gr-O como forma de apoio ao teste de sistemas com GUIs complexas e sujeitas a alterações constantes. A validade do método pôde ser comprovada por meio dos resultados desse segundo experimento. Adicionalmente, os estudos realizados servem como um passo-a-passo que demonstre a aplicabilidade e flexibilidade da técnica proposta.

Na Tabela 6.3 são apresentados os resultados da aplicação do oráculo 2 em um screenshot da ferramenta JaBUTi, tendo o screenshot da Figura 6.11a como modelo e a Figura 6.11b como screenshot da aplicação em teste. Também são apresentados na tabela os resultados da aplicação de cada um dos extratores em cada uma das regiões ajustadas por 
meio da descrição do oráculo gráfico. Analisando aspectos visuais entre modelo e aplicação em teste, nos moldes de oráculo humano, é possível notar a consistência dos resultados apontados. A SUTs não passaram no teste pelo fato de que os extratores de checkBox tiveram retorno distintos após a inserção do caso de teste. Adicionalmente, notou-se que a alteração nos L\&Fs não influenciaram na alteração dos resultados, fato que apoia a validação do extrator implementado.

Tabela 6.3: Resultados para segundo estudo de caso com o Oráculo 2

\begin{tabular}{|c|c|c|c|c|}
\hline \multicolumn{5}{|c|}{ Oráculo 2 } \\
\hline \hline & Modelo & SUT (Metal) & SUT (Motif) & SUT (Windows) \\
\hline checkBox 1 & 1.0 & 1.0 & 1.0 & 1.0 \\
checkBox 2 & 0.0 & 1.0 & 1.0 & 1.0 \\
checkBox 3 & 1.0 & 1.0 & 1.0 & 1.0 \\
checkBox 4 & 0.0 & 0.0 & 0.0 & 0.0 \\
checkBox 5 & 0.0 & 1.0 & 1.0 & 1.0 \\
\hline oráculo & 0.0 & 1.0 (falhou) & 1.0 (falhou $)$ & 1.0 (falhou $)$ \\
\hline
\end{tabular}

Na Tabela 6.4 são apresentados os resultados de execução do oráculo 3. Observou-se que o extrator desenvolvido é capaz de quantificar os aspectos visuais de um componente Swing do tipo ProgressBar. Sendo assim, pelo fato do estudo utilizar um oráculo gráfico simples com um extrator único, os resultados foram satisfatórios e condizentes com o que era esperado. Na tabela são apresentados os resultados do extrator progressBar, juntamente com as distâncias euclidianas aplicados aos dois screenshots das aplicações em teste e na aplicação modelo. Na referida tabela, o campo teste foi utilizado para representar qual screenshot foi considerado. Assim, T1 representa o screenshot antes da mudança de cobertura e T2 representa o screenshot uma alteração de um caso de teste que influencie na cobertura. Por meio da análise do oráculo humano, é possível notar que os componentes progressBar representado por T1, como é apresentado na tabela, tem $92 \%$ de preenchimento da barras, enquanto o T2 correspondente tem $100 \%$ de preenchimento. Assim, é possível afirmar que os resultados do extrator de progressBar se aproximam bastante do que é apresentado visualmente.

Tabela 6.4: Resultados para segundo estudo de caso com o Oráculo 3

\begin{tabular}{|c|c|c|c|c|c|c|c|}
\hline \multicolumn{9}{|c|}{ Oráculo 3 } \\
\hline \hline & Model & \multicolumn{2}{c|}{ Metal } & \multicolumn{2}{c|}{ Motif } & \multicolumn{2}{c|}{ Windows } \\
\hline \hline \multicolumn{2}{|c|}{ teste } & T1 & T2 & T1 & T2 & T1 & T2 \\
\hline progressBar & 0.8744 & 0.8744 & 0.9360 & 0.7543 & 0.9948 & 0.8239 & 0.9746 \\
label R1 & 0.01432 & 0.01432 & 0.03456 & 0.0765 & 0.1713 & 0.0276 & 0.2002 \\
label R2 & 0.01024 & 0.01024 & 0.01087 & 0.0978 & 0.1186 & 0.0953 & 0.1386 \\
\hline \hline \multicolumn{2}{|c|}{ euclidean } & 0.0 & 0.0652 & 0.1608 & 0.2257 & 0.09960 & 0.2472 \\
\hline \multicolumn{2}{|c|}{ resultados } & passou & falhou & passou & falhou & passou & falhou \\
\hline
\end{tabular}




\subsection{Considerações Finais}

Este capítulo apresenta resultados empíricos de um estudo realizado com a intenção de levantar requisitos para avaliar a disponibilidade e viabilidade de recursos para a validação da estratégia Gr-O para o teste de sistemas com GUIs. Para tanto, estudos empíricos foram elaborados, executados e descritos detalhadamente. Por meio deles foi possível extrair informações a respeito de diferentes aspectos do método proposto. Resumidamente, a utilização de Gr-O para o teste de sistemas com GUIs se mostrou uma técnica válida e flexível. Adicionalmente, este capítulo, juntamente com os comparativos apresentados no Capítulo 5, podem servir como referência para estudos empíricos futuros que visem a estabelecer dados que evidenciem vantagens e desvantagens de novos métodos ou processos em Engenharia de Software.

No Capítulo 7 são apresentadas as principais conclusões tiradas do trabalho de mestrado realizado. Além disso, são apresentadas algumas limitações do método Gr-O e os trabalhos futuros, incluindo estudos empíricos mais complexos.

A partir do trabalho conduzido foi possível observar que a estratégia é útil como uma alternativa entre as custosas abordagens que requerem conhecimento e exploração de estruturas das GUIs como, por exemplo, o mapeamento entre eventos para a automatização de oráculos. Adicionalmente, por meio da estratégia, automatizando oráculos específicos é possível reduzir os esforços de testadores que têm a função de observar e detectar erros e diferenças indesejadas em sistemas com interfaces gráficas. Um framework de teste foi ajustado para seu funcionamento no contexto de sistemas com GUIs, o que permite a transferência tecnológica entre acadêmia e indústria, o que constitui sólida contribuição. 


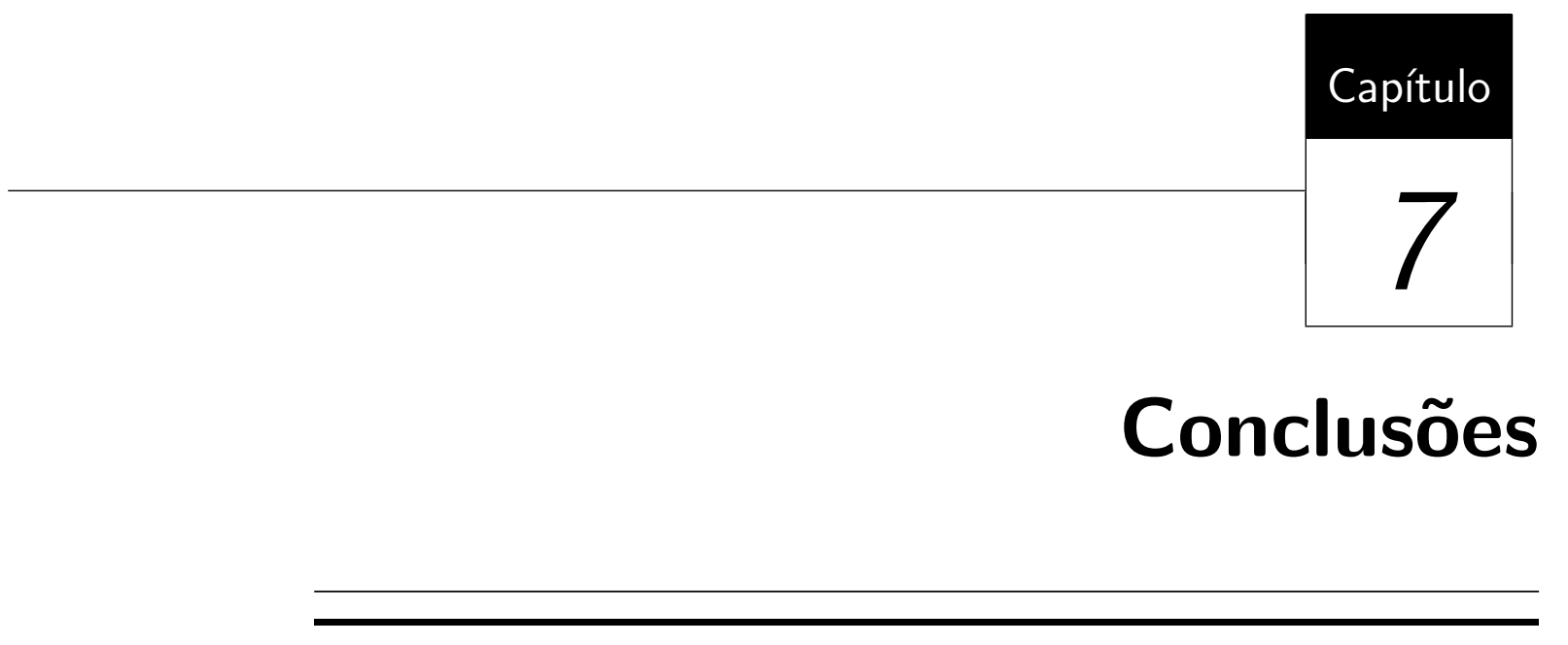

A automatização da atividade de teste é essencial para o aumento da produtividade das equipes de desenvolvimento. Essa atividade é considerada redutora de custo de desenvolvimento de um produto, permitindo que processos automatizados sejam utilizados. Adicionalmente, a automatização diminui necessidades de interação com o testador, elevando a produtividade e qualidade, reduzindo a ocorrência de erros humanos. Neste trabalho de mestrado buscou-se relatar as experiências do uso de conceitos de Processamento de Imagem e CBIR, por meio do método Gr-O, para a definição de oráculos de teste para sistemas de software com GUIs.

Além das experiências de pesquisas descritas como, por exemplo, a condução de uma Revisão Sistemática e de estudos empíricos, o presente trabalho serve como uma referência de como o método Gr-O funciona. Foi apresentado um método para verificação automatizada de alterações indesejadas de estados em componentes de sistemas com GUIs complexas. É preciso destacar que os esforços dessa pesquisa são principalmente no desenvolvimento de extratores de características úteis para GUIs implementadas com recursos da biblioteca Swing. Além disso, o estudo visa a contribuir com o cenário do teste de software no Brasil, haja vista a carência de trabalhos que relatem experiências no uso de oráculos de teste para diferentes domínios (Durelli et al., 2011).

A condução dos estudos empíricos mostrou que o método Gr-O é uma alternativa válida para o teste de sistemas com GUIs. No Capítulo 5 do trabalho é apresentada uma análise comparativa visando a investigar e avaliar a flexibilidade do método Gr-O diante 
das duas técnicas de teste tradicionais para sistemas com GUIs. Indiretamente, outros aspectos puderam ser notados como, por exemplo, a vantagem de Gr-O em aspectos de manutenção. Pode-se ter uma noção da complexidade e do tempo que seria necessário em técnicas tradicionais para reajustes de classes de teste em casos de manutenção nos componentes de uma GUI a ser testada.

Adicionalmente, é preciso destacar que quando não há extratores disponíveis para o domínio que se deseja testar é necessário implementá-los. Isso tomaria muito tempo em um projeto real, o que poderia ser definido como um ponto desfavorável em relação a técnicas mais dinâmicas como, por exemplo, a captura e reprodução. O método Gr-O, após o estudo realizado, configurou o processo que mais necessita de insumos para utilizações em diferentes domínios. Considera-se tal fato como natural por ser uma técnica proposta recentemente e que está sendo submetida a constantes avaliações.

A partir do trabalho conduzido foi possível observar que a estratégia é útil como uma alternativa entre as custosas abordagens que requerem conhecimento e exploração de estruturas das GUIs como, por exemplo, o mapeamento entre eventos para a automatização de oráculos. Adicionalmente, por meio da estratégia, automatizando oráculos específicos é possível reduzir os esforços de testadores que têm a função de observar e detectar erros e diferenças indesejadas em sistemas com interfaces gráficas. Um framework de teste foi ajustado para seu funcionamento no contexto de sistemas com GUIs, o que permite a transferência tecnológica entre academia e indústria, o que constitui sólida contribuição.

\subsection{Limitações e Ameaças à Validade}

Definir análises genéricas de resultados do uso de uma técnica ou processo por meio de estudos empíricos é uma tarefa complexa e de difícil interpretação. Não é possível generalizar efeitos da estratégia proposta para todas as situações. Além disso, entre as técnicas de estudo empírico conhecidas, o estudo de caso é aquela que oferece maiores empecilhos para replicação. A replicação de um estudo permite evidenciar que os dados revelados por determinado estudo são válidos para uma população maior. Estudos de caso geralmente são elaborados para projetos particulares, por isso, esse fato pode ser considerado uma ameaça à validade do trabalho apresentado.

Em relação às limitações, as experiências com o método Gr-O revelaram que, para seu melhor aproveitamento, a técnica exige testadores que tenham conhecimentos, ainda que mínimos, de conceitos básicos de PI. Além disso, apesar do fato de que a implementação dos extratores de características de imagens seja uma atividade que conta com o apoio de ferramentas e algoritmos tradicionais de PI, o fato de ter que desenvolver módulos durante a etapa de teste pode ser vista como um empecilho para o uso do método Gr-O. 
Entretanto, caso existam extratores especificados testados como, por exemplo, os extratores apresentados nesta dissertação, o uso do método pode ser mais aceito em organizações de desenvolvimento.

\subsection{Trabalhos Futuros}

Pode-se definir que o método Gr-O se mostrou complementar às outras técnicas em alguns aspectos. Por isso, há a possibilidade das técnicas serem associadas e utilizadas conjuntamente durante a elaboração de projetos de teste. Um dos trabalhos futuros que será executado é a realização de um experimento explorando a associação do método Gr-O às técnicas tradicionais que configuram oráculos para sistemas com GUIs. Inicialmente pensa-se em utilizar Gr-O para alguns contextos específicos e as técnicas tradicionais para outros contextos, verificando a produtividade dessa associação.

A área de Engenharia de Software como um todo é carente de estudos experimentais. Diante disso, como forma de futuras contribuições, pretende-se inserir novas atividades de automatização no contexto do framework O-FIm e do uso de CBIR para a automatização de oráculos. Desse modo, além de dar continuidade à exploração do método Gr-O para o contexto de sistemas com GUIs, pesquisas futuras serão direcionadas para a investigação de aspectos relacionados ao uso do método Gr-O para apoiar o desenvolvimento de oráculos para o teste de sistemas com outros tipos de saídas. 


\section{CAPÍTULO 7. CONCLUSÕES}


API:

Biblioteca:

Caso de teste:

Dados de teste:

Defeito:

Depuração:

Engano:

Erro:

conjunto de rotinas definidas podem ser utilizadas em formato de serviços, 18

conjunto de código pronto para utilização em contextos específicos, 18

par composto por entrada e saída esperada, 11

Um conjunto de valores de entrada de teste que são usados durante a execução de um teste, 12

passo ou processo de definição incorretos, 8 monitorar a execução de um programa com a intenção de identificar possíveis erros., 17

interpretação de requisito ou código imperfeitos, 8

estado inconsistente ou inesperado ocorrido por um defeito, 8

Falha: $\quad$ resultado de uma execução diferente do esperado, 8

Freeware: $\quad$ software livre, gratuito., 18 
Opensource: $\quad$ software com código fonte gratuito disponível para alterações particulares., 18

Requisitos de teste: definição de quais aspectos devem ser testados em um sistema., 11

teste de unidade: teste da menor unidade dos sistemas como, por exemplo, funções ou métodos., 17

Trial: versões parciais de sistemas que não permitem a realização de algumas funcionalidades, 18 


\section{Referências}

Agerholm, S.; Lecoeur, P.-J.; Reichert, E. Formal Specification and Validation at Work: a Case Study Using VDM-SL. In: Proceedings of the $2^{\text {nd }}$ Workshop on Formal Methods in Software Practice (FMSP 1998), New York, NY, USA, 1998, p. 78-84.

Araújo, M. R. B.; Traina Jr., C.; Traina, A. J. M.; Marques, P. M. A. Recuperação de Exames em Sistemas de Informação Hospitalar com Suporte a Busca de Imagens Baseada em Conteúdo. In: Anais do VIII Congresso Brasileiro de Informática em Saúde (CBIS 2002), Natal, RN, Brasil, 2002, p. 1-6.

Ariss, O. E.; Xu, D.; Dandey, S.; Vender, B.; McClean, P.; Slator, B. A Systematic Capture and Replay Strategy for Testing Complex GUI Based Java Applications. In: Proceedings oft the $3^{\text {rd }}$ International Conference on Information Technology: New Generations, Los Alamitos, CA, USA, 2010, p. 1038-1043.

Associated Press/Houston Chronicle, S. Jet breaks up in Poland; 2 dead, 45 hurt. online, sec. A, pag. 11, http://bit.1y/srXjiA - Acessado em 18/08/2011, 1993.

Barbosa, A.; Paiva, A. C.; Campos, J. C. Test Case Generation from Mutated Task Models. In: Proceedings of the $3^{\text {rd }}$ ACM SIGCHI Symposium on Engineering interactive computing systems (EICS 2011), Pisa, Italy, 2011, p. 175-184.

Baresi, L.; Young, M. Test Oracles. Technical Report CIS-TR-01-02, University of Oregon, Deptartment of Computer and Information Science, Eugene, Oregon, U.S.A., http://bit.1y/9fkDwJ - Acessado em 09/02/2011, 2001.

Beizer, B. Software Testing Techniques. $2^{\text {nd }}$ ed. New York, NY, USA: Van Nostrand Reinhold Co., 580 p., 1990. 
Bellotti, R.; Carlo, F. D.; Tangaro, S.; Gargano, G.; Maggipinto, G.; Castellano, M.; Massafra, R.; Cascio, D.; Fauci, F.; Magro, R.; Raso, G.; Lauria, A.; Forni, G.; Bagnasco, S.; Cerello, P.; Zanon, E.; Cheran, S. C.; Torres, E. L.; Bottigli, U.; Masala, G. L.; Oliva, P.; Retico, A.; Fantacci, M. E.; Cataldo, R.; Mitri, I. D.; Nunzio, G. D. A Completely Automated CAD System for Mass Detection in a Large Mammographic Database. Medical Physics, v. 33, n. 8, p. 3066-3075, 2006.

Bernardo, P. C.; Kon, F. A Importância dos Testes Automatizados - Controle Ágil, Rápido e Confiável de Qualidade. Engenharia de Software Magazine, v. 3, n. 1, p. 54-57, 2008.

Binder, R. V. Testing Object-oriented Systems: Models, Patterns, and Tools. $1^{\text {st }}$ ed. Boston, MA, USA: Addison-Wesley Longman Publishing Co., Inc., 1248 p., 1999.

Biolchini, J.; Mian, P. G.; Natali, A. C. C.; Travassos, G. H. Systematic Review in Software Engineering. Technical Report RT-ES 679/05, Systems Engineering and Computer Science Deptartment, COPPE/UFRJ, Rio de Janeiro, RJ, Brasil, http: //bit.1y/soX2Sv - Acessado em 20/03/2009, 2005.

Bueno, J. M.; Chino, F. J. T.; Traina, A. J. M.; Traina Jr., C.; Marques, P. M. A. How to Add Content-based Image Retrieval Capability in a PACS. In: Proceedings of the $15^{\text {th }}$ IEEE International Conference on Computer Based Medical Systems (CBMS 2002), Maribor, Slovenia, 2002, p. 321-326.

Buschmann, F.; Meunier, R.; Rohnert, H.; Sommerlad, P.; Stal, M. Pattern-oriented software architecture: A system of patterns. Indianapolis - IN: John Wiley \& Sons, Inc., 1996.

Chan, W. K.; Ho, J. C. F.; Tse, T. H. Piping Classification to Metamorphic Testing: An Empirical Study Towards Better Effectiveness for the Identification of Failures in Mesh Simplification Programs. In: Proceedings of the $31^{\text {st }}$ Annual International Computer Software and Applications Conference (COMPSAC 2007), Beijing, China, 2007, p. 397-404.

Chang, T.-H.; Yeh, T.; Miller, R. C. GUI testing using computer vision. In: Proceedings of the $28^{\text {th }}$ International Conference on Human Factors in Computing Systems (CHI 2010), Atlanta, GA, USA, 2010, p. 1535-1544.

Charette, R. N. Why Software Fails. Online, iEEE Spectrum, 2005.

Chen, J.; Subramaniam, S. Specification-based Testing for Gui-based Applications. Software Quality Control, v. 10, n. 3, p. 205-224, 2002. 
Ciaccia, P.; Patella, M.; Zezula, P. M-tree: An Efficient Access Method for Similarity Search in Metric Spaces. In: Proceedings of the $23^{\text {rd }}$ International Conference on Very Large Data Bases (VLDB 1997), Atenas, Greece, 1997, p. 426-435.

Coppit, D.; Haddox-Schatz, J. On the Use of Specification-Based Assertions as Test Oracles. In: Proceedings of the 29 $9^{\text {th }}$ Annual IEEE/NASA on Software Engineering Workshop (SEW 2005), Greenbelt, MD, USA, 2005, p. 305-314.

CppTest CppTest - Unit Testing for $\mathrm{C}_{++}$Programs. Online, http://cpptest. sourceforge.net/ - Acessado em 29/03/2011, 2011.

Cultural, L. Grande Enciclopédia Larousse Cultural. N. 18 in 1, $1^{\text {st }}$ ed. São Paulo, SP, Brasil: Nova Cultura LTDA., 200 p., 1998.

Datta, R.; Joshi, D.; Li, J.; Wang, J. Z. Image Retrieval: Ideas, Influences, and Trends of the New Age. ACM Computing Surveys, v. 40, n. 2, p. 1-60, 2008.

Day, J.; Gannon, J. A Test Oracle Based on Formal Specifications. In: A $2^{\text {nd }}$ Conference on Software Development Tools, Techniques, and Alternatives (SoftFair 1985), San Francisco, CA, USA, 1985, p. 126-130.

Deitel, H.; Deitel, P. Java Como Programar. $\quad 6^{\text {th }}$ ed. São Paulo, SP, Brasil: Pearson Education do Brasil - Pearson Hall, 1110 p., tradução de Edson Furmankiewwicz; revisão técnica de Fábio Lucchini, 2005.

Deitel, H. M.; Deitel, P. J. Java How to Program. $6^{\text {th }}$ ed. Upper Saddle River, NJ, USA: Prentice-Hall, Inc., 1110 p., 2004.

Delamaro, M. E.; Maldonado, J. C.; Jino, M. Introdução ao Teste de Software. Campus, $1^{\text {st }}$ ed. Rio de Janeiro, RJ, Brasil: Elsevier Editora Ltda, 394 p., 2007.

Delamaro, M. E.; Nunes, F. L. S.; Oliveira, R. A. P. Using Concepts of Content-based Image Retrieval to Implement Graphical Testing Oracles. Software Testing, Verification and Reliability, v. n/a, n. n/a, p. 1-28, published online in http://bit.1y/soFMwS - To appear, 2011.

DeMillo, R. A. Completely Validated Software: Test Adequacy and Program Mutation (panel session). In: Proceedings of the $11^{\text {th }}$ International Conference on Software Engineering (ICSE 1989), New York, NY, USA, 1989, p. 355-356.

Durelli, V. H. S.; Araujo, R. F.; Silva, M. A. G.; Oliveira, R. A. P.; Maldonado, J. C.; Delamaro, M. E. What a long, strange trip it's been: Past, present, and future pers- 
pectives on software testing research. In: Proceeding of the $25^{\text {th }}$ Brazilian Symposium on Software Engineering (SBES 2011), Sao Paulo, SP, Brasil, 2011, p. 30 - 39.

El-Naqa, I.; Yang, Y.; Galatsanos, N.; Nishikawa, R.; Wernick, M. A Similarity Learning Approach to Content-based Image Retrieval: Application to Digital Mammography. IEEE Transactions on Medical Imaging, v. 23, n. 10, p. 1233-1244, 2004.

Fayad, M.; Schmidt, D. C. Object-oriented Application Frameworks. Communications of the $A C M$, v. 40, n. 10, p. 32-38, 1997.

Fenkam, P.; Gall, H.; Jazayeri, M. Constructing CORBA-supported Oracles for Testing: a Case Study in Automated Software Testing. In: Proceedings of the 1 ${ }^{\text {th }}$ IEEE International Conference on Automated Software Engineering (ASE 2002), Los Alamitos, CA, USA, 2002, p. 129-138.

Fischer, T.; Sadeghi, A.-R.; Winandy, M. A Pattern for Secure Graphical User Interface Systems. In: Proceedings of the $20^{\text {th }}$ International Workshop on Database and Expert Systems Application (DEXA 2009), Linz, OO, Austria, 2009, p. 186-190.

Gamma, E.; Helm, R.; Johnson, R.; Vlissides, J. Design patterns: Elements of reusable object-oriented software. Boston, MA: Addison-Wesley, 1995.

Gato, H. E. R.; Nunes, F. L. S.; Schiabel, H. Uma Proposta de Recuperação de Imagens Mamográficas Baseada em Conteúdo. In: Anais do IX Congresso Brasileiro de Informática em Saúde (CBIS 2004), Ribeirão Preto, SP, Brasil, 2004, p. 1-5.

Giger, M. Computer-aided Diagnosis of Breast Lesions in Medical Images. Computing in Science Engineering, v. 2, n. 5, p. 39-45, 2000.

Gonçalves, V. M.; Oliveira, R. A. P.; Delamaro, M. E.; Nunes, F. L. S. Avaliação de funções de similaridade em um framework de teste para programas com saídas gráficas. In: Anais da XXXVII Conferência Latinoamericana de Informática (XXXVII CLEI), Quito, Equador, 2011, p. 653-668.

Gonzalez, R. C.; Woods, R. E. Digital Image Processing. $3^{\text {rd }}$ ed. Upper Saddle River, NJ, USA: Prentice-Hall, Inc., 976 p., 2006.

Hafner, J.; Sawhney, H. S.; Equitz, W.; Flickner, M.; Niblack, W. Efficient Color Histogram Indexing for Quadratic Form Distance Functions. IEEE Transactions on Pattern Analysis and Machine Intelligence (TPAMI), v. 17, n. 7, p. 729-736, 1995. 
Hofer, B.; Peischl, B.; Wotawa, F. GUI Savvy end-to-end Testing with Smart Monkeys. In: Proceedings of the $4^{\text {th }}$ ICSE Workshop on Automation of Software Test (AST 2009), Vancouver, Canada, 2009, p. 130-137.

Hoffman, D. A Taxonomy for Test Oracles. In: Proceedings of the $11^{\text {th }}$ International Quality Week (QW 98), San Francisco, SA, USA, 1998, p. 1-8.

Hoffman, D. Using Oracles in Test Automation. In: Proceedings of the $19^{\text {th }}$ Pacific Northwest Software Quality Conference (PNSQC 2001), Portland, OR, USA, 2001, p. 91-102.

Hoffman, D. Using Oracles in Testing and Test Automation. Online, logiGear Magazine (online), 2006.

Hummel, O.; Atkinson, C. Automated Harvesting of Test Oracles for Reliability Testing. In: Proceedings of the 29 $9^{\text {th }}$ Annual International Computer Software and Applications Conference (COMPSAC 2005), Washington, DC, USA, 2005, p. 196-202.

Hunter, C.; Strooper, P. Systematically Deriving Partial Oracles for Testing Concurrent Programs. In: Proceedings of the 24th Australasian Computer Science Conference (ACSC 2001), Gold Coast, Queensland, Australia, 2001, p. 83-91.

Ivory, M. Y.; Hearst, M. A. The State of the Art in Automating Usability Evaluation of User Interfaces. ACM Computing Surveys, v. 33, n. 4, p. 470-516, 2001.

Jin, H.; Wang, Y.; Chen, N.-W.; Gou, Z.-J.; Wang, S. Artificial Neural Network for Automatic Test Oracles Generation. In: Proceedings of the 2008 International Conference on Computer Science and Software Engineering (CSSE 2008), Wuhan, China, 2008, p. 727-730.

JSUnit JSUnit - Unit Testing for JavaScript Programs. Online, http://www . j sunit . net/ - Acessado em 29/03/2011, 2011.

JUnit JUnit - Unit testing for Java Programs. Online, http://junit.org/ - Acessado em 29/03/2011, 2011.

Kitchenham, B. Procedures for Performing Systematic Reviews. Technical Report TR/SE-0401 (Keele) - 0400011T.1 (NICTA), Software Engineering Group - Department of Computer Science - Keele University and Empirical Software Engineering - National ICT Australia Ltd, Keele/Staffs-UK and Eversleigh-Australia, http://bit . 1y/u2GcEM - Acessado em 08/10/2011, 2004. 
Leveson, N. G. An Investigation of the Therac-25 Accidents. IEEE Computer, v. 26, n. 7, p. 18-41, 1993.

Lieberman, H.; Rozenweig, E.; Singh, P. Aria: An Agent for Annotating and Retrieving Images. Computer, v. 34, n. 7, p. 57-62, 2001.

Mafra, S. N.; Travassos, G. H. Estudos Primários e Secundários Apoiando a Busca por Evidência em Engenharia de Software. Relatório Técnico ES 687/06, PESC - Programa de Engenharia de Sistemas de Computação - COOPE/UFRJ, Rio de Janeiro, RJ, Brasil, http://bit.1y/tIwqrl, 2006.

Manjunath, B.; Ma, W. Texture Features for Browsing and Retrieval of Image Data. IEEE Transactions on Pattern Analysis and Machine Intelligence (TPAMI), v. 18, n. 8, p. 837-842, 1996.

Marick, B. When Should a Test Be Automated. In: Proceedings of the $11^{\text {th }}$ International Software Quality Week (QW 98), San Francisco, CA, USA, 1998, p. 1-20.

Mathur, A. P. Foundations of Software Testing. $1^{\text {st }}$ ed. Boston, MA, USA: Addison-Wesley Professional - Pearson Education, 689 p., 2007.

Mayer, J.; Guderlei, R. On Random Testing of Image Processing Applications. In: Proceedings of the $6^{\text {th }}$ International Conference on Quality Software (QSIC 2006), Washington, DC, USA, 2006, p. 85-92.

McDonald, J.; Strooper, P. Translating Object-Z Specifications to Passive Test Oracles. In: Proceedings $2^{\text {nd }}$ International Conference on Formal Engineering Methods (ICFEM 98), Brisbane, Queensland, Australia, 1998, p. 165-174.

Memon, A.; Banerjee, I.; Hashmi, N.; Nagarajan, A. DART: A Framework for Regression Testing "Nightly/daily Builds"of GUI Applications. In: Proceedings of the $19^{\text {th }}$ International Conference on Software Maintenance (ICSM 03), Washington, DC, USA, 2003a, p. 410-419.

Memon, A.; Nagarajan, A.; Xie, Q. Automating Regression Testing for Evolving GUI Software. Journal of Software Maintenance, v. 17, n. 1, p. 27-64, 2005.

Memon, A.; Xie, Q. Using Transient/Persistent Errors to Develop Automated Test Oracles for Event-Driven Software. In: Proceedings of the $19^{\text {th }}$ IEEE International Conference on Automated Software Engineering (ASE 2004), Linz, Austria, 2004a, p. $186-195$. 
Memon, A. M. A Comprehensive Framework for Testing Graphical User Interfaces. Ph.d. thesis, University of Pittsburgh, Pittsburgh, PA, USA, 2001.

Memon, A. M. Employing User Profiles to Test a New Version of a GUI Component in its Context of Use. Software Quality Control, v. 14, n. 4, p. 359-377, 2006.

Memon, A. M. An Event-flow Model of GUI-based Applications for Testing: Research Articles. Software Testing, Verification and Reliability, v. 17, n. 3, p. 137-157, 2007.

Memon, A. M.; Banerjee, I.; Nagarajan, A. What test oracle should I use for effective GUI testing? In: Proceedings of the IEEE International Conference on Automated Software Engineering, IEEE Computer Society, 2003b, p. 164-173.

Memon, A. M.; Pollack, M. E.; Soffa, M. L. Automated Test Oracles for GUIs. ACM SIGSOFT Software Engineering Notes, v. 25, n. 6, p. 30-39, 2000.

Memon, A. M.; Xie, Q. Empirical Evaluation of the Fault-Detection Effectiveness of Smoke Regression Test Cases for GUI-Based Software. In: Proceedings of the 20 $0^{\text {th }}$ IEEE International Conference on Software Maintenance (ICSM 2004), Washington, DC, USA, 2004b, p. 8-17.

Memon, A. M.; Xie, Q. Studying the Fault-Detection Effectiveness of GUI Test Cases for Rapidly Evolving Software. IEEE Transactions on Software Engineering, v. 31, n. 10, p. 884-896, 2005.

Myers, B. A. User Interface Software Tools. ACM Transactions on Computer-Human Interaction, v. 2, n. 1, p. 64-103, 1995.

Myers, G. J. The Art of Software Testing. $1^{\text {st }}$ ed. New York, NY, USA: John Wiley and Sons Inc, 192 p., 1979.

Myers, G. J. The Art of Software Testing. $2^{\text {nd }}$ ed. New York, NY, USA: John Wiley and Sons Inc, 256 p., 2004.

Nunes, F. L. S. Esquema de diagnóstico auxiliado por computador para detecção de agrupamentos de microcalcificações por processamento de imagens mamográficas. Dissertação de Mestrado, Escola de Engenharia de São Carlos - Universidade de São Paulo - USP, São Carlos-SP - Brasil, 1997.

Ogle, V. E.; Stonebraker, M. Chabot: Retrieval from a Relational Database of Images. IEEE Computer, v. 28, n. 9, p. 40-48, 1995. 
Oliveira, R. A. P.; Delamaro, M. E. Apoio à Automatização de Oráculos de Teste para Programas com Interfaces Gráficas. In: Anais do IX Simpósio Brasileiro de Qualidade de Software (SBQS 2010) - VIII Workshop de Teses e Dissertações em Qualidade de Software (WTDQS 2010), Belém, PA, Brasil, 2010, p. 36-40.

Oliveira, R. A. P.; Delamaro, M. E.; Nunes, F. L. S. Estrutura para Utilização de Recuperação de Imagens Baseada em Conteúdo em Oráculos de Teste de Software com Saída Gráfica. In: Anais do IV Workshop de Visão Computacional (WVC 2008), Bauru, SP, Brasil, 2008, p. 7-12.

Oliveira, R. A. P.; Delamaro, M. E.; Nunes, F. L. S. O-FIm - Oracle for Images. In: Proceedings of the 23th Brazilian Symposium on Software Engineering (SBES 2009) XVI Tools Session of the SBES 2009, Fortaleza, CE, Brasil, 2009a, p. 1-6.

Oliveira, R. A. P.; Delamaro, M. E.; Nunes, F. L. S. Oráculos de Teste para Domínios GUI: Uma Revisão Sistemática. In: Proceedings of the $3^{\text {th }}$ Brazilian Workshop on Systematic and Automated Software Testing (SAST 2009), Gramado, RS, Brasil, 2009b, p. $22-32$.

Oliveira, R. A. P.; Delamaro, M. E.; Nunes, F. L. S. Exploring the O-FIm framework to Support the Test of Programs with GUIs. In: Proceedings of the $4^{\text {th }}$ Brazilian Workshop on Systematic and Automated Software Testing (SAST 2010), Natal, RN, Brasil, 2010, p. 31-40.

Oliveira, R. A. P.; Oliveira, L. B. R.; Cafeo, B. B. P.; Durelli, V. H.; Delamaro, M. E. Sistema de Apoio ao Ensino do Teste de Mutação para Programas em Linguagem Pascal, artigo em elaboração, 2011.

Paiva, A.; Faria, J. C. P.; Vidal, R. F. A. M. Towards the Integration of Visual and Formal Models for GUI Testing. In: Proceedings of the $3^{\text {rd }}$ Workshop on Model Based Testing (MBT 2007), Braga, Portugal, 2007, p. 99-111.

Paquerault, S.; Yarusso, L. M.; Papaioannou, J.; Jiang, Y.; Nishikawa, R. M. Radial Gradient-based Segmentation of Mammographic Microcalcifications: Observer Evaluation and Effect on CAD Performance. Medical Physics, v. 31, n. 9, p. 2648-2657, 2004.

Peters, D.; Parnas, D. L. Generating a Test Oracle from Program Documentation: Work in Progress. In: Proceedings of the 1994 International Symposium on Software Testing and Analysis (ISSTA 1994), Seattle, WA, USA, 1994, p. 58-65. 
Peters, D. K.; Parnas, D. L. Using Test Oracles Generated from Program Documentation. IEEE Transactions on Software Engineering, v. 24, n. 3, p. 161-173, 1998.

Rauf, A.; Anwar, S.; Ramzan, M.; ur Rehman, S.; Shahid, A. Ontology Driven Semantic Annotation Based GUI Testing. In: Proceedings of the $6^{\text {th }}$ International Conference on Emerging Technologies (ICET 2010), Islamabad, Pakistan, 2010, p. 261-264.

Reddi, V. J.; Connors, D.; Cohn, R.; Smith, M. D. Persistent Code Caching: Exploiting Code Reuse Across Executions and Applications. In: Proceedings of the $5^{\text {th }}$ International Symposium on Code Generation and Optimization (CGO 2007), San Jose, CA, USA, 2007, p. 74-88.

Richardson, D.; Aha, S.; O’Malley, T. Specification-based Test Oracles For Reactive Systems. In: Proceedings of the $14^{\text {th }}$ International Conference on Software Engineering (ICSE 1992), Melbourne, Australia, 1992, p. 105-118.

Rubner, Y.; Tomasi, C.; Guibas, L. A Metric for Distributions with Applications to Image Databases. In: Proceedings of the $6^{\text {th }}$ International Conference on Computer Vision (ICCV 1998), Bombay, India, 1998, p. 59-66.

Sierra, K.; Bates, B. Use a Cabeça! Java. 2 ed. Rio de Janeiro, RJ, Brasil: Alta Books, 470 p., tadução de Aldir José Coelho; revisão técnica de Késsia Nina, 2005.

Smeulders, A. W. M.; Worring, M.; Santini, S.; Gupta, A.; Jain, R. Content-Based Image Retrieval at the End of the Early Years. IEEE Transactions on Pattern Analysis and Machine Intelligence (TPAMI), v. 22, n. 12, p. 1349-1380, 2000.

Smith, J. R.; Chang, S.-F. Visually Searching the Web for Content. IEEE MultiMedia, v. 4, n. 3, p. 12-20, 1997.

Sneed, H. M.; Mérey, A. Automated Software Quality Assurance. IEEE Transactions on Software Engineering, v. 11, n. 9, p. 909-916, 1985.

Sommerville, I. Software Engineering. $7^{\text {th }}$ ed. Harlow, UK: Addison Wesley (International Computer Science Series), 784 p., 2004.

SUnit SUnit - Unit Testing for Smaltalk Programs - The Mother of All Unit Testing Frameworks. Online, http://sunit.sourceforge.net/ - Acessado em 29/03/2011, 2011.

Swain, M. J.; Ballard, D. H. Color Indexing. International Journal of Computer Vision, v. 7, n. 1, p. 11-32, 1991. 
Takahashi, J. An Automated Oracle for Verifying GUI Objects. ACM SIGSOFT Software Engineering Notes, v. 26, n. 4, p. 83-88, 2001.

TestNG TestNG - A Testing Framework Inspired from JUnit. Online, http://testng. org/ - Acessado em 29/03/2011, 2011.

Treharne, H.; Draper, J.; Schneider, S. Test Case Preparation Using a Prototype. In: Proceedings of the $2^{n d}$ International B Conference on Recent Advances in the Development and Use of the B Method (B 1998), London, UK, 1998, p. 293-311.

Tse, T. H.; Lau, F. C. M.; Chan, W. K.; Liu, P. C. K.; Luk, C. K. F. Testing Object-oriented Industrial Software Without Precise Oracles or Results. Communications of the ACM, v. 50, n. 8, p. 78-85, 2007.

Vasconcelos, N. On the Efficient Evaluation of Probabilistic Similarity Functions for Image Retrieval. IEEE Transactions on Information Theory, v. 50, n. 7, p. 1482-1496, 2004.

Vincenzi, A. M. R. Subisídios para o Estabelecimento de Estratégias de Teste Baseadas na Técnica de Mutação. Disertação de mestrado, Universidade de São Paulo - Instituto de Ciências Matemáticas e de Computação - (ICMC-USP), São Carlos, SP, Brasil, 1998.

Vincenzi, A. M. R.; Wong, W. E.; Delamaro, M. E.; Maldonado, J. C. JaBUTi: A Coverage Analysis Tool for Java Programs. In: Proceedings of the 1th Brazilian Symposium on Software Engineering (SBES 2003) - X Tools Session of the SBES 2003, Manaus, AM, Brasil, 2003, p. 79-84.

Weyuker, E. J. On Testing Non-Testable Programs. The Computer Journal, v. 25, n. 4, p. $465-470,1982$.

Wilkins, P.; Ferguson, P.; Smeaton, A. F. Using Score Distributions for Query-time Fusion in Multimediaretrieval. In: Proceedings of the $8^{\text {th }}$ ACM International Workshop on Multimedia Information Retrieval (MIR 06), Santa Barbara, CA, USA, 2006, p. 51-60.

Wohlin, C.; Runeson, P.; Höst, M.; Ohlsson, M. C.; Regnell, B.; Wesslén, A. Experiments in Software Engineering: an Introduction. $1^{\text {st }}$ ed. Norwell, MA, USA: Kluwer Academic Publishers, 204 p., 2000.

Xie, Q. Developing Cost-effective Model-based Techniques for GUI Testing. Ph.d. thesis, University of Maryland at College Park, College Park, MD, USA, 2006a. 
Xie, Q. Developing Cost-effective Model-based Techniques for GUI Testing. In: Proceedings of the 28 $8^{\text {th }}$ International Conference on Software Engineering (ICSE 2006), Shanghai, China, 2006b, p. 997-1000.

Xie, Q.; Memon, A. M. Designing and Comparing Automated Test Oracles for GUI-based Software Applications. ACM Transactions on Software Engineering and Methodology (TOSEM), v. 16, n. 4, p. 1-36, 2007.

Xing, X.; Jiang, F. GUI Test Case Definition with TTCN-3. In: Proceedings of the2009 International Conference on Computational Intelligence and Software Engineering (CiSE 2009), Wuhan, China, 2009, p. 1-5.

Ye, M.; Feng, B.; Zhu, L. Automated Oracle Based on Multi-weighted Neural Networks for GUI Testing. Information Technology Journal, v. 3, n. 6, p. 370-375, 2007.

Zenarosa, G. L.; Leonard, R. J. Towards Automated Oracles for GUI Input Validation. In: Proceeding of the $6^{\text {th }}$ International Workshop on Automation of Software Test (AST 2011), Waikiki, Honolulu, HI, USA, 2011, p. 113-114.

Zhu, H. A Note on Test Oracles and Semantics of Algebraic Specifications. In: Proceedings of the $3^{\text {rd }}$ International Conference on Quality Software (QSIC 2003), Dallas, TX, USA, 2003, p. 91-98.

\footnotetext{
${ }^{1}$ Alguns dos link encontrados na presente seção foram comprimidos por meio do encurtador de links "bitly" - acesse: https://bitly.com/
} 



\section{Wizard do framework O-FIm}

Os oráculos definidos no framework O-FIm dependem de uma estrutura que consiste de uma descrição textual, feita em arquivo texto. A partir dessa descrição o testador pode exprimir suas especificações particulares para um oráculo. Para a criação de arquivos descritores de modo seguro, com mais produtividade e correto, foi implementado um wizard. Neste apêndice são apresentados aspectos de implementação e aspectos operacionais do wizard da ferramenta O-FIm.

Instalação ou remoção de plugins, edição ou recuperação de descritores de oráculo, execução de teste particulares são algumas das funcionalidades oferecidas pelo wizard por meio de um interface gráfica intuitiva e simples. Tal interface gráfica, que foi implementada, principalmente, para apoiar a realização dos estudo empíricos apresentados no Capítulo 6, pode ser visualizada na Figura A.1.

As principais funcionalidades do wizard que facilita a interação do testador com o framework são apresentadas a seguir:

1. Instalação de novas classes (extratores ou funções de similaridade): como forma de alternativa ao uso de linhas de comando, o wizard do framework possui o botão Install que fornece uma GUI com campos específicos para que o testador instale novos plugins de modo seguro, sistemático e guiado. Como é mostrado na Figura A.2;

2. Pesquisas por extratores ou similaridades instaladas e configuração de descritores: O botão Search pode ser utilizado pelo testador para fazer pesquisas 


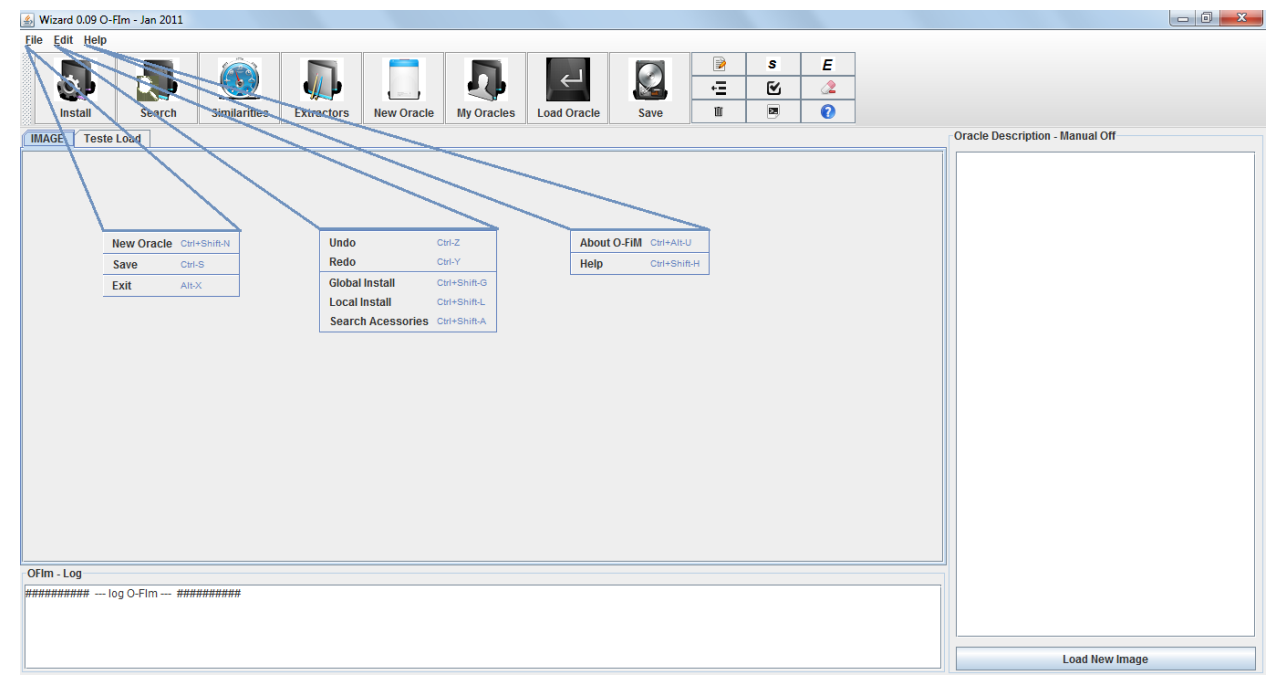

Figura A.1: Interface principal do framework O-FIm

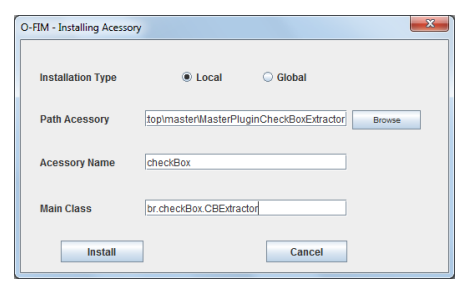

Figura A.2: GUI para instalação de plugin O-FIm

na ferramenta acerca dos puglins instalados e disponíveis para a configuração de oráculos gráficos. Ainda por meio da interface Search é possível que o usuário testador configure seus oráculos gráficos. O testador deve selecionar uma Função de Similaridade. Os extratores de características de imagem podem ser selecionados por meio de botões checkbox referente ao extrator. Caso os extratores selecionados possuam parâmetros ajustáveis, outra interface gráfica possibilitará que o usuário ajuste os parâmetros da maneira que considerar adequado. A Figura A.3 mostra a tela da interface disponibilizada pelo botão Search.

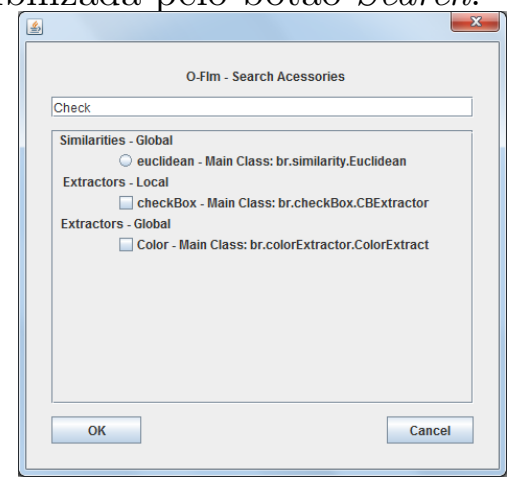

Figura A.3: GUI da O-FIm para pesquisas sobre plugins

3. Persistência de descritores de oráculos gráficos: após a configuração de um oráculo gráfico, o Botão Save serve para que o usuário possa gravá-lo, em um dire- 
tório denominado myOracles. Todos os oráculos gravados podem ser recuperados, reeditados e utilizados em processos de teste posteriores.

4. Visualização de Imagens: para diminuir os esforços do testador, o O-FIm oferece um Painel no qual podem ser carregadas imagens digitalizadas. Sendo assim, o testador pode carregar imagens que não passaram nas avaliações do oráculo para que uma análise mais minuciosa possa ser feita. Isso pode ser feito com um clique do mouse no botão Load New Image, na interface principal do framework. A Figura A.4 mostra a interface gráfica de O-FIm com uma imagem carregada pelo usuário testador.

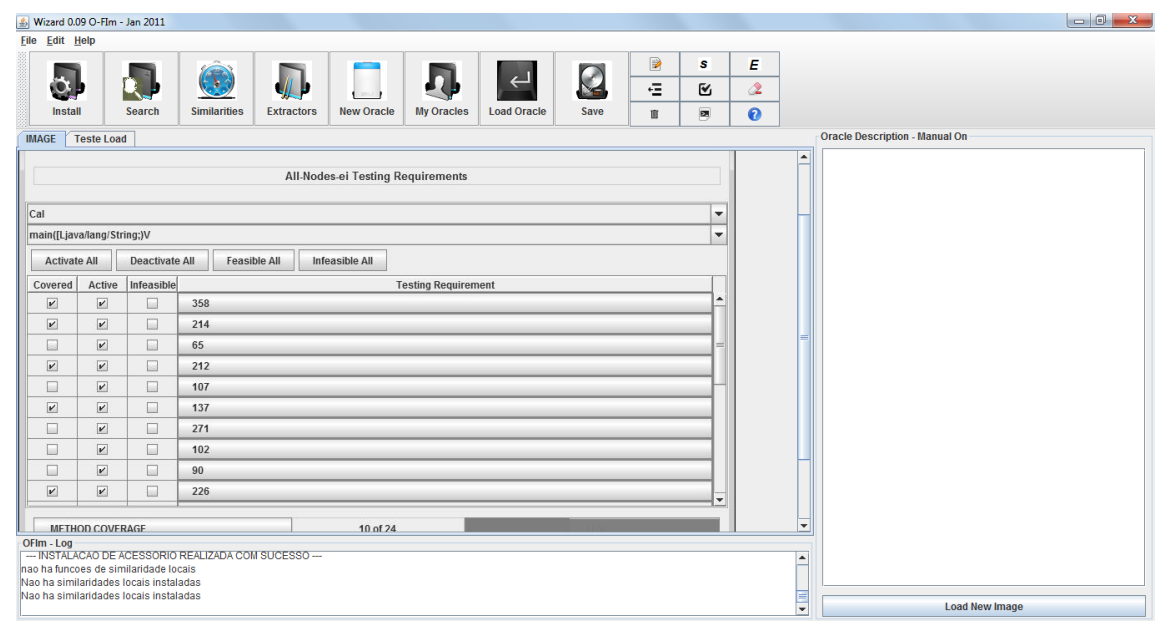

Figura A.4: Interface de O-FIm com a imagem de um GUI carregada internamente

5. Comparação de um conjunto de imagens: O-FIm permite a execução de um oráculo gráfico comparando dois conjuntos de imagens. O usuário deve acionar o botão Load Oracle e ajustar os seguintes parâmetros:

- Models - Campo em que deve ser configurado o caminho para as imagens consideradas como modelo pelo framework. Ex: /rafael/images1/Models

- Auts - Campo em que deve ser configurado o caminho para as imagens em teste pela ferramenta O-FIm. Ex:/rafael/images1/Submited

- Oracle - Campo em que deve ser configurado o caminho em disco para o arquivo .txt que corresponda ao oráculo gráfico que será utilizado no teste. Ex: /rafael/oracles/myOracle.txt

Adicionalmente, o testador ainda pode ajustar uma precisão ou threshold (limiar) que será utilizado para fazer as comparações na execução do teste. Sendo assim, qualquer diferença resultante entre imagem sendo comparada e imagem modelo acima do limiar irá considerar um teste como falho. Na Figura A.5 pode ser observada GUI do framework após a execução de um oráculo gráfico ajustado. Nota-se que os resultados são apresentados de modo visual para o testador. 


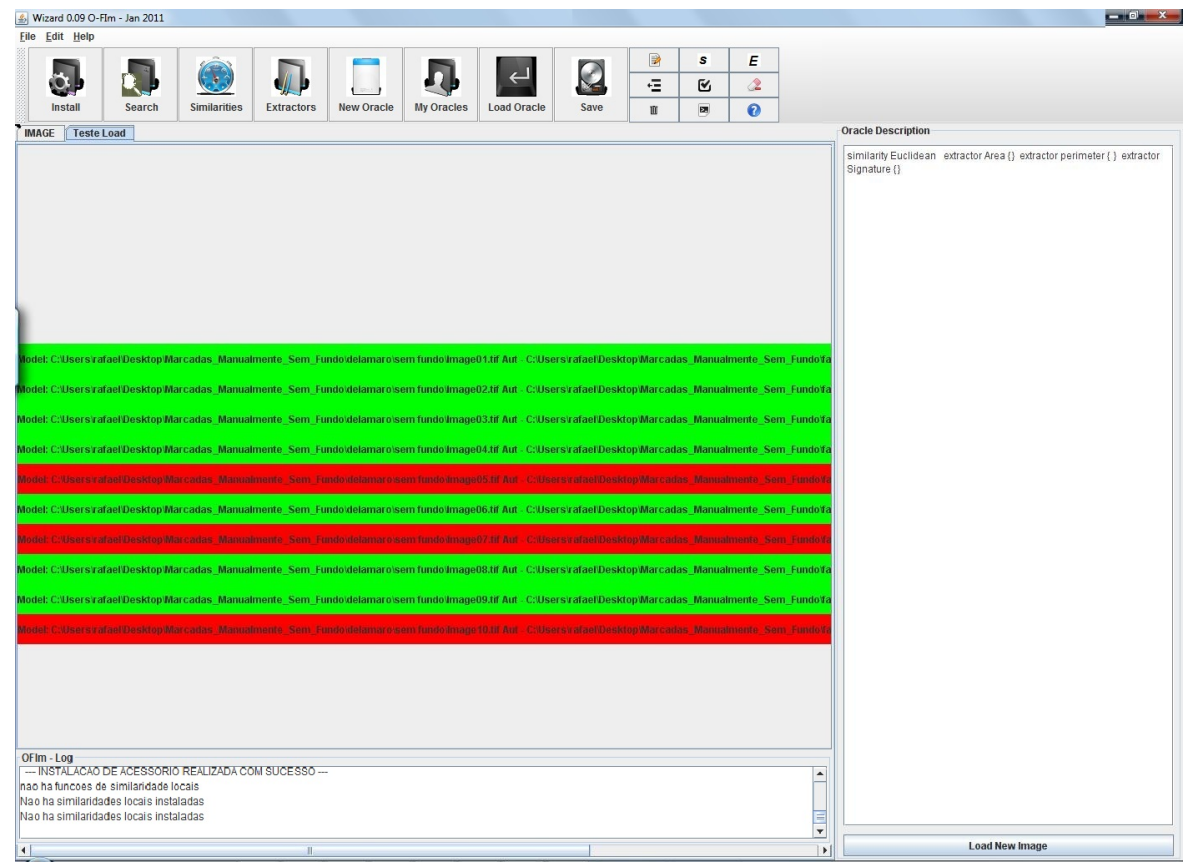

Figura A.5: Interface de O-FIm após execução de um oráculo gráfico

A wizard foi projetada segundo o padrão arquitetural MVC (Model-View-Controller) (Buschmann et al., 1996), uma vez que esse é conhecido por prover adequada separação de interesses em sistemas interativos. Além disso, com o propósito de promover uma melhor modularização e reutilização, foram utilizados três padrões de projeto definidos por Gamma et al. (1995): Comando (Command), Mediador (Mediator) e Objeto Único (Singleton). A utilização do padrão Comando permite que objetos sejam utilizados na representação de eventos, encapsulando informações necessárias às chamadas dos métodos de forma a permitir que esses possam ser utilizados posteriormente. O padrão Mediador define uma interface para a comunicação entre objetos, visando à redução do acoplamento. Por fim, padrão Objeto Único, utilizado na implementação do histórico de atividades, garante a existência de uma única instância de determinada classe, tornando-a acessível a todos os objetos de um sistema. Em geral, a maior vantagem em explorar tais padrões são as facilidades encontradas quando é necessário algum tipo de manutenção no código das aplicações. Fato esse que facilita e incentiva a continuidade do trabalho aqui apresentado. 